\title{
Biomimetic Approaches to Synthesis of Cannabidiol
}

\author{
By \\ Daniel Brumar
}

\begin{abstract}
A thesis submitted to the Faculty of Graduate and Postdoctoral Affairs in partial
\end{abstract} fulfillment of the requirements for the degree of

Master of Science

in

Chemistry

Carleton University

Department of Chemistry

Ottawa, Ontario,

August 2018

CCopyright 2018, Daniel Brumar 


\begin{abstract}
$\underline{\text { Abstract }}$
Found in cannabis, cannabidiol (CBD) holds promise as a nonpsychoactive cannabinoid in treating a number of conditions, including anxiety, schizophrenia, and some forms of epilepsy. However, large scale studies on the therapeutic use of CBD are lacking, and more research is needed to precisely establish its safety and efficacy. Extraction of CBD from cannabis is challenging, and past methods of synthesizing CBD have suffered from at least one of the following: poor selectivity, low yields, complex and laborious reaction sequences, or unavailable starting materials. We report here a concise approach to CBD synthesis from readily available nerol. This route uses directed orthometallation to regioselectively allylate olivetol dimethyl ether, followed by a biomimetic oxidative cyclization with $\mathrm{Mn}(\mathrm{III})$ to cleanly generate dimethyl CBD in low yield. We also demonstrate that using cationic polyene cyclization as the key ringforming step produces a similar yield of dimethyl CBD in a complex mixture of isomers.
\end{abstract}




\section{Acknowledgements}

I would like to sincerely thank Jeff Manthorpe for all your guidance, and for giving me the chance to pursue a masters when you took me on as a student at the last minute. In every meeting, you took the time to teach me about named reactions, new reagents, and useful techniques.

I would like to thank Peter Buist, Maria DeRosa, Bob Crutchley, Jeff Smith, and Chantelle Gravelle for their kindness and guidance in navigating my degree when I felt lost. Thank you to the Smith lab, who took me under their wing when I was alone in Dr Manthorpe's absence.

Thank you to Trennick Walker for being there to help with numerous experiments, and while we sometimes got off-track, you were always there to encourage me. Thank you to Mark "Zolk" Zolkiewski, Ryan Tang, Alex Aitken, Alex S. Zhou, Hengguang $\mathrm{Xu}$, and Carrrlossss Canez for helping me keep my sanity during long, otherwise lonely hours in the lab, by helping to brainstorm solutions, or just sharing some pretty cool tunes and moist memes. Thank you to Sam "Blast" Shields, Christopher "Sword" Mattice, Matt Griffiths, Peter "PPal" Pallister and especially Monica "Wizard" Gill for sharing their wealth of knowledge. Most of what I know about how to carry out chemistry in the lab I learned from you. I can't thank Monica enough. Whether it be referencing help, brainstorming, advice, chemistry lessons, or life lessons, or just being someone who listened, your short time in the lab with me made me think finishing was actually possible, and made me interested in my research once more.

I am indebted to Jim Logan for his technical expertise, and Karl Wasslen for providing beautiful GCMS data. Susa, Peter, Kyle, and Tanya in stores deserve special mention for always being so helpful and cheerful, and dealing with messes no one wanted to deal with, and preventing harm to the environment and human health.

I thank my parents for fostering my curiosity growing up. You led me to enter science and always pushed me to go further. Particularly, I could not do this without the help of my mom, whose tireless support went above and beyond what any mother should do. Thanks to Gerry and my sister Monika for help with editing. Larva, Dylan, Nixsala, competitive player of the year Shaun Gordon and the rest of Monday Night Crew, Jarrod, Josh, Alyssa, Elizabeta and Denis, for moral support, and for believing in me when I didn't think I could keep going. 
"Things are only impossible until they're not." - Captain Jean Luc Picard 


\section{Table of Contents}

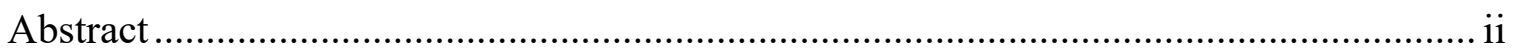

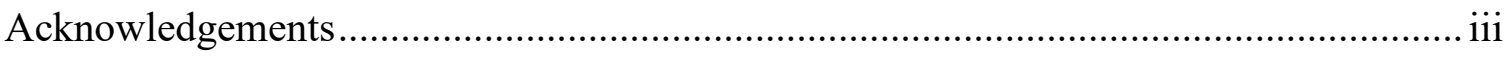

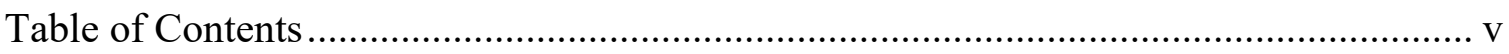

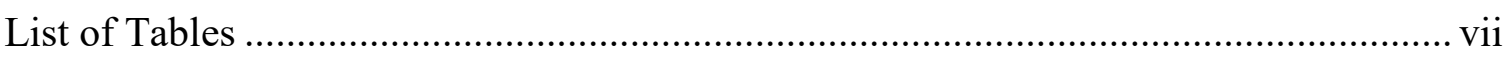

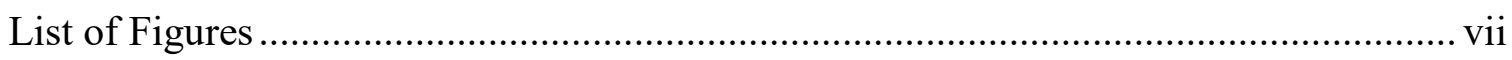

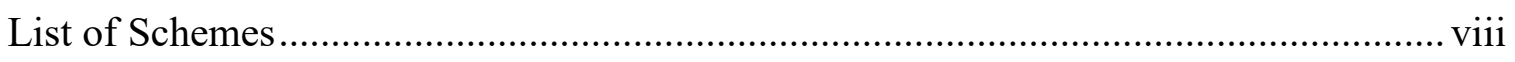

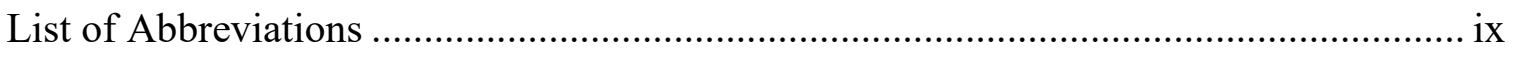

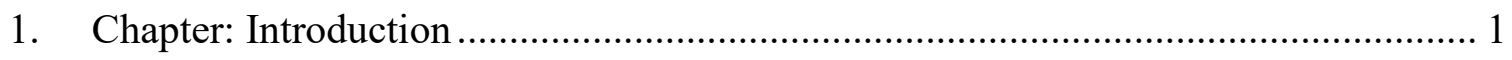

1.1. Cannabidiol and Other Cannabinoids: Structure and History ................................. 1

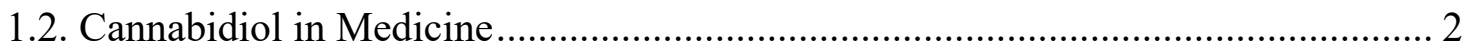

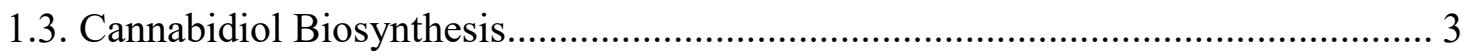

1.4. Selected Syntheses of CBD and Related Cannabinoids ........................................ 6

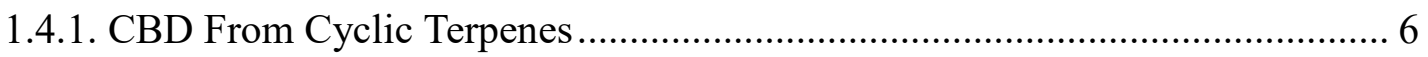

1.4.2. CBD From Non-Terpenoids.................................................................... 9

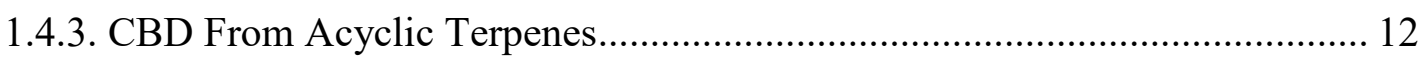

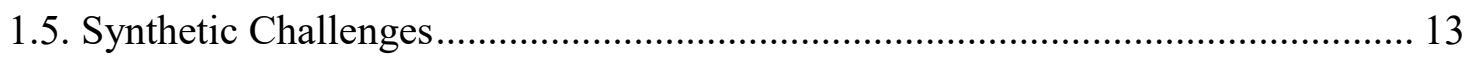

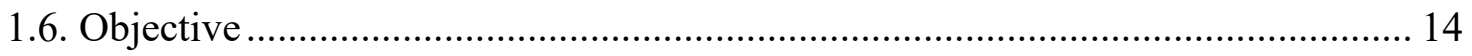

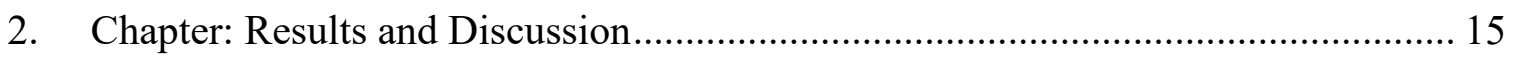

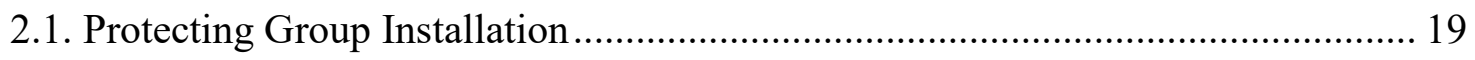

2.2. First Approach: 1,2-Addition to citral ........................................................... 23

2.2.1. DoM, Chelation, and 1,2-Addition ........................................................... 23

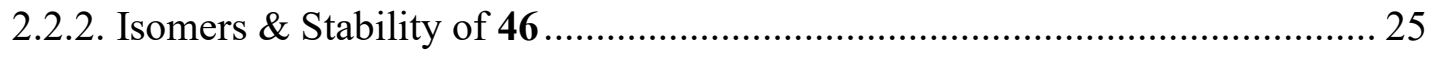

2.2.3. Acid Catalyzed Cyclization of 46c ………………...................................... 27

2.3. Second Approach: Allylation and Oxidative Cyclization..................................... 32

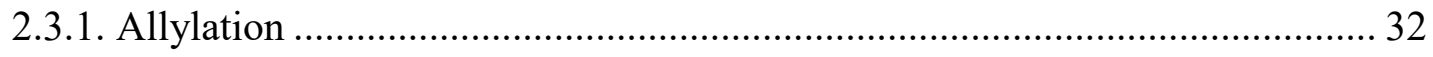

2.3.2. Oxidation: Reaction Monitoring \& Product Separation ……………….......... 35

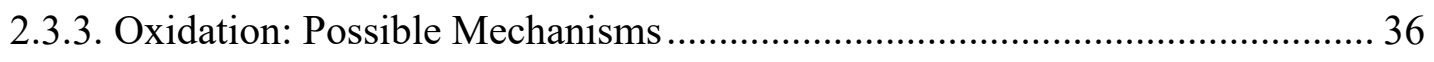

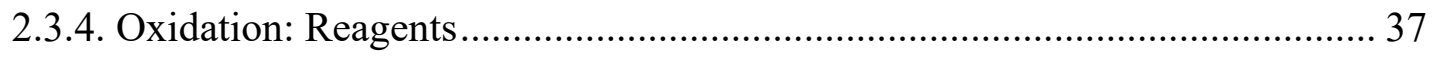

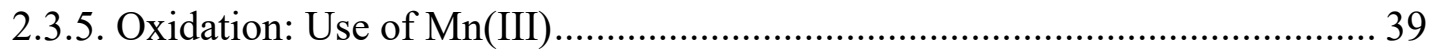

2.4. Future Work: Deprotection, Oxidation Optimization, Stereoselectivity, and

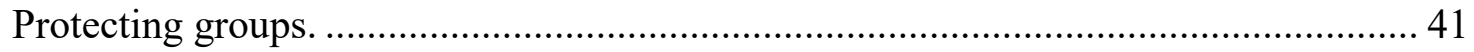

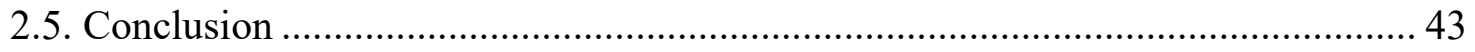

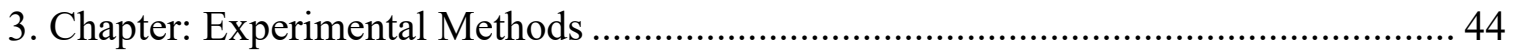




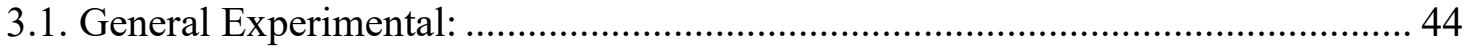

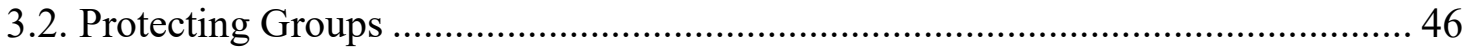

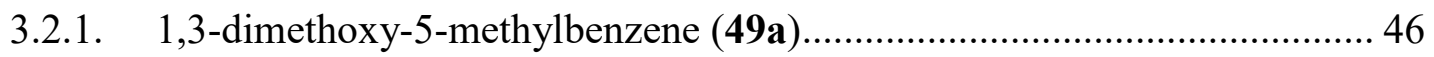

3.2.2. 1,3-dimethoxy-5-pentylbenzene (17a) .................................................. 47

3.2.3. (1R,2R)-2',6'-dimethoxy-5-methyl-4'-pentyl-2-(prop-1-en-2-yl)-1,2,3,4-

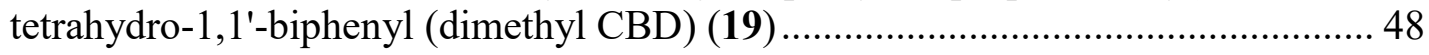

3.2.4. methyl THC (71) ................................................................................ 49

3.2.5. 5-methyl-1,3-phenylene bis(dimethylcarbamate) (49b) ............................. 50

3.2.6. 5-methyl-1,3-phenylene bis(diphenylcarbamate) (49c)............................. 52

3.2.7. 1,3-bis(methoxymethoxy)-5-methylbenzene (49d) …………………….... 53

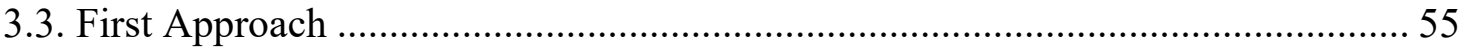

3.3.1. 1-(2,6-dimethoxy-4-methylphenyl)-3,7-dimethyloct-6-en-1-ol (58).......... 55

3.3.2. 1-(2,6-dimethoxy-4-methylphenyl)-3,7-dimethylocta-2,6-dien-1-ol (46a

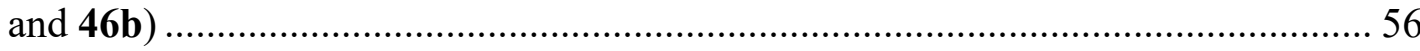

3.3.3. (E)-1-(2,6-dimethoxy-4-methylphenyl)-3,7-dimethylocta-1,6-dien-3-ol (46c) 57

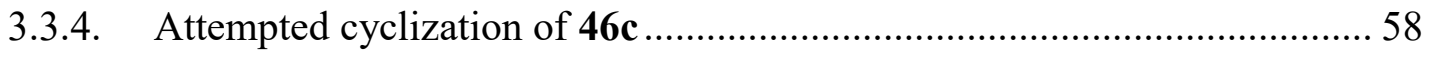

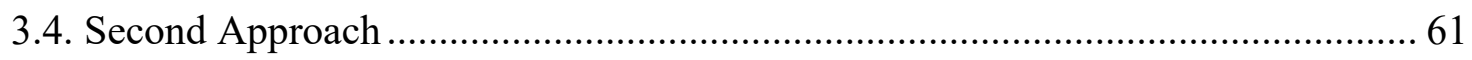

3.4.1. (Z)-1-chloro-3,7-dimethylocta-2,6-diene (neryl chloride)(68) ................... 61

3.4.2. (Z)-2-(3,7-dimethylocta-2,6-dien-1-yl)-1,3-dimethoxy-5methylbenzene $(69 a)$

3.4.3. (Z)-2-(3,7-dimethylocta-2,6-dien-1-yl)-1,3-dimethoxy-5-pentylbenzene (69b) 63

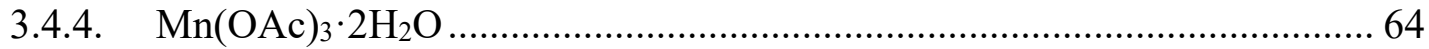

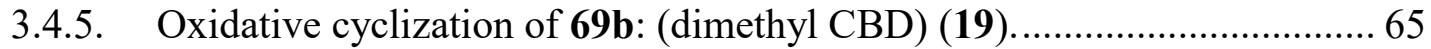

3.4.6. 2,3-dichloro-5-(2,6-dimethoxy-4-pentylphenyl)-7-(4-methylpent-3-en-1yl)-1,4-dioxo-1,4,4a,5,8,8a-hexahydronaphthalene-4a,8a-dicarbonitrile (80) ......... 65

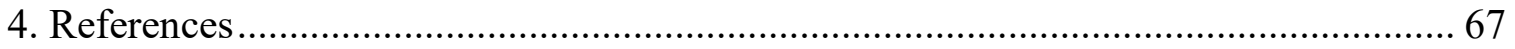

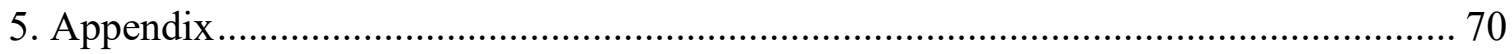




\section{List of Tables}

Table 1 Acid catalyzed cyclization of allylic alcohol 46c; identified compounds ...... 28

Table 2 Screening of oxidants for the oxidative cyclization of $69 \mathbf{b} \ldots \ldots \ldots \ldots \ldots \ldots \ldots . . . . . . . . . . . . . .38$

\section{List of Figures}

Figure 1.1.Some cannabinoids found in C. sativa, and the endocannabinoid anandamide 1

Figure 1.2. Carbon numbering system used in this thesis........................................... 5

Figure 1.3.Four isomeric $p$-menthadienols relevant in cannabinoid syntheses ................ 8

Figure 2.1. Some common naturally occurring cyclic monoterpenes .......................... 17

Figure 2.2.Possible co-operativity of DMGs by chelation during directed ortho

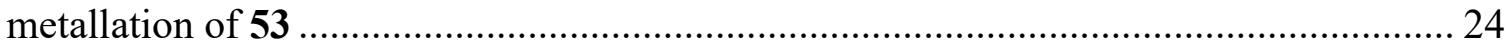

Figure 2.3.Citral pseudodimer side product........................................................... 24

Figure 2.4. Key NOESY correlations in 69b indicative of $(Z)$ double bond geometry ... 34

Figure 2.5. Key characteristic ${ }^{1} \mathrm{H}$ NMR resonances of $\mathbf{1 9}$ useful to assigning relative

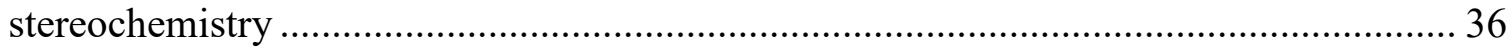




\section{List of Schemes}

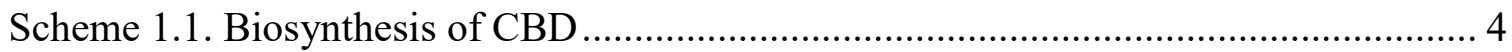

Scheme 1.2. Cannabinoid syntheses based on electrophilic aromatic substitution............ 7

Scheme 1.3. Rickards' and Rönneberg's synthesis of CBD ............................................. 9

Scheme 1.4. Three approaches to constructing the terpene moiety of cannabinoids ....... 11

Scheme 1.5. Mechoulam and Gaoni's first synthesis of CBD ......................................... 12

Scheme 1.6. Hetero-Diels-Alder approach to cis-cannabinoid synthesis .......................... 13

Scheme 2.1. Suggested possible synthetic routes to CBD, via (A) Claisen rearrangement,

(B) decarboxylative allylation, and (C) organometallic reagents ................................... 16

Scheme 2.2. Suggested route to isopulegol $\mathbf{3 6}$ and menthadienol $\mathbf{9 c}$ via ene reaction.... 17

Scheme 2.3. Possible routes to CBD via conjugate additions to citral 13 ....................... 17

Scheme 2.4. Possible route to menthadienyl aryl ether 39 via epoxide ring opening ...... 18

Scheme 2.5. Proposed route to CBD from citral 13 ...................................................... 18

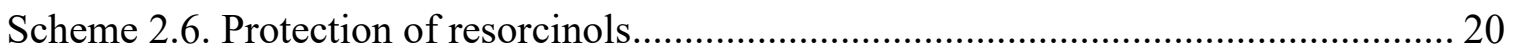

Scheme 2.7. DoM and 1,2-addition to aldehyde 13 ................................................... 23

Scheme 2.8. Carbamoyl migration and phenolate rearrangement ................................... 25

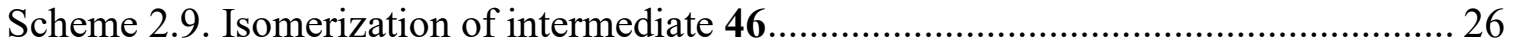

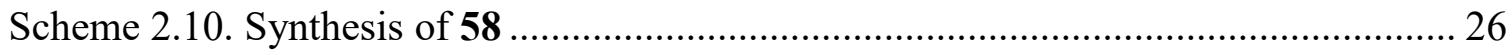

Scheme 2.11. Acid catalyzed cyclization of 46c . ....................................................... 29

Scheme 2.12. Tail to Head Terpene cyclizations in nature; (reproduced from reference

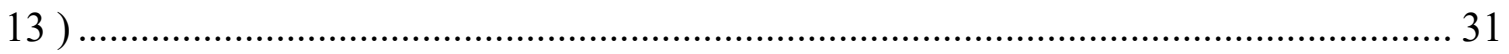

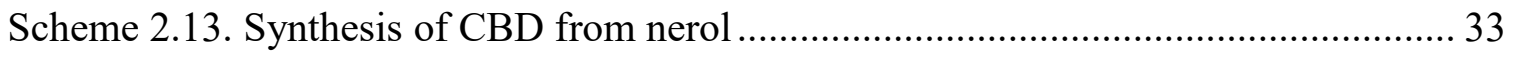

Scheme 2.14. Oxidative cyclization pathways: (A) cationic and (B) radical mechanisms

Scheme 2.15. Probable oxidation of 69b with DDQ ...................................................... 38

Scheme 2.16. Possible radical cyclization pathway with NBS ........................................... 39 


\section{$\underline{\text { List of Abbreviations }}$}

\begin{tabular}{|c|c|}
\hline $\mathrm{ABB}^{\prime}$ & ABB' system [in Pople nomenclature] \\
\hline br & broad \\
\hline CAM & ceric ammonium molybdate stain \\
\hline CAN & ceric ammonium nitrate \\
\hline CB1 & cannabinoid receptor type 1 \\
\hline CB2 & cannabinoid receptor type 2 \\
\hline $\mathrm{CBC}$ & cannabichromene \\
\hline CBD & cannabidiol \\
\hline CBDA & cannabidiolic acid \\
\hline $\mathrm{CBG}$ & cannabigerol \\
\hline CBGA & cannabigerolic acid \\
\hline $\mathrm{CoA}$ & coenzyme A \\
\hline COSY & homonuclear correlation spectroscopy \\
\hline $\mathrm{d}$ & doublet \\
\hline DCM & dichloromethane \\
\hline DCVC & dry column vacuum chromatography \\
\hline DDQ & 2,3-dichloro-5,6-dicyanobenzoquinone \\
\hline DIPEA & diisopropylethylamine \\
\hline DKR & dynamic kinetic resolution \\
\hline DMAPP & dimethylally pyrophosphate \\
\hline $\mathrm{DMC}$ & $N, N$-dimethyl carbamoyl \\
\hline
\end{tabular}




$\begin{array}{ll}\text { DMF } & \text { dimethylformamide } \\ \text { DMG } & \text { directed metalation group } \\ \text { DoM } & \text { directed ortho metallation } \\ \text { DPC } & N, N \text {-diphenyl carbamoyl } \\ \text { EI } & \text { electron impact ionization } \\ \text { ESI } & \text { electrospray ionization } \\ \text { FAD } & \text { flavin adenine dinucleotide } \\ \text { FADH } & \text { flavin adenine dinucleotide [reduced form] } \\ \text { FCC } & \text { flash column chromatography } \\ \text { FTIR } & \text { Fourier transform infrared [spectrometry] } \\ \text { GC } & \text { gas chromatography } \\ \text { GCMS } & \text { gas chromatography-mass spectrometry } \\ \text { GPP } & \text { geranyl pyrophosphate } \\ \text { HPLC } & \text { high performance liquid chromatography } \\ \text { HRMS } & \text { high resolution mass spectrometry } \\ \text { IPP } & \text { isopentenyl pyrophosphate } \\ \text { m } & \text { multiplet } \\ \text { MOM } & \text { methoxymethyl } \\ \text { MOMCl } & \text { methoxymethyl chloride } \\ \text { MSCl } & \text { melting point } \\ \text { Mass spectrometry }\end{array}$




\begin{tabular}{ll} 
NMR & nuclear magnetic resonance \\
NOESY & nuclear Overhauser enhancement spectroscopy \\
OAC & olivetolic acid cyclase \\
o-DCB & $o$-dichlorobenzene \\
PTLC & preparatory thin layer chromatography \\
q & quartet \\
RT & room temperature \\
s & singlet \\
t & triplet \\
THC & tetrahydrocannabinol \\
THF & tetrahydrofuran \\
THT & tail to head terpene [cyclization] \\
TLC & thin layer chromatography \\
TMEDA & $N, N, N{ }^{\prime}, N$ '-tetramethylethylenediamine \\
TMS & trimethylsilyl \\
TMSE & 2-trimethylsilylethyl \\
TMSEOH & 2-trimethylsilylethanol \\
TsCl & $p$-toluenesulfonyl chloride \\
UV & ultraviolet light \\
w.r.t. & with respect to \\
\hline
\end{tabular}




\section{Chapter: Introduction}

\subsection{Cannabidiol and Other Cannabinoids: Structure and History}

Cannabinoids are a class of compounds found in plants from the genus Cannabis, mostly found in the trichomes of the flowers. Their role in plants is unclear, but they are thought to serve as a defense mechanism. At least 70 naturally occurring cannabinoids are known from various strains of Cannabis sativa ${ }^{1}$, as well as numerous synthetic analogues, and some cannabinoid-like natural products found in other organisms ${ }^{2,3}$. A few of the most important ones are depicted in [Figure 1.1.].They have diverse structures, but all the $C$. sativa-derived compounds contain an alkylresorcinol attached to a monoterpene moiety ${ }^{1}$.
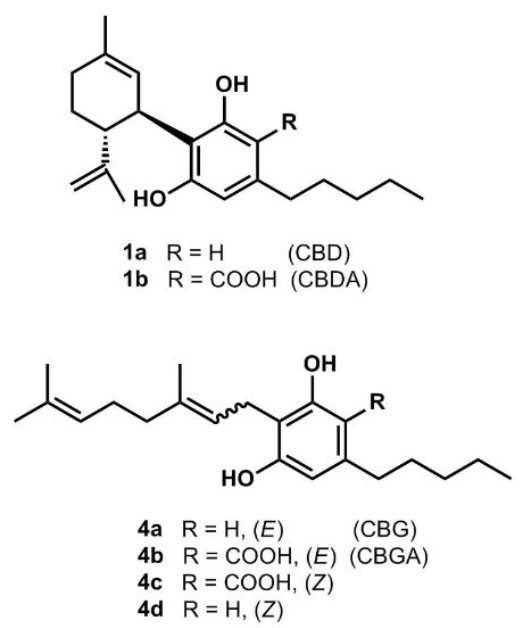
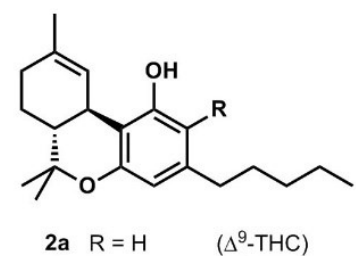

2b $\mathrm{R}=\mathrm{COOH}\left(\Delta^{9}-\mathrm{THCA}\right)$

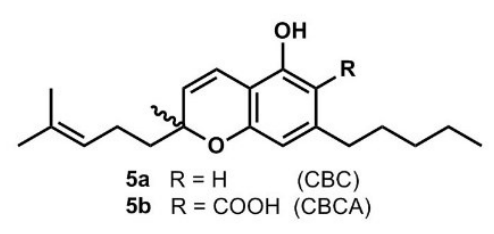

5b $\quad \mathrm{R}=\mathrm{COOH}(\mathrm{CBCA})$

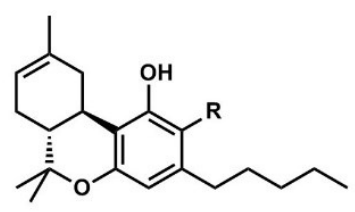

3a $\mathrm{R}=\mathrm{H} \quad\left(\triangle^{8}-\mathrm{THC}\right)$

3b $\mathrm{R}=\mathrm{COOH}\left(\Delta^{8}-\mathrm{THCA}\right)$

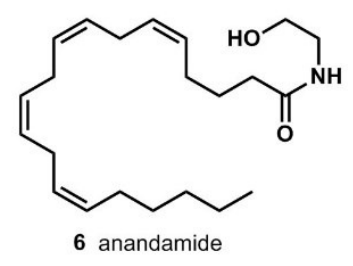

Figure 1.1. Some cannabinoids found in $C$. sativa, and the endocannabinoid anandamide

Cannabis has been used for about 5000 years for medicine, construction, cordage, and food in a number of cultures. It was first described in modern western medicine in 1830 by Theodor Friedrich Ludwig Nees von Esenbeck, and popularized a few years later by Sir William Brooke O'Shaughnessy ${ }^{4,5}$. Because the complex mixtures of neutral hydrophobic cannabinoids defied isolation and characterization with the techniques of the 
time, use of cannabis as a medication declined in the early $20^{\text {th }}$ century. Medical professionals did not want to prescribe something that could not be characterized, accurately standardized and dosed ${ }^{5}$.

The first cannabinoid to be isolated and its structure determined was the nonpsychoactive cannabinol $(\mathrm{CBN})$, thought perhaps to be an artefact of autoxidation of $\mathrm{THC}^{1,4,6}$. It was not until 1963 that the structure of cannabidiol $(\mathrm{CBD}, \mathbf{1})$ was determined with the advent of NMR spectroscopy ${ }^{6}$. CBD's first synthesis in 1965 and its conversion to $\Delta^{9}$-tetrahydrocannabinol $(\mathrm{THC}, 2)^{7}$ were important to proving the structure of the main psychoactive component THC, only first isolated one year earlier ${ }^{6,8}$. Numerous other cannabinoids were later characterized, including the isomer $\Delta^{8}$ tetrahydrocannabinol $\left(\Delta^{8}-\mathrm{THC}, \mathbf{3}\right)$, cannabigerol $(\mathrm{CBG}, \mathbf{4})$, cannabichromene $(\mathrm{CBC}, \mathbf{5})$, cannabicyclol (CBL), cannabielosin (CBE), cannabinodiol (CBND), their analogues, and many others ${ }^{1}$. Many of these compounds can be found in the cannabis plant as the corresponding carboxylic acids $\mathbf{1 b} \mathbf{\mathbf { 5 }} \mathbf{b}$ that decarboxylate readily.

\subsection{Cannabidiol in Medicine}

Much research over the decades has gone into the function of psychoactive components of cannabis, of which THC is the most important. Psychoactive cannabinoids act by binding to the $\mathrm{G}$-protein linked receptors $\mathrm{CB}_{1}$ and $\mathrm{CB}_{2}$, and inhibiting adenylate cyclase as part of a cellular signalling cascade ${ }^{4,5}$. In the absence of cannabinoids, these receptors are meant to bind to endogenous ligands (endocannabinoids) such as anandamide6, that modulate the release of other neurotransmitters. There is also evidence that cannabinoids can also bind to other receptors, inhibit certain cytochrome P450 
enzymes, and affect physical properties of lipid membranes ${ }^{4,5,9}$. Different cannabinoids have been shown to have drastically different effects on a variety of receptors and enzymes, even with only small differences in structure.

However, $\mathrm{CBD}$ does not bind to $\mathrm{CB}_{1}$ or $\mathrm{CB}_{2}$, and lacks much of the psychotropic activity of some of the other cannabinoids ${ }^{4,10,11}$. Instead, it interacts with a variety of receptors including TRPM8, TRPA1, TRPV1 5-HT1a, and some glycine receptors. It also inhibits enzymatic degradation of anandamide, and is an antioxidant ${ }^{10}$. In addition, it has a potent inhibitory effect on several cytochrome P450 enzymes involved in the activation of some procarcinogens such as polycyclic aromatic hydrocarbons, and in the degradation of some antiepileptic and neuroleptic medications ${ }^{5,9}$.

There is preliminary evidence to suggest that CBD may be effective in treating a variety of disorders including anxiety, schizophrenia, dystonia, and some forms of epilepsy, such as Dravet syndrome and Lennox-Gastaut syndrome ${ }^{5,10}$. CBD produces fewer side effects than THC, and can reduce some of the psychoactive effects of THC, making it tolerable in higher doses when the two are used in combination ${ }^{5,10}$. However, there are relatively few studies on medical use of $\mathrm{CBD}$, and rigorous large scale medical trials are lacking.

\subsection{Cannabidiol Biosynthesis}

Biosynthesis of CBD and other cannabinoids follows a convergent synthesis from isoprenoid and polyketide pathways [Scheme 1.1.]. The alkylresorcinol moiety begins from hexanoyl-CoA, which takes part in successive acylations with malonyl-CoA to form 
a tetraketide $7^{12}$. This polyketide is then cyclised by olivetolic acid cyclase (OAC) in an aldol condensation. Keto-enol tautomerism ensues, aromatizing the intermediate cyclohexene to form olivetolic acid $\mathbf{8}$.

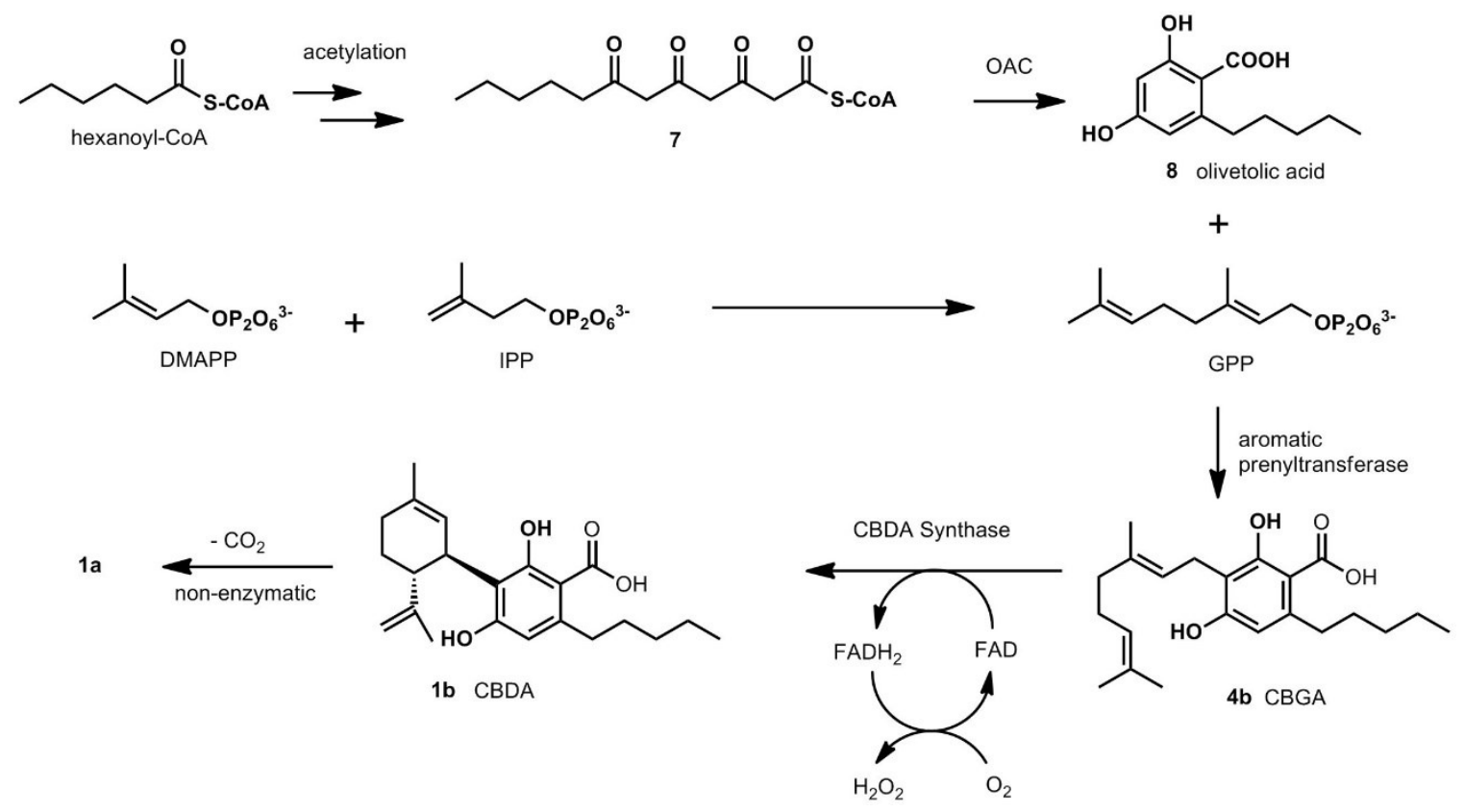

Scheme 1.1. Biosynthesis of CBD

Terpenoids are constructed from dimethylally pyrophosphate (DMAPP) and isopentenyl pyrophosphate (IPP). It has been shown that in cannabinoid biosynthesis, DMAPP and IPP are synthesized through the deoxyxylulose phosphate pathway. ${ }^{13}$ DMAPP and IPP are oligomerized to form open-chain precursors geranyl pyrophosphate (GPP), farnesyl pyrophosphate, and geranylgeranyl pyrophosphate as the starting points for synthesis of all monoterpenes $\left(\mathrm{C}_{10}\right)$, sesquiterpenes $\left(\mathrm{C}_{15}\right)$, and diterpenes $\left(\mathrm{C}_{20}\right)$, respectively ${ }^{14,15}$. In cannabinoid biosynthesis geranyl pyrophosphate is attached to olivetolic acid in a electrophilic aromatic substitution by the prenyltransferase CBGA synthase, forming cannabigerolic acid (CBGA, $4 \mathbf{b})^{12,16,17}$, the common intermediate in the biosynthesis of all $\mathrm{C}_{21}$ cannabinoids. 
While several different numbering systems for cannabinoids exist, the one used in this thesis is that used by Taura, Morimoto, and Shoyama ${ }^{18}$, and by Verpoorte et al., ${ }^{19}$ for CBG and $\Delta^{9}$-THC shown in [Figure 1.2.].

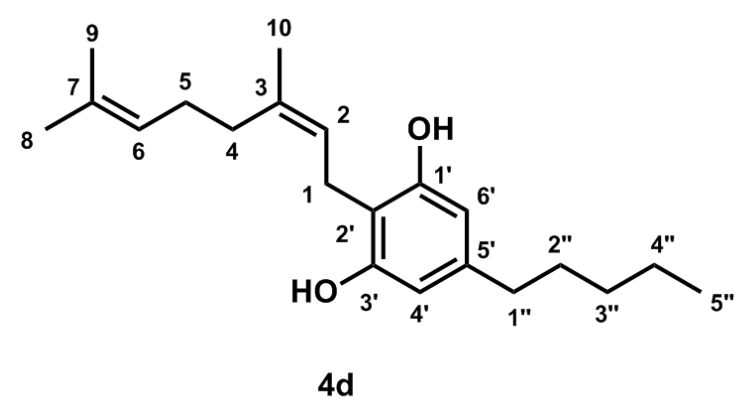

Figure 1.2. Carbon numbering system used in this thesis

The last enzyme-promoted step in the biosynthesis of CBDA $\mathbf{1 b}$ is effected by CBDA synthase from $\mathrm{CBGA}^{20}$. CBDA synthase is an oxidoreductase protein that shares much of its structure and function with that of THCA synthase. Both proteins use covalently bound FAD to catalyze the aerobic oxidation, forming hydrogen peroxide as a byproduct $^{21}$. The mechanism is proposed to proceed by hydride abstraction at the C-1 site by FAD, followed by $(E) /(Z)$ isomerization and stereoselective cyclization of the resultant carbocation. CBDA and THCA synthases are supposed to differ only by the site of the final proton elimination step ${ }^{20}$. Molecular oxygen then regenerates the $\mathrm{FADH}_{2}$ to FAD to complete the catalytic cycle. Finally, decarboxylation of CBDA to CBD is thought to occur non-enzymatically ${ }^{12}$. 


\subsection{Selected Syntheses of CBD and Related Cannabinoids}

There have been many approaches to the synthesis of cannabinoids, but many follow a common theme. Discussed here will be some of the more notable examples that highlight some of the challenges involved.

\subsubsection{CBD From CyclicTerpenes}

The most commonly employed approach to synthesis of THC, CBD, and derivatives is to begin with a cyclic terpene synthon and install it onto a resorcinol via electrophilic aromatic substitution [Scheme 1.2.]. One of the earliest examples of this was in 1967 using DMF-di-neopentyl acetal to effect the reaction between (+)-p-mentha-2,8dien-1-ol 9a and olivetol $1 \mathbf{1 0}^{22}$. The DMF acetal in this case can be replaced by a variety of Brønsted or Lewis acids with similar results ${ }^{23,24}$. In all cases, the acid is used to activate the alcohol and generate an allylic carbocation which is captured by the highly nucleophilic resorcinol. 


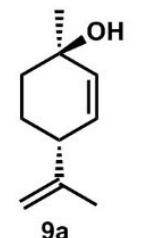

9a

or
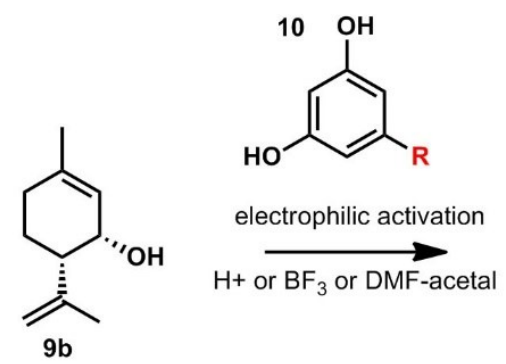

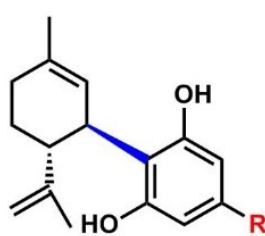

$(-)-1 a$

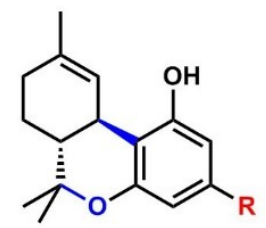

$(-)-2 a$

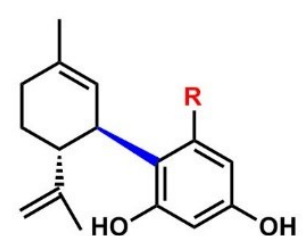

14

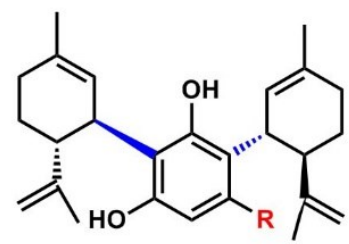

15

$\mathrm{R}=\mathrm{n}-\mathrm{C}_{5} \mathrm{H}_{11}$

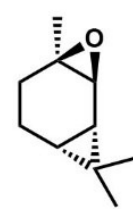

11

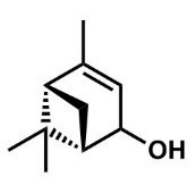

12

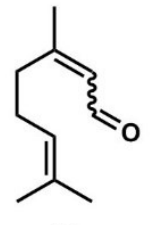

13

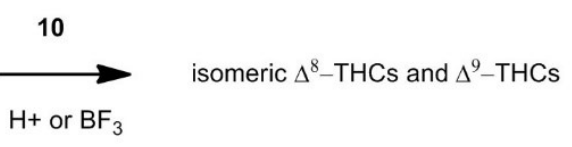

$\mathrm{H}+$ or $\mathrm{BF}_{3}$

Scheme 1.2.Cannabinoid syntheses based on electrophilic aromatic substitution. Blue colour indicates key bond formation.

What makes this method popular is that the stereochemistry of the terpene is used to direct the formation of the new stereocenter, providing acess to optically active CBD. Using the unnatural terpenes - the various isomeric $p$-menthadienols 9a-d[Figure 1.3.] is problematic because they do not occur naturally. Several naturally occurring or derived terpenes such as carene oxide $\mathbf{1 1}^{25}$ and verbenol $\mathbf{1 2}^{8}$ have been used to produce the cyclohexene skeleton of $\mathrm{CBD}$ with the required stereocenters. However, these conditions lead to further cyclizations, forming THC and its isomers instead, making it a leading method of THC synthesis ${ }^{8,23,25}$. The acyclic aldehyde citral $\mathbf{1 3}$ was shown to be a suitable starting material for the $\mathrm{BF}_{3}$ catalyzed synthesis of $\mathrm{CBD}$, but in only $3 \%$ yield ${ }^{24}$, being more amenable to THC synthesis ${ }^{8}$. 


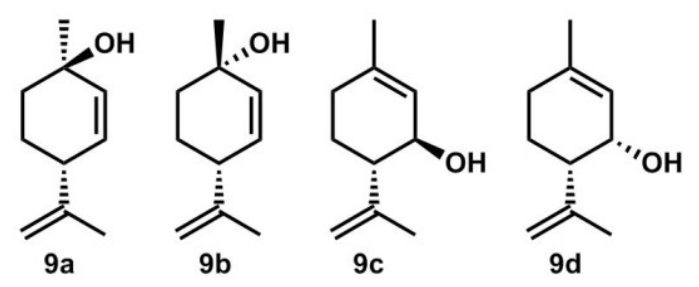

Figure 1.3.Four isomeric $p$-menthadienols relevant in cannabinoid syntheses

Three main problems arise in using acid catalysis for CBD synthesis by electrophilic aromatic substitution of resorcinols. The first is regioselectivity on the aromatic ring. The alkylresorcinols used all contain three ortho or para directing groups of similar steric demand. As such, all three remaining positions are either ortho or para to all of the directing groups, making regioselectivity poor. All of these CBD or THC syntheses produce both the desired 2'-alkylated (1a, 2a) and the undesired 4'-alkylated regioisomers such as $\mathbf{1 4}$ in varying degrees ${ }^{8,23,24,26}$. Even 2',4'-dialkylated resorcinols such as $\mathbf{1 5}$ are often produced ${ }^{8,23,24}$. Two factors can influence regioselectivity here. Derivatives of cannabinoids with different alkyl substituents on the aromatic ring have been synthesized over the years, and show steric factors play an important role. Linear alkyl subtituents show only moderate to poor regioselectivity at the desired site, while tertiary alkyls such as 1,1-dimethylheptyl show good (eg. $93 \%{ }^{23}$ ) selectivity, and unsusbstituted resorcinols show opposite selectivity as well as additional alkylation patterns ${ }^{23,26}$. The other factor is if the undesired site is blocked or not. Natural cannabinoids are biosynthesized as their carboxylic acid or ester derivatives, and several syntheses of various cannabinoids have used resorcylic acid esters, blocking one of the 4'- positions.

Another problem with these methods is that the rather harsh conditions lead to some formation of the undesired diastereomers - products with the aryl moiety cis to the 
isopropenyl group, such as $\mathbf{1 6}^{8,25}$. This was often also accompanied by supplementary cyclizations by addition of the phenols to either one or both of the alkenes. Often reported as well was shifting of the $\Delta^{9}$-double bond to the $\Delta^{8}$-position (at least in THC systems), and even carbon skeletal rearrangements ${ }^{8,23,25}$. In 1985 Baek et al. ${ }^{24}$ improved a method using $\mathrm{BF}_{3}$ etherate adsorbed on silica or alumina, providing $\mathrm{CBD}$ from $\mathbf{9 b}$ in modest yields without further cyclizations or isomerizations reported. This method is still used for preparing CBD and its analogues for research ${ }^{26,27}$.

The problems of regioselectivity and multiple additions to the aromatic ring remained until Rickards and Rönneberg ${ }^{28}$ used directed ortho metallation to regiospecifically lithiate olivetol dimethyl ether $\mathbf{1 7}$ at C-2'. The resulting carbanion was converted to a diarylcuprate, and coupled together with the menthadienyl acetate $\mathbf{1 8}$ under $\mathrm{BF}_{3} \cdot \mathrm{Et}_{2} \mathrm{O}$ catalysis to afford the $\mathrm{CBD}$ dimethyl ether $\mathbf{1 9}$ in $78 \%$ yield [Scheme 1.3.]. However, this still leaves the problem of access to the staring material $\mathbf{1 8}$ unsolved.
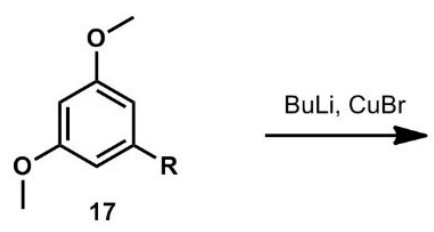

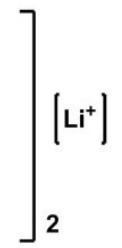

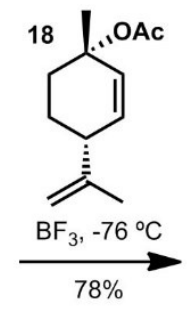

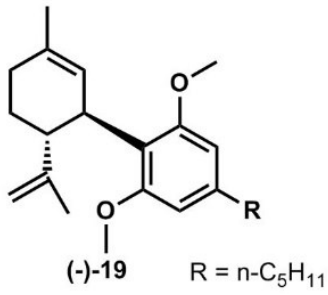

Scheme 1.3. Rickards' and Rönneberg's synthesis of CBD

\subsubsection{CBD From Non-Terpenoids}

Another approach taken by several CBD and THC syntheses is the stepwise construction of the terpene moiety from smaller pieces onto a funtionalized olivetol 
group. Many of these THC syntheses could reasonably be modified to make CBD instead.

For example, Farenholtz et al. ${ }^{29}$ in 1967 used aldol chemistry to form the cyclohexene ring from a $\mathrm{C}_{7}$ keto ester, and a series of alkylations, reduction, and elimination to obtain the racemic menthadienyl core of THC. ApSimon et al. ${ }^{30}$ used a similar approach to racemic THC, but with a Diels-Alder reaction as the key ring-closing step, and obtaining the correct $\Delta^{9}$-double bond position as well.

In 1997, Evans et al. ${ }^{31}$ used a chiral $\mathrm{Cu}(\mathrm{II})$ Lewis acid catalyst to promote an enatioselective Diels-Alder cyclization from simple starting materials [Scheme 1.4.A]. The resultant cyclohexene $\mathbf{2 0}$, which was obtained in $98 \%$ ee as the major diastereomer after direct recrystallization, gave $\Delta^{9}$-THC in 4 steps, with a $21 \%$ overall yield.

Childers and Pinnick ${ }^{32}$ used a remarkable rearrangement to obtain 19 in relatively few steps. Starting from methyl vinyl ketone, methyl methacrylate, and a Wittig reagent derived from olivetol 22, they obtained the diene $\mathbf{2 3}$ [Scheme 1.4.B]. While Claisen rearrangements usually require high temperatures to operate, this one reportedly occurred at room temperature to provide $\mathbf{2 1}$ in high yield. Another Wittig olefination gave a mixture of $(E)$ and $(Z)$ isomer of methyl ether 19. 
A Evans et al,.. Asymetric Synthesis of THC

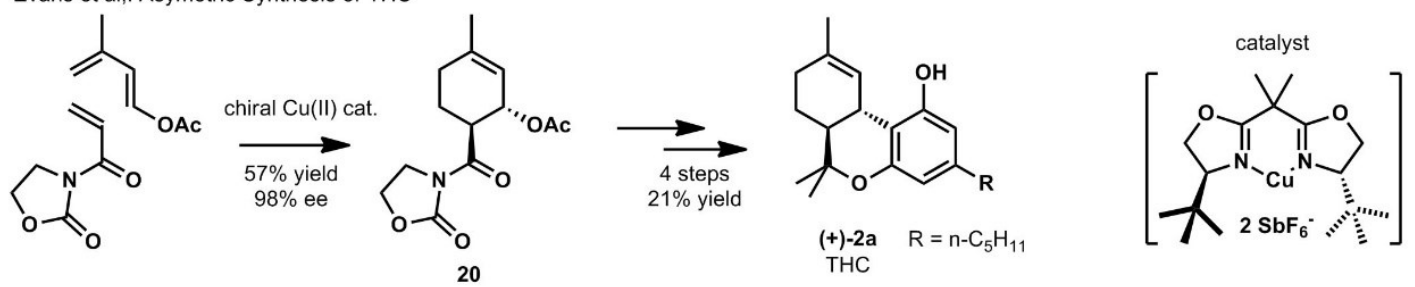

B Childers and Pinnick, Synthesis of racemic 19

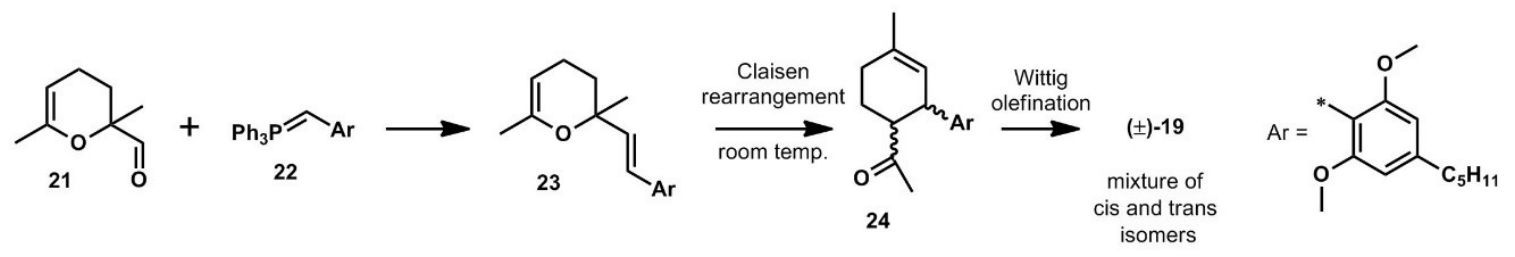

C Kobayashi et al., Assymetric Synthesis of CBD

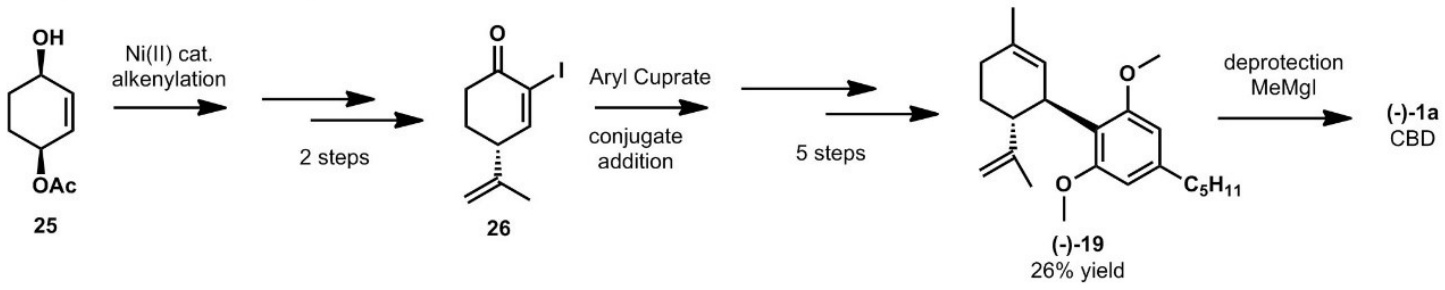

Scheme 1.4. Three approaches to constructing the terpene moiety of cannabinoids

Kobayashi, Takeuchi, and Wang ${ }^{33}$ began their enantioselective route to CBD from 2-cyclohexen-1,4-diol monoacetate25. This route employed a Ni(II)-catalyzed isopropenylation, and an aryl cuprate conjugate addition as key stereoselective $\mathrm{C}-\mathrm{C}$ bond forming steps [Scheme 1.4.C]. In all, five steps involved pyrophoric organometallic reagents, and furnished 19 in $26 \%$ yield from the acetate 25 (no \% ee given).

One year later, Trost and Dogra ${ }^{34}$ reported an asymmetric synthesis of THC using a Mo-catalyzed asymmetric allylic alkylation to introduce a single stereocenter with $95 \%$ ee. Olefin metathesis was used to close the cyclohexenyl ring, and base-catalyzed enolization used to equilibrate the mixture of diastereomers towards the desired one. This eventually provided enantiomerically pure THC in 30\% yield from 17 over 11 steps. 
While most of these routes are ingenious, enantioselective, and amenable to making CBDs modified in any number of places, most of them involve many steps. The extensive use of pyrophoric organometallic reagents by Kobayashi et al., and the purification problems (and low atom economy) associated with the method of Childers and Pinnick make these routes unattractive for large scale production.

\subsubsection{CBD From Acyclic Terpenes}

A biomimetic approach has been taken by a few researchers for concisely constructing the cyclic terpenoid core of CBD and other cannabinoids. Noting that THC and CBD are both putatively produced in vivo through cyclization of CBG 4a, Mechoulam ${ }^{7,8}$ demonstrated a simple procedure in 1965 starting by coupling the methylated olivetol 17 with the naturally occurring aldehyde citral 13 [Scheme 1.5.]. The resulting crude mixture (likely consisting of $\mathbf{2 6 a}$ ) was tosylated, and following in situ thermal rearrangement at room temperature, gave 19 in $2 \%$ yield, alongside a number of other similar products.

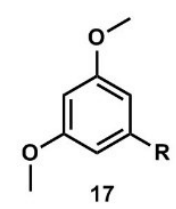

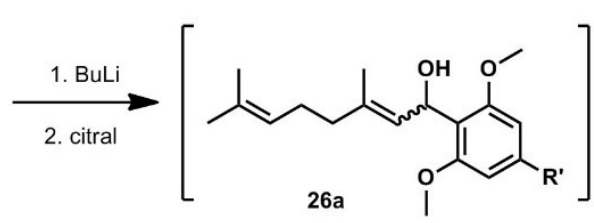
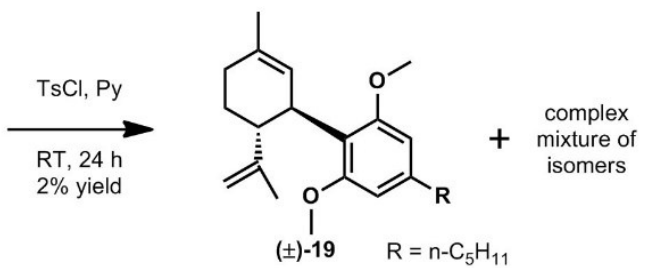

Scheme 1.5.Mechoulam and Gaoni's first synthesis of CBD

In 2004, a similar sequence [Scheme 1.6.] was used again to generate the cyclohexene system of cannabinoids. Again, from the aldehyde 13, Snider and Lobera ${ }^{2}$, and later Park and Lee ${ }^{3}$, made intermediates with the core structure of $\mathbf{2 8}$. When exposed 
to $\mathrm{HCl}$, deprotection of the phenols with concomitant cyclization to the cyclohexene occurred in moderate to high yield. However, not only did this produce the $c i s$-fused ringsystem 30, but the second cyclization (to form the pyran ring) was probably key to driving the reaction toward one major product. This cyclization is thought to proceed through an intramolecular hetero-Diels-Alder mechanism from the quinone methide 29 (and is likely the reason that this reaction works well), whereas that of Mechoulam does not.
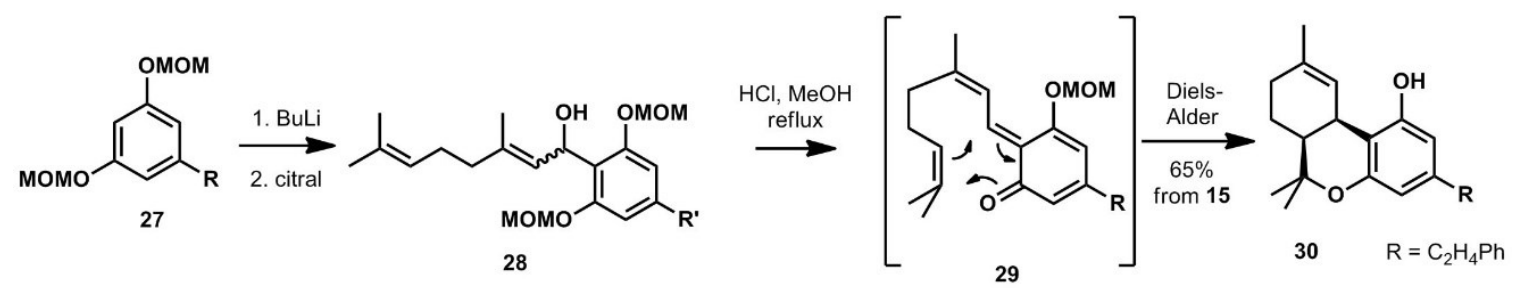

Scheme 1.6. Hetero-Diels-Alder approach to cis-cannabinoid synthesis

This last example illustrates the necessity of using protecting groups on the phenols in cyclization approaches to CBD synthesis. Employing citral $\mathbf{1 3}$ or citronellal $\mathbf{3 1}$ as the acyclic terpenes under various conditions, $\mathbf{2 a}, \mathbf{3 a}, \mathbf{5 a}$, and hexahydrocannabinols have been obtained in moderate to good yields $s^{8,35-37}$, while there is only one report of producing CBD this way in only $3 \%$ yield $^{24}$.

\subsection{Synthetic Challenges}

From the pitfalls of past syntheses of cannabinoids, we can see where the main challenges lie for synthesizing CBD selectively. In order to obtain high regioselectivity at the C-2' site when joining together the terpene and resorcinol moieties, electrophilic aromatic substitutions should be avoided. Because therapeutically relevant doses of THC 
tend to be far lower than those of CBD, even small amounts of THC side products that are difficult to separate may be detrimental in a pharmaceutical application. Therefore, acidic conditions should be avoided in the late stages of the synthesis to avoid unwanted double bond isomerizations or cyclization to THC. In a synthetic route starting from acyclic terpenes, the course of the key cyclization step must be controlled to favour formation of the least substituted alkene. Finally, substitution on the cyclohexene ring and enantioselectivity must be controlled to obtain the (-)-trans-substituted diastereomer.

\subsection{Objective}

As research into therapeutic uses of CBD increases in scale, and it becomes more widely used, there is a need for methods to produce CBD on a large scale and in high purity. Extraction and purification of CBD from the many other components of cannabis is challenging and costly, and at the outset of this project, all current synthetic approaches suffered from at least one of several drawbacks. Therefore, we set out to find an alternative synthetic route to synthesis of CBD that would be scalable and selective. 


\section{Chapter: Results and Discussion}

In order to find an industrially useful synthetic route to medicinal CBD, we set out looking for a route that meets several criteria. An ideal synthetic route should:

a. begin with inexpensive and commercially available starting materials,

b. involve few steps to reduce the costs of reactors, solvents, reagents, purifications, and disposal of waste,

c. produce few side products (such as THC) to reduce operational challenges and costly purification,

d. avoid hazardous materials (such as heavy metals) that could pose a health risk if present in the final product, and

e. have high yield.

Previous syntheses (see introduction) suffered from at least one of the following detrimental characteristics: they involved many steps, inaccessible starting materials, produced complex mixtures of isomers, or resulted in low yield.

To avoid possible acid-catalyzed cyclization to THC or other products, we sought reactions where free phenols would only be manipulated in basic or neutral conditions. Our early ideas of how this could be achieved centered around three main themes. The first was connecting a menthadienyl moiety to the oxygen of a resorcinol, followed by a Claisen rearrangement of 32[Scheme 2.1.A]. The second was based on a decarboxylative allylation of a menthadienol-resorcinol mixed carbonate33[Scheme 2.1.B]. Another possibility was coupling a menthadiene $\mathbf{3 4}$ having an appropriate leaving group, together with the carbanion of a resorcinol [Scheme 2.1.C]. However, all three of these methods 
required access to one of two isomers of $p$-menthadienol 9a or 9c or equivalent as a chiral building block.

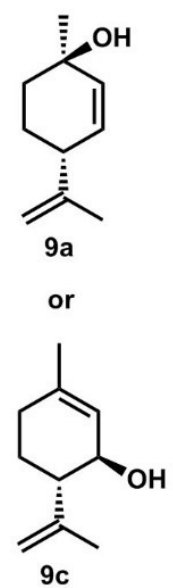

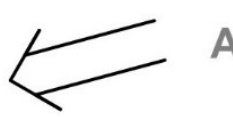<smiles>[R]c1cc(O)cc(O[C@]2(C)C=C[C@@H](C(=C)C)CC2)c1</smiles>

32
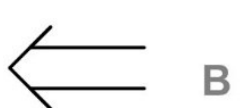<smiles>[R]c1cc(O)cc(OC(=O)O[C@]2(C)C=C[C@@H](C(=C)C)CC2)c1</smiles>

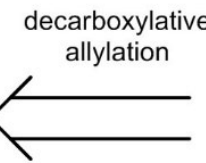

$$
33
$$

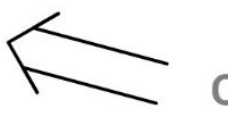

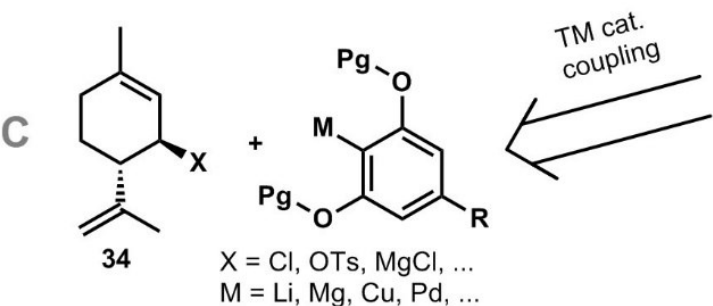

Scheme 2.1. Suggested possible synthetic routes to CBD, via (A) Claisen rearrangement, (B) decarboxylative allylation, and $(C)$ organometallic reagents

Many six-membered cyclic terpenes exist in nature, and are valuable chiral pool building blocks in organic synthesis, with asymmetric centers and a variety of functional groups at various positions [Figure 2.1.]. However, the required menthadienols 9a or 9c are relatively rare. Cis- and trans-p-mentha-2,8-dien-1-ol (9a and 9b) are found in the essential oils of the grass Elyonurus hensii, and some Cymbopogon species ${ }^{38}$. However, at the outset of this project, we could not find any commercial source of these compounds, and synthesis of $9 \mathbf{a}$ and $9 \mathbf{c}$ were deemed not efficient enough for our needs. Thus, we explored methods to access 9a or 9c from available terpenes. 

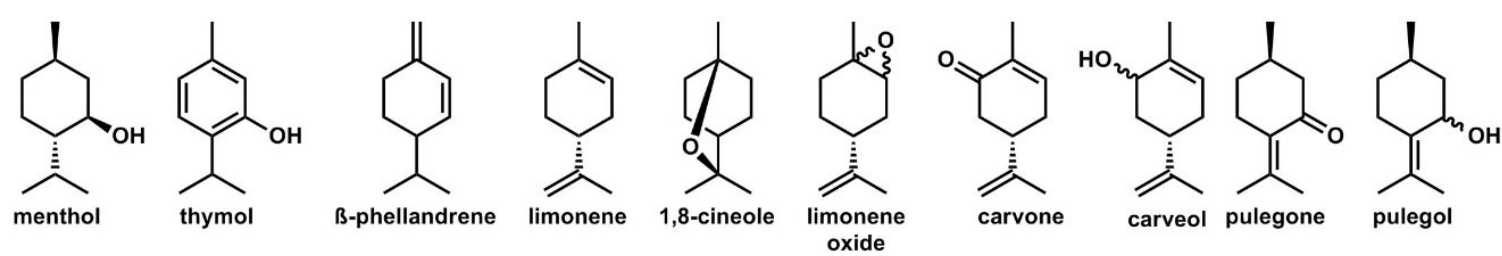

Figure 2.1. Some common naturally occurring cyclic monoterpenes

One such route was envisioned to begin from the aldehyde 13, through an ene reaction [Scheme 2.2.]. While highly enantioselective ene catalysts have been developed, and even demonstrated with citronellal $\mathbf{3 1}{ }^{39}$, ene reactions fail with $\alpha, \beta$-unsaturated carbonyls ${ }^{40}$.<smiles>CC(C)=CCCC(C)CC=O</smiles>

(R)-31

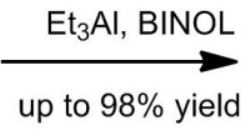

Itoh et al. stereoselective ene reaction

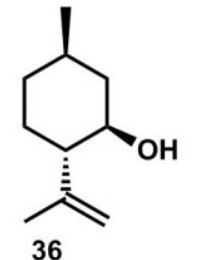

36

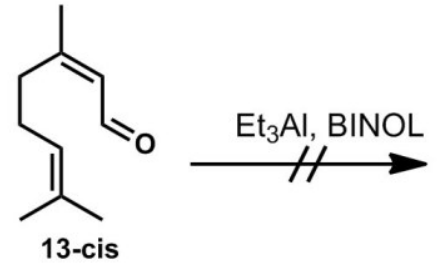

13-cis

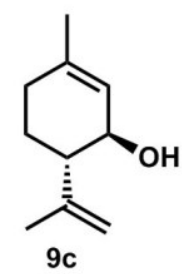

Scheme 2.2. Suggested route to isopulegol 36 and menthadienol $9 \mathrm{c}$ via ene reaction

Schemes in which a conjugate addition to the aldehyde was used to remove the $\alpha, \beta$-unsaturation, then restore it after cyclization, quickly became too lengthy and complex, with concerns over the regioselectivity of sulfoxide pyrolysis [Scheme 2.3].

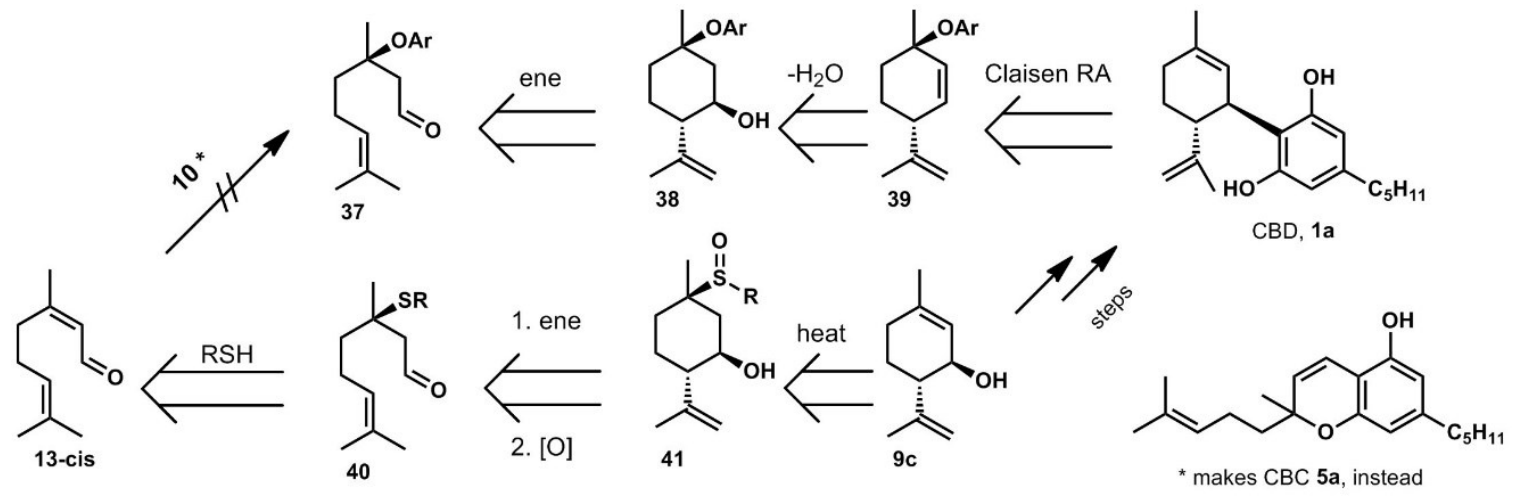

Scheme 2.3. Possible routes to CBD via conjugate additions to citral 13 
Another potential route we envisioned involved a regio- and stereo-selective ring opening of limonene oxide 43 [Scheme 2.4]. This route also seemed problematic because of the need to resolve the commercially available mixture of diastereomers of 43 , as well as concerns about the regio and stereospecificity of the ring opening favouring the wrong isomers $^{41}$.

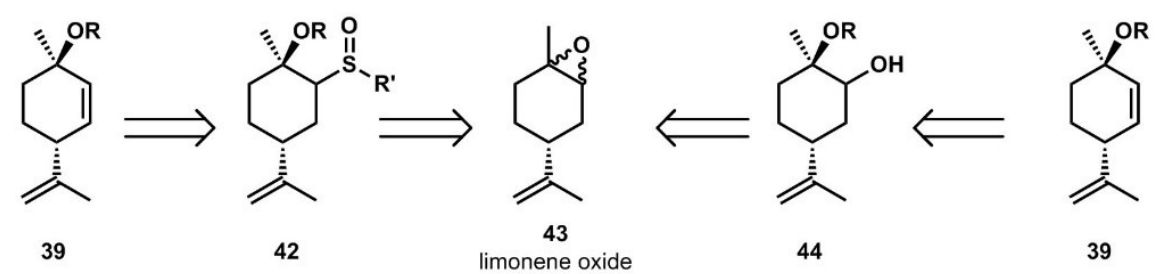

Scheme 2.4. Possible route to menthadienyl aryl ether 39 via epoxide ring opening

We decided to take a different approach to $\mathrm{CBD}$, wherein coupling of the terpene and resorcinol would be done first, followed by cyclization. This route more closely resembles the biosynthesis from $\mathrm{CBG}$, and just like in nature, would potentially allow access to a range of other cannabinoids from a common intermediate. This route [Scheme 2.5] would involve a directed ortho metallation of an O-protected resorcinol 45, followed by 1,2-addition to citral, modification of the resulting alcohol 46 into an appropriate leaving group, followed by cyclization, and finally deprotection of the phenols.
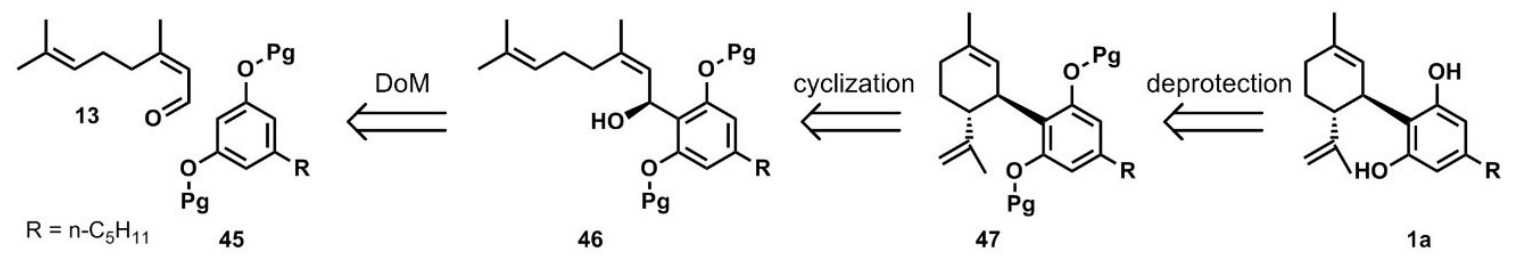

Scheme 2.5. Proposed route to CBD from citral 13 


\subsection{Protecting Group Installation}

In order to prevent a variety of unwanted reactions at the phenols, we elected to install protecting groups on them. These protecting groups must be resistant to BuLi and be removed under neutral, basic or reductive conditions. These two criteria greatly reduced the pool of possible groups to just a few: methyl ethers, carbonate or carbamate esters, and 2-trimethylsilylethyl ethers. The use of allyl or benzyl ethers was ruled out, since the hydrogenative or strongly acidic deprotection methods would likely interfere with the other alkenes in CBD.

We began by making resorcinols with several different protecting groups, using orcinol 48 as a cheaper and readily available homologue of olivetol 10. Methylation with MeI and $\mathrm{K}_{2} \mathrm{CO}_{3}$ in acetone proceeded slowly but cleanly at room temperature, though requiring a large excess of reagents to obtain good yield [Scheme 2.6]. While the most commonly employed conditions to cleave methyl aryl ethers involve harsh Lewis acids, they can also be cleaved under basic conditions using exceptionally good nucleophiles and forcing conditions ${ }^{42}$. Nucleophiles used have ranged from iodide, thiolates, and diphenylphosphide anions. However, one reagent that has had demonstrated utility in cannabinoid systems is MeMgI at high temperature ${ }^{7,27}$. Even if deprotection of methyl aryl ethers requires harsh or impractical conditions, they were a good choice for later method development due to their robustness. 


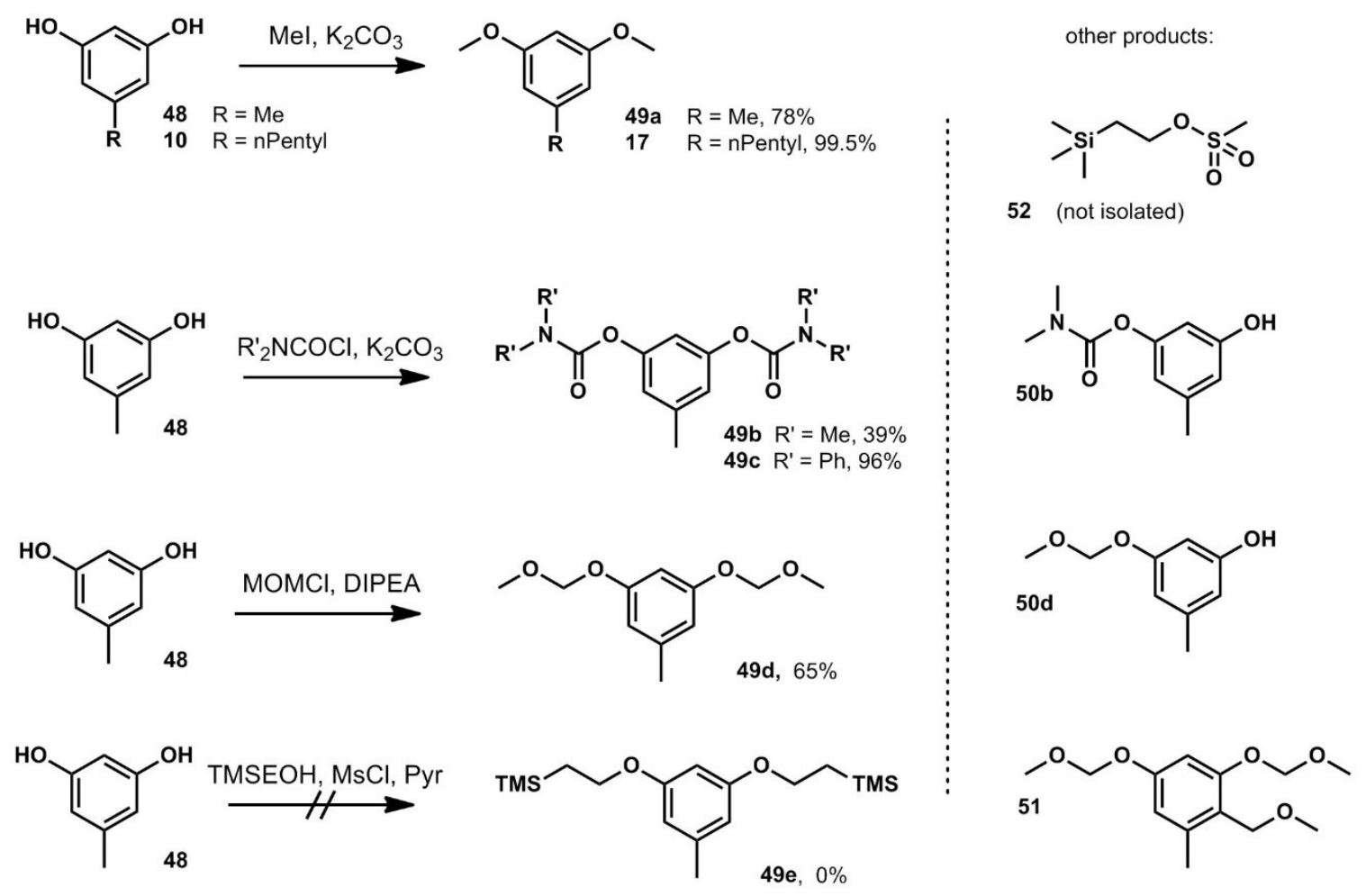

Scheme 2.6. Protection of resorcinols

At the time, carbamates seemed like good choices for protecting the phenol functions. Being very electron-rich carbonyls, they are relatively resistant to nucleophiles. Moreover they have been shown to be excellent directing groups in DoM reactions ${ }^{43}$. We chose $N, N$-dimethyl carbamate (DMC) for simplicity, and $N, N$-diphenyl carbamate (DPC) as one that would likely form crystalline products and simplify purification. Protection of orcinol with diphenylcarbamoyl chloride proceeded in $96 \%$ yield to give an easily crystallized product $49 \mathrm{c}$ [Scheme 2.6]. Although not very atomeconomical, this protecting group is attractive for an industrial process, since recrystallization is among the cheapest and most efficient forms of purification on a large scale, and the amine could be recycled. The DMC protection under similar conditions provided $\mathbf{4 9 b}$ in poo yield, as well as some of the mono-protected $\mathbf{5 0 b}$, and starting material [Scheme 2.6]. An accidental shut-off of the heat source part way through the 
reaction is likely the reason it did not go to completion. While the monoprotected orcinol 50b was crystalline, the bi-protected 49b was not, likely due to more rotatable bonds and lack of hydrogen bond donors, though this method is still worthwhile to investigate.

Silyl based protecting groups are attractive in many total syntheses of natural products since they can be removed under very mild conditions with soluble fluoride sources. However, they can also cleaved with a variety of acids, bases, Lewis acids, and a plethora of other reagents ${ }^{42}$. Bulkier silyl groups tend to be more resistant, but we were worried that very bulky protecting groups would be too sterically hindering for orthodeprotonation of the aromatic ring. The 2-trimethylsilylethyl (TMSE) group seemed ideal, since it leaves the ortho position relatively unhindered, is fairly inert to most bases, and can be deprotected with fluoride in mild conditions. However, installing this group on a phenol is usually done from 2-trimethylsilylethanol using a Mitsunobu reaction ${ }^{44,45}$. Due to the dangerous nature of the azodicarboxylate reagents used in Mitsunobu reactions ${ }^{46}$, a safer method was sought after. Activating the alcohol of TMSEOH with $\mathrm{MsCl}$ [Scheme 2.6] was inspired by a similar reaction by Ortega et al. ${ }^{47}$. However, while the first step appeared to give the expected mesylate 51by NMR of the crude reaction mixture, attempted isolation failed. Formation of the mesylate and reaction with orcinol in a one-pot sequence also failed. Gas evolution during the failed reaction suggests that nucleophilic attack at the silicon by phenolate and/or residual water led to elimination of the TMS and mesylate, producing ethylene. This is a known problem for protection of unhindered phenols under the standard Mitsunobu conditions as well ${ }^{44}$. In light of this, we did not pursue this protecting group further. 
We decided to include methoxymethyl (MOM) ethers in our protecting groups, because CBD would likely be able to survive the mild deprotection conditions without cyclizing to $\mathrm{THC}^{23}$. Additionally, there are some MOM deprotection protocols that do not involve acids ${ }^{42}$. Several attempts at MOM protection of orcinol failed. Reactions in THF appeared to produce large amounts of intractable solids and insoluble tars on workup. Changing the solvent to DCM led to the desired product 49d being formed in moderate yield [Scheme 2.6.], even though the starting material 48is insoluble. Looking at 51, one of the of side products isolated, points to a possible explanation. The extremely electronrich dianion of orcinol is more prone to electrophilic aromatic substitution than the monodeprotonated and the neutral forms. A good coordinating solvent like THF likely led to formation and stabilization of the phenolate anions, leading to $\mathrm{C}$-alkylation, while in a non-coordinating solvent like DCM, the neutral form dominated in solution, leading to Oalkylation. Formation of hard brown insoluble solids, on quenching of the reaction mixtures with water is likely the result of forming phenol-formaldehyde polymers ${ }^{48}$. It was found that removing the volatile components under vacuum before quenching the reaction with water reduced the production of these polymers and simplified workup. Nonetheless, the presence of C-alkylated products demonstrates again the poor regioselectivity of the electrophilic aromatic substitution route we aimed to avoid in our synthesis of CBD. 


\subsection{First Approach: 1,2-Addition to citral}

\subsubsection{DoM, Chelation, and 1,2-Addition}

Based on the work by Park and Lee ${ }^{3}$ and Snider and Lobera ${ }^{2}$, easy access to the desired intermediate 46a could be gained from the 1,2-addition of the appropriate carbanion to the cheap and readily available citral $\mathbf{1 3}$ [Scheme 2.7.]. Although several methods of generating the appropriate carbanion $\mathbf{5 3}$ exist, the simplest method was to use directed ortho metallation (DoM). DoM relies on the presence of a Lewis basic substituent on the aromatic ring to coordinate to the metal of an organolithium reagent, thereby promoting abstraction of the nearest aromatic proton. All three or the aryl protons in our substrates (49aor17)are ortho to a directing group, and have similar steric environments.

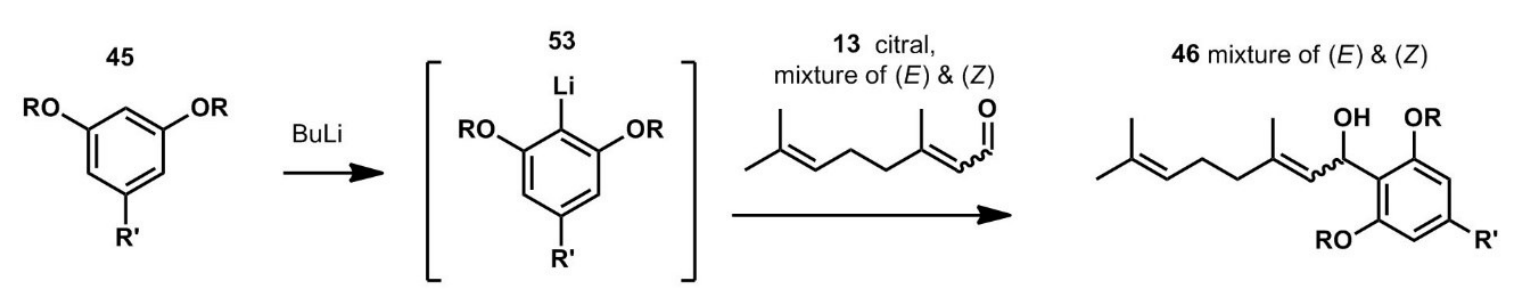

Scheme 2.7. DoM and 1,2-addition to aldehyde 13

We thought using protecting groups that could cooperatively chelate to lithium through additional heteroatoms [Figure 2.2.] would promote regioselectivity at the 2position over the 4-position, hence the choice of methoxymethyl and carbamoyl protecting groups. 


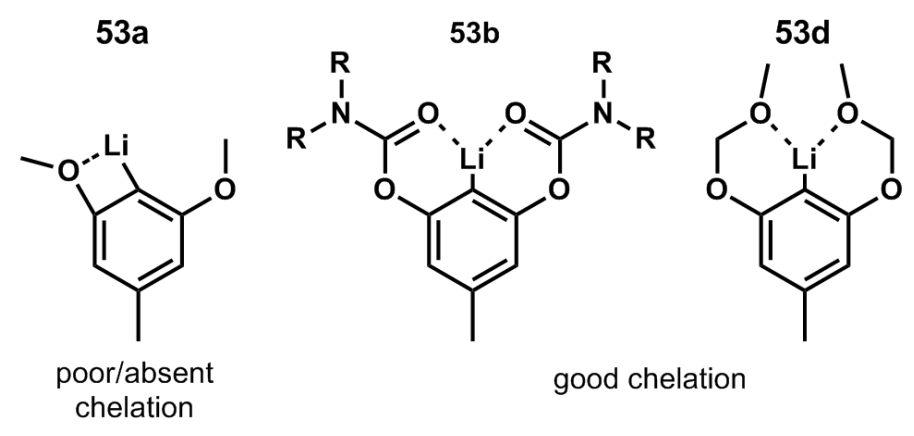

Figure 2.2. Possible co-operativity of DMGs by chelation during directed ortho metallation of 53

However, we found that the methyl protected orcinol 49a underwent deprotonation only at $\mathrm{C}-2$ ' with ${ }^{\mathrm{n}} \mathrm{BuLi}$ in $\mathrm{THF}$, even though $\mathrm{Li}$ cannot coordinate to both oxygens simultaneously. This is likely caused by 49 a coordinating to organolithium clusters - the dominant species in solution ${ }^{43}$ - rather than the ${ }^{\mathrm{n}} \mathrm{BuLi}$ monomer. Addition of the intermediate aryllithium 53a to citral (itself a mixture of $(E)$ and $(Z)$ isomers) gave what appeared to be almost entirely a 1:1 mixture of $\mathbf{4 6} \mathbf{a}$ and $\mathbf{4 6} \mathbf{b}$ [Scheme 2.7.], along with some unreacted starting materials, and what was later identified as $\mathbf{5 4}$ [Figure 2.3.]. The analogous reaction with $\mathbf{4 9 d}$ gave poor results and much more 54, likely due to the presence of water in the starting material.

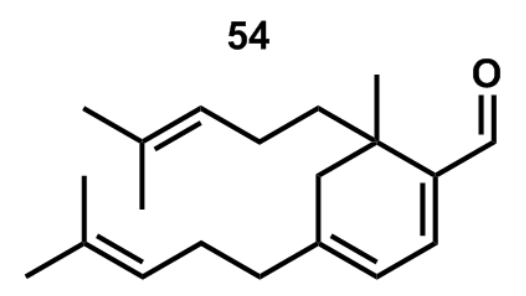

Figure 2.3. Citral pseudodimer side product

It was now that we came upon work by Snieckus \& co-workers showing that when -OCONEt 2 are used as DMGs, and $\alpha, \beta$-unsaturated aldehydes as the electrophiles, an undesired rearrangement occurs ${ }^{37}$. This consists of deprotection of the phenol by an $O$ aryl to $O$-alkyl carbamoyl migration, followed by a cyclization to yield a chromene57 
[Scheme 2.8.]. Attempts to isolate or trap synthetically useful intermediates were reportedly unsuccessful. In our case, this reaction would lead to cannabichromene $\mathbf{5 c}$, itself a biologically relevant cannabinoid ${ }^{10}$. Another problem with dimethyl carbamates in DoM reactions (as opposed to the commonly used diethyl-) is that they tend to undergo anionic ortho-Fries rearrangements ${ }^{43}$. Since steric factors play an important role in cleavage of $O$-aryl carbamates ${ }^{43}$, the DPC protecting group might perhaps be still useful in this synthetic route to CBD.

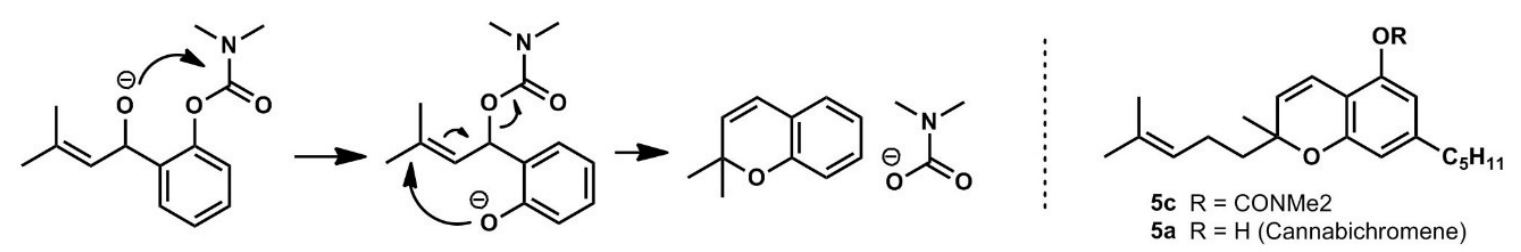

Scheme 2.8. Carbamoyl migration and phenolate rearrangement

\subsubsection{Isomers \& Stability of $\mathbf{4 6}$}

Attempts at purification by column chromatography failed to give 46a. Instead, the tertiary alcohol $\mathbf{4 6 c}$ was obtained as the E-isomer exclusively [Scheme 2.9.]. In an attempt to avoid acid catalyzed isomerization, replacing the silica gel with basic alumina provided improvement, but some isomerization still occurred, giving an impure mixture of substituted nerol- 46a, geraniol- 46b, and linalool- derivatives 46c. Though not our intended molecule, 46c still has the potential to undergo cyclization to $\mathrm{CBD}$, so we attempted to isomerize the crude $\mathbf{4 6 a}$ completely to $\mathbf{4 6 c}$ by mixing with silica. However, this also gave incomplete isomerization, and a complex mixture of impurities began to appear as well. Storage of the $\mathrm{SiO}_{2}$-isomerised $46 \mathbf{c}$ at $\mathrm{RT}$ after several months led to significant decomposition, possibly due to trace $\mathrm{SiO}_{2}$. However even a portion of the crude reaction mixture, which had been worked up in basic conditions, had isomerised 
cleanly to 46c after several months' storage. This suggests that adventitious water or other 46a molecules are enough to catalyze the isomerization.
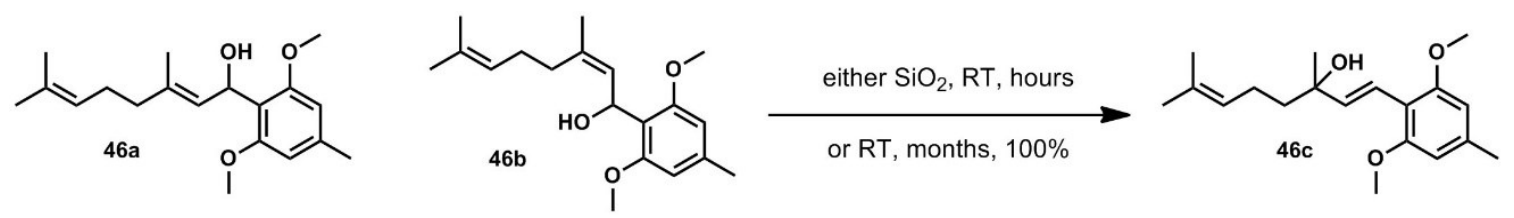

Scheme 2.9. Isomerization of intermediate 46

Addition of 53a to the non-conjugated aldehyde, citronellal 31, gave a mixture of diastereomers of $\mathbf{5 8}$ [Scheme 2.10.]. This compound, unlike 46a, presented no problems upon purification by FCC on silica, and showed no decomposition after one year of storage at room temperature. As will be discussed later, the deoxygenated analogue, 69a, was prepared and was also quite stable. Missing the aryl moiety, the corresponding naturally occurring alcohols nerol, geraniol, and linalool are also stable. The combination of an electron-rich alkene and an electron-rich benzene ring are able to stabilize a carbocation at $\mathrm{C}-1$ so well that even a poor leaving group like $\mathrm{OH}$ becomes labile under oxygen or trace acid. Removing any one of the alkene, the arene, or the oxidized center makes the system much more stable.<smiles>COc1cc(C)cc(OC)c1</smiles>

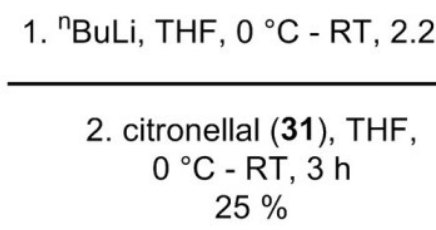<smiles>COc1cc(C)cc(OC)c1[C@H](O)C[C@@H](C)CCC=C(C)C</smiles>

Scheme 2.10. Synthesis of 58 


\subsubsection{Acid Catalyzed Cyclization of $46 c$}

Our initial goal was to use a dynamic kinetic resolution (DKR) to convert the racemic secondary alcohol $\mathbf{4 6 a}$ to a single enantiomer. This perhaps could be achieved through the use of a Meerwein-Ponndorf-Verley reduction or Oppenauer oxidation system ${ }^{49}$. The advantage of DKR is that $100 \%$ yield is theoretically possible, whereas the limit is $50 \%$ for a simple resolution. This would be followed by converting the alcohol to an appropriate leaving group, and performing a stereoselective transition-metal-catalyzed cyclization, for example, through the use of a Pd-catalyzed Heck reaction ${ }^{50}$, or the Ir catalytic system developed by Carreira ${ }^{51}$. In order to obtain the desired structure, such a transformation requires a cascade of two steps: a 6-exo-trig cyclization with trans stereoselectivity, followed by a regiopecific elimination to generate the terminal alkene. Given the instability of $46 \mathbf{a}, \mathbf{4 6} \mathbf{b}$, and $\mathbf{4 6 c}$ (as well as any derivatives of them), the problems associated with their purification and their potential racemization, this route now seemed much more problematic.

Rather than fight against the easy isomerization of $46 \mathbf{a a n d} \mathbf{4 6} \mathbf{c}$, we thought we might use it to our advantage. Inspired by the work of W Johnson ${ }^{52}$ on biomimetic polyene cyclizations, we decided to try a cationic cyclization by protonation of the alcohol.

Tertiary allylic alcohol $46 \mathbf{c}$ was stirred at room temperature in 50:50 ethanol:water with HOAc at $\mathrm{pH}$ 3.5-4.0 [Scheme 2.11.]. These conditions were chosen because they would likely be mild enough for MOM groups to survive, if these were later chosen. Water was used as a nucleophilic cosolvent so that trapping of reactive intermediate carbocation $\mathbf{6 0}$ would occur rather than further cyclizations or 
rearrangements. Ethanol was chosen for its distinctive ${ }^{1} \mathrm{H}$ NMR pattern that would be easy to identify if incorporated into the products. After less than 15 minutes, new products were observed by TLC. After $6 \mathrm{~h}$, NMR of a portion of the mixture showed a complex composition of products. Even after 14 days, TLC appeared to show that starting material remained. The remainder of the reaction mixture was quenched and purified via flash chromatography, producing an interesting array of products, summarized in Table 1.

Table 1 Acid catalyzed cyclization of allylic alcohol 46c; identified compounds

\begin{tabular}{ccr}
\hline Fraction & Product & \% Yield [semi] isolated \\
\hline $\mathrm{a}$ & $\mathbf{6 2}$ & 1.0 \\
\hline $\mathrm{b}$ & $\mathbf{6 3}$ & 6.3 \\
\hline $\mathrm{c}$ & $\mathbf{6 6 a}$ & 2.3 \\
& $\mathbf{6 6 b}$ & 1.4 \\
& $\mathbf{6 6 c}$ & 2.9 \\
\hline $\mathrm{d}$ & $\mathbf{6 4}$ & 10.0 \\
& $\mathbf{6 5}$ & 5.0 \\
\hline & total & 28.9 \\
& unidentified & 71.1 \\
\hline
\end{tabular}

The first substance identified, and the only one isolated in pure form was the cymene 63, showing that indeed the desired 6-exo-trig cyclization took place. However, the resulting $\alpha$-terpinyl cation $\mathbf{6 0}$ underwent a 1,2-hydride shift followed by deprotonation to one of two possible cyclohexadienes $66 \mathbf{d}$ or $66 \mathbf{e}$ which were not isolated[Scheme 2.11.]. Facile aerobic oxidation ensued to aromatize the ring. Reexamination of the crude mixture after months of storage showed, by NMR, the amount of $\mathbf{6 3}$ had increased from trace levels to a significant fraction of the whole. 


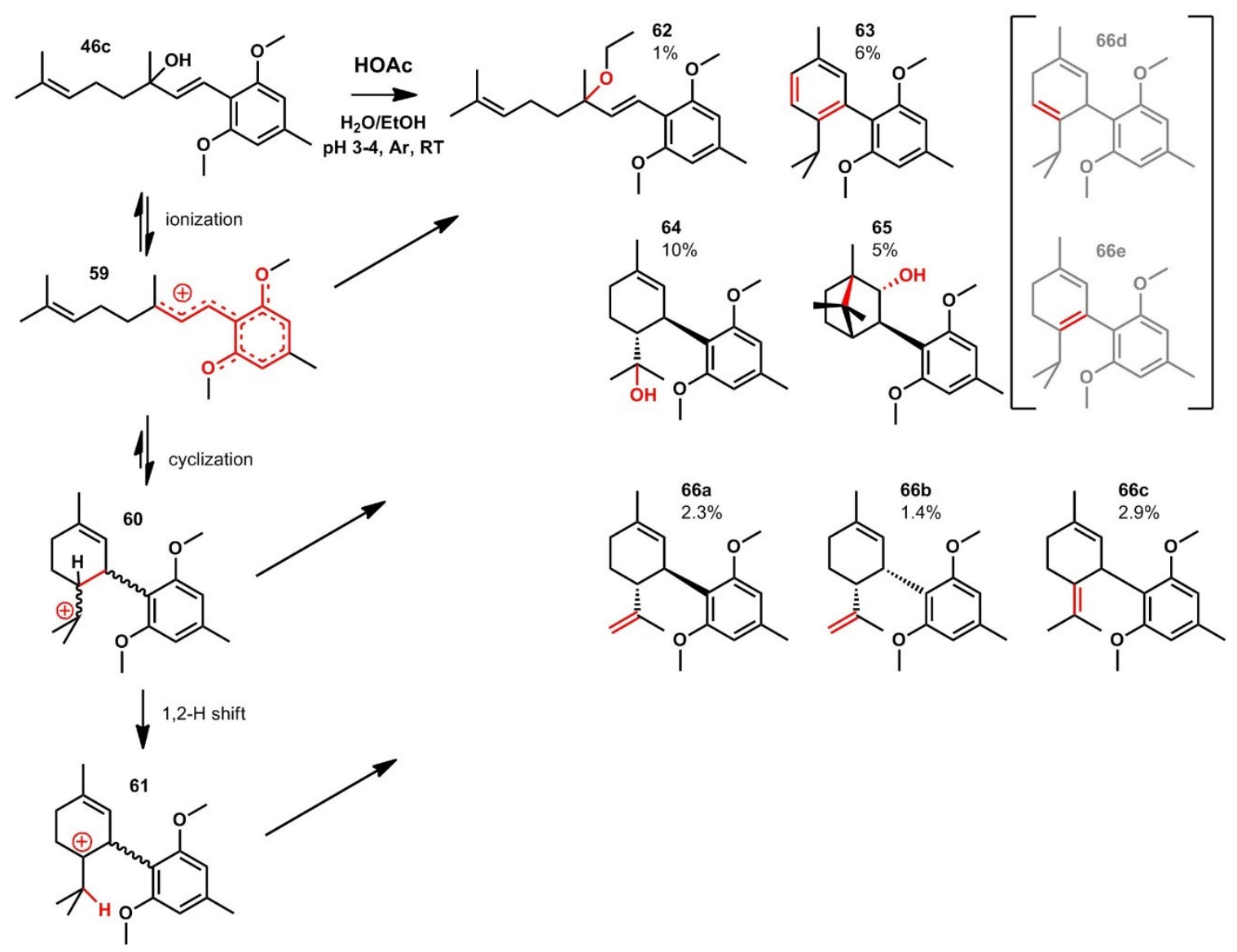

Scheme 2.11. Acid catalyzed cyclization of 46c. Colour indicates key bonds changing.

Not surprisingly, impure 62 was identified, by the distinctive NMR signals of the ethoxy group. This results from quenching of the carbocation $\mathbf{5 9}$ by solvent. The rest of the products eluded identification until after the results of chapter 2.3.5. were obtained. One fraction was identified as a mixture of $\mathbf{6 4}$ (which matches well with the known pentyl analogue ${ }^{34}$ ) and what is believed to be $\mathbf{6 5}$. The alcohol 64 is not undesired, since a relatively straightforward dehydration would give the desired protected CBD, 66a. The other product 65, is interesting because it originates from the undesired ring closure leading to the cis diastereomer. Whatever its exact structure, placement of one of the geminal methyl groups above the plane of the aryl ring gives it a unique ${ }^{1} \mathrm{H}$ chemical shift. Restricted rotation of the aromatic ring causes the methoxy groups to be 
inequivalent. Another chromatographic fraction contained a mixture of three nonpolar products, which are believed to be the desired $66 \mathbf{a}$, as well as undesired $66 \mathbf{b}$, and $66 \mathbf{c}$. Under these conditions, it is not surprising that elimination favoured the most stable alkene 66c.

This distribution of products is similar to the cationic cyclization reported by Mechoulam ${ }^{7,8}$, which used the corresponding tosylate of $\mathbf{4 6 a}$ in pyridine at room temperature. This system, while in drastically different conditions, also provided about $2 \%$ yield of the desired CBD methyl ether $\mathbf{6 6 a}$, as well as low yields of the $\mathbf{6 3}, \mathbf{6 6} \mathbf{b}$, and 66c analogues [Scheme 1.5]. In the works of Park and Lee ${ }^{3}$, and of Snider and Lobera ${ }^{2}$, they reported moderate yields and reasonable stereoselectivity in similar cyclizations. However this was achieved through the use of either an intramolecular trapping of the $\alpha$ terpinyl cation, or an entirely different Diels-Alder mechanism, to yield tricyclic cisTHC-like materials[Scheme 1.6.].

In the cationic polyene cyclizations used in the construction of steroid backbones, each subsequent cyclization erases the previous functionality, leaving only one pathway possible for polycyclization ${ }^{52}$. However, in our case, we require halting the reaction after just one cyclization, leaving some functionality intact. This makes finding the right reaction conditions more difficult.

In nature, monoterpenes are synthesized from GPP by ionization to the allylic cation (with $(E)$ to $(Z)$ isomerization), promoted by metal ions. This occurs inside the hydrophobic pocket of monoterpene and sesquiterpene synthase enzymes, where it is thought the reactive intermediates are stabilized by cation-dipole and cation- $\pi$ interactions, and protected from premature quenching by nucleophiles ${ }^{14,15}$. The Tail to 
Head terpene (THT) cyclization allows access to a plethora of natural products from a single common precursor by a cascade of cyclizations, hydride shifts, and carbon skeletal rearrangements, before termination by either elimination or quenching with a nucleophile [Scheme 2.12. $\left.{ }^{14}\right]$.

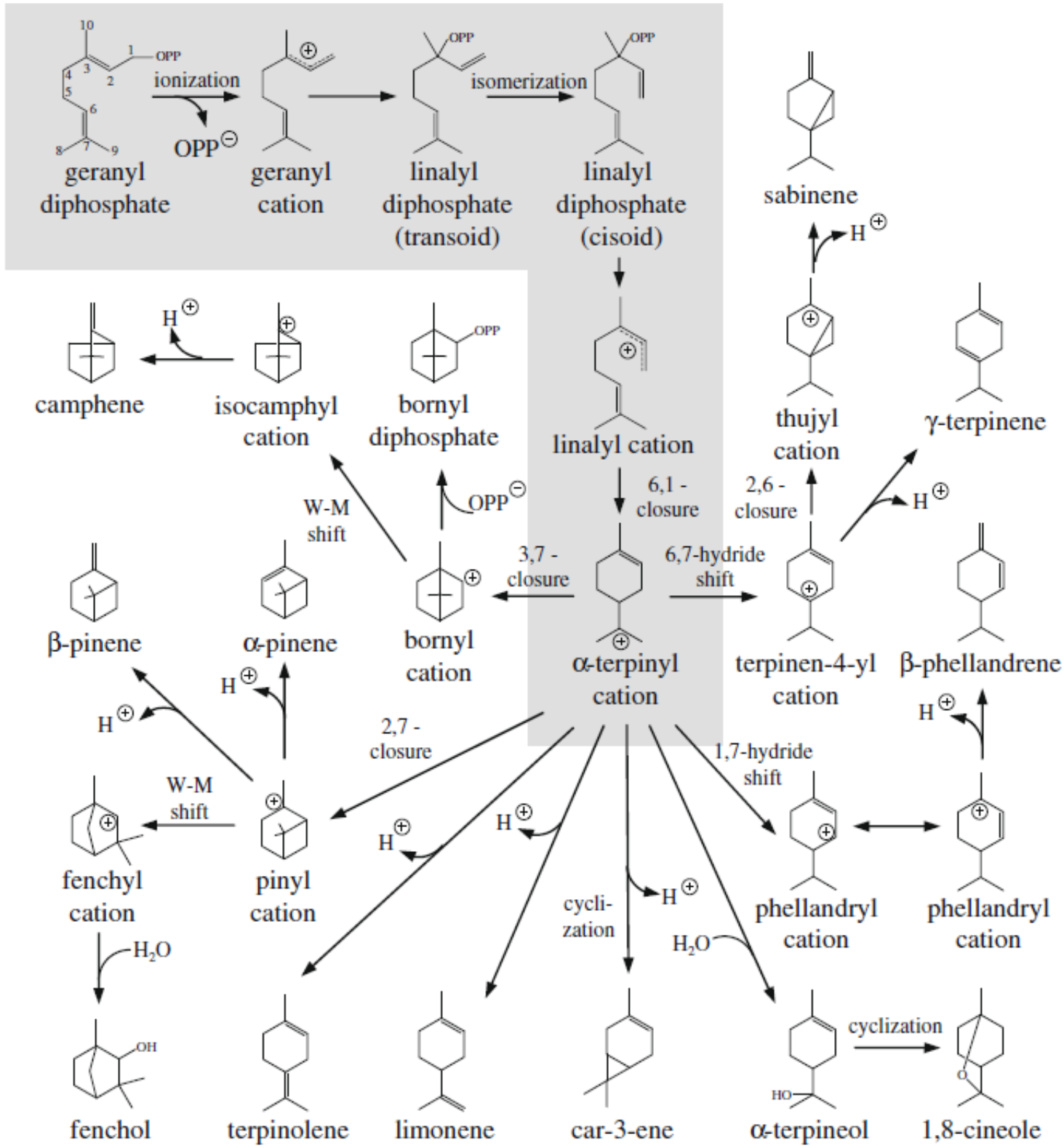

Scheme 2.12. Tail to Head Terpene cyclizations in nature; (reproduced from reference 14 ) 
Another complicating factor is the nature of the starting material. The $(E)$ double bond in GPP must isomerize to the cisoid carbocation to access the universal $\alpha$-terpinyl cation. In the absence of enzymes, THT cyclizations tend to be very difficult to control, and produces a multitude of products ${ }^{15,53}$. In an example by Zhang et al. ${ }^{15}$ THT cyclizations inside an enzyme-mimicking hydrophobic cavity produced different product distributions whether initiated from geraniol, nerol, or linalool.

\subsection{Second Approach: Allylation and Oxidative Cyclization}

In light of the difficulties involved with purification and stability of $\mathbf{4 6}$ as well as having no clear way to control the cationic cyclization, we sought to find a different method of cyclization. Looking back to the biosynthesis of cannabinoids, the common acyclic precursor CBG must undergo an oxidation before cyclization can take place. We decided to access CBD through intermediate 69, and use an oxidative approach to cyclization. The advantage of using $\mathbf{6 9}$ is that it is bench-stable, and the configuration of the double bond can be fixed into the desired $(Z)$ configuration. Removing the oxygen at C-1 also reintroduces the carbamates as potential protecting groups.

\subsubsection{Allylation}

This route [Scheme 2.13.] began by chlorination of nerol with $\mathrm{PPh}_{3}$ and $\mathrm{CCl}_{4}$. Precipitation of the bulk of the phosphine and phosphine oxide gave a relatively clean product, and short-path distillation produced pure 68. Although organic halides are often scrubbed of HX by filtering though basic alumina immediately before use, even recently distilled 68 reacted vigorously and exothermically with alumina. This caused a drastic 
colour change and some loss of purity, and accordingly, this purification technique was bypassed for experiments with $\mathbf{6 8}$.
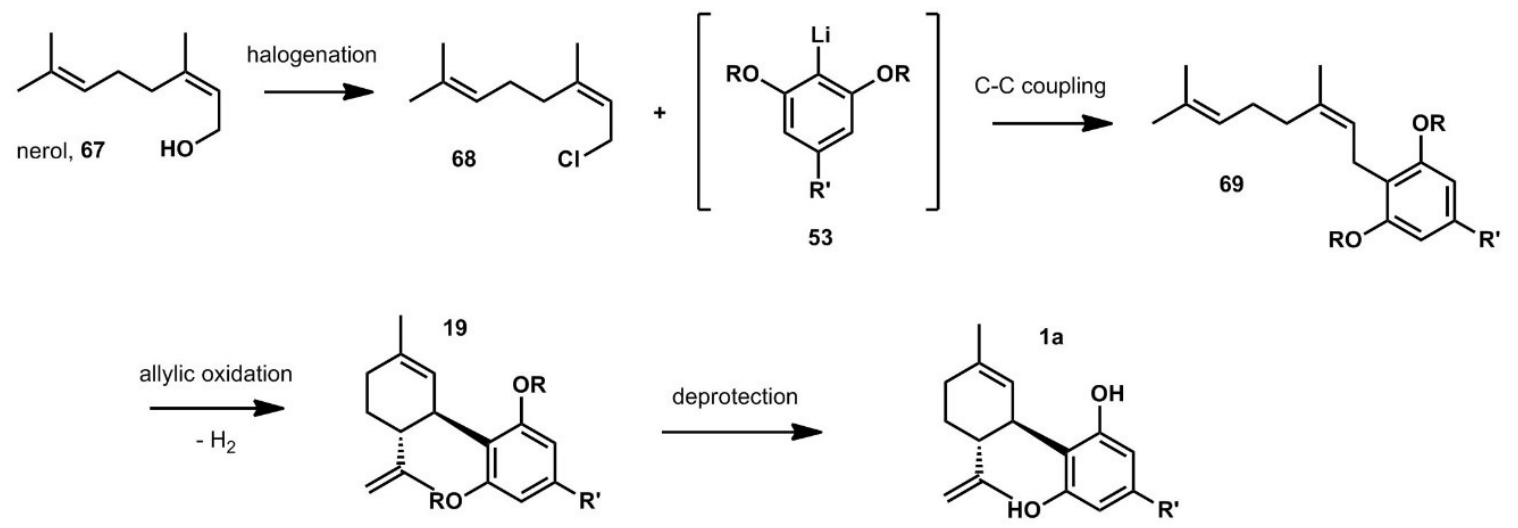

Scheme 2.13. Synthesis of CBD from nerol

Coupling was again achieved by DoM of 49a followed by quenching with the electrophile, 68. In THF, this reaction failed (the cause was later identified as the presence of peroxides in THF). In cyclohexane, $36 \%$ yield was obtained. This material appeared pure by NMR, but showed some impurities by TLC, suggesting perhaps minor amounts of $(E)$ isomer or regioisomers. Conducting the metallation in $\mathrm{Et}_{2} \mathrm{O}$ with TMEDA, and the alkylation in xylenes gave pure 69a in 19\% yield after two cycles of chromaography. A NOESY analysis [see F2.17] of this material showed the (Z) configuration of the nerol starting material $\mathbf{6 7}$ was preserved. The latter two reactions appeared relatively clean by crude NMR, with 69a as the only main product, and hydrocarbon impurities easily separable. However, the iterative chromatography used to separate 49a from 69a likely led to low recovery. Perhaps evaporation of 49a would be more efficient for purification on a larger scale. 
At this time, an affordable source of olivetol $\mathbf{1 0}$ and CBD $\mathbf{1}$ became available, allowing us to compare our results to the naturally occurring $\mathrm{CBD}$, with a pentyl endchain. By making the pentyl analogue $69 \mathrm{~b}$, we reasoned we could make screening and optimization of oxidative cyclization conditions much more focused and efficient, by comparing reaction mixtures to authentic methylated CBD. By monitoring many reactions in parallell with TLC, we should achieve higher throughput.

Methylation of olivetol with MeI was made nearly quantitative, by employing a large excess of $\mathrm{K}_{2} \mathrm{CO}_{3}$ [Scheme 2.6.]. Methylation of CBD 1 also appeared to be relatively clean and high yielding by NMR, but losses in purification by preparatory TLC provided only $21 \%$ yield of 19 . In the event that a further unwanted cyclization to THC occurred in the oxidative reaction, methyl THC 71 was analogously prepared.

Alkylation of $\mathbf{1 7}$ was conducted as before in $\mathrm{Et}_{2} \mathrm{O} /$ xylenes, but with the addition of catalytic LiBr. Crude NMR showed 50:50 17:69b as the only major aryl compounds, corresponding to 50\% yield, but DCVC purification proved inefficient, and once again, losses led to only $92 \%$ pure $69 \mathrm{~b}$ in $28 \%$ yield. A NOESY experiment [F2.17] showed the (Z) double bond was preserved under these conditions as well.

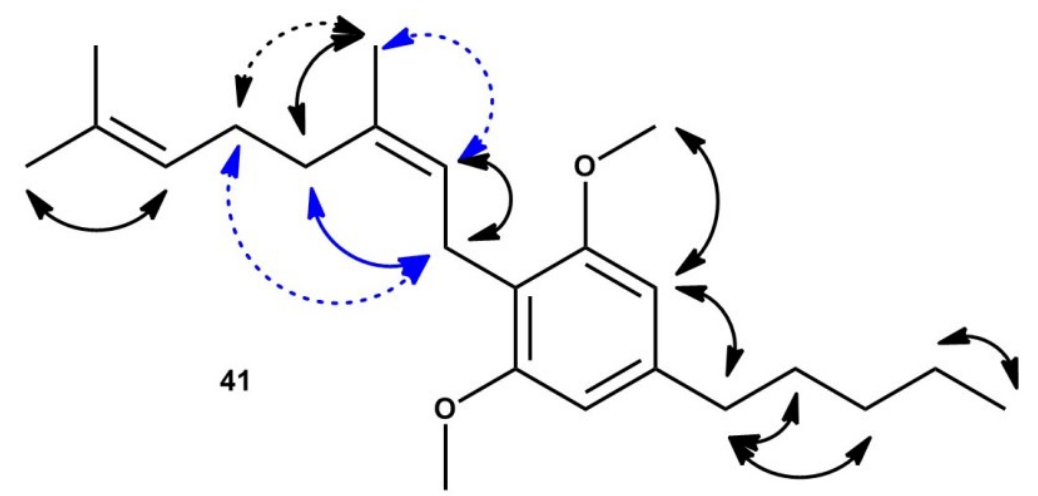

Figure 2.4. Key NOESY correlations in $69 \mathrm{~b}$ indicative of $(Z)$ double bond geometry 


\subsubsection{Oxidation: Reaction Monitoring \& Product Separation}

With 69b, 19 and 71 in hand, all that remained was screening oxidants and reaction conditions by TLC. Alas, 19 and $69 \mathrm{~b}$ have identical normal-phase chromatographic properties in nearly all solvents, though they are readily separated from 71. The only solvent systems found able to provide minimal separation were $p$-cymene in $\mathrm{CyH}$, and $o$-dichlorobenzene (o-DCB) in $\mathrm{CyH}$. While more toxic and less pleasantsmelling, $o$-DCB was the solvent of choice at the time for its higher purity. Staining TLC plates with anisaldehyde, $\mathbf{1 9}$ spots quickly turned a bright cyan colour upon applying heat, while most other compounds resulted in often dull colours after prolonged heating. This minimal separation and distinct colour made it possible to detect 19 in reaction mixtures, though only in very high concentration, and without a high degree of confidence. Additionally, removal of $o$-DCB (bp. $180^{\circ} \mathrm{C}$ ) was so slow as to make monitoring at regular time intervals impractical.

Without convenient or reliable TLC monitoring conditions, or ready access to an HPLC or GC, the main method of detecting 19 in reaction mixtures was ${ }^{1} \mathrm{H}$ NMR. The peaks from any of the alkene protons proved to not be very useful. Though not at first apparent, the benzylic-allylic proton at C-1 and that at C-6 (assigned by COSY, [Figure 2.5.], see also Appendix Figure A30) were most easily detected. 

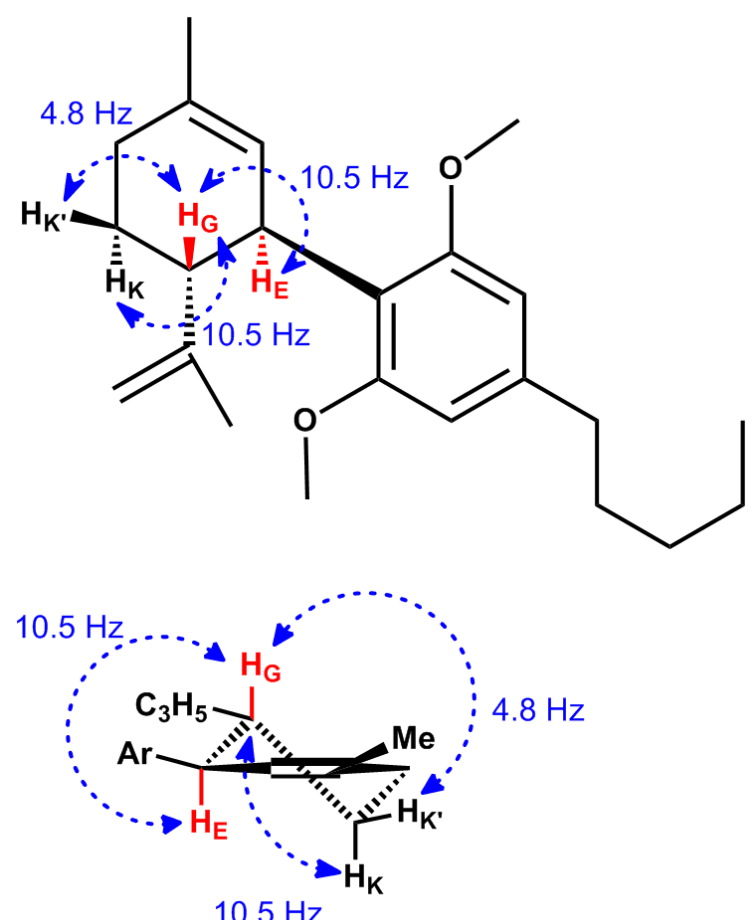

Figure 2.5. Key characteristic ${ }^{1} \mathrm{H}$ NMR resonances of 19 useful to assigning relative stereochemistry

\subsubsection{Oxidation: Possible Mechanisms}

Oxidative cyclization of 19 to $69 \mathrm{~b}$ might occur through either a cationic or a radical process. Two-electron oxidation [Scheme 2.14.A.], such as with 2,3-dichloro-5,6dicyanobenzoquinone (DDQ), begins with abstraction of a hydride, generating benzylic carbocation 72. This cation must then undergo capture by the distal alkene, before regiospecific deprotonation of the tertiary carbocation $\mathbf{7 4}$ by a base. As suggested by Park $^{3}$ and by Snider ${ }^{2}$, for similar molecules, cyclization could occur though a heteroDiels-Alder reaction from the quinone methide resonance form 73. In these examples, cyclization resulted in a cis- $\Delta^{9}$-THC core 16, but the desired trans product should not be ruled out. From the resulting oxonium 75, deprotonation must be favoured over demethylation to arrive at 19. 


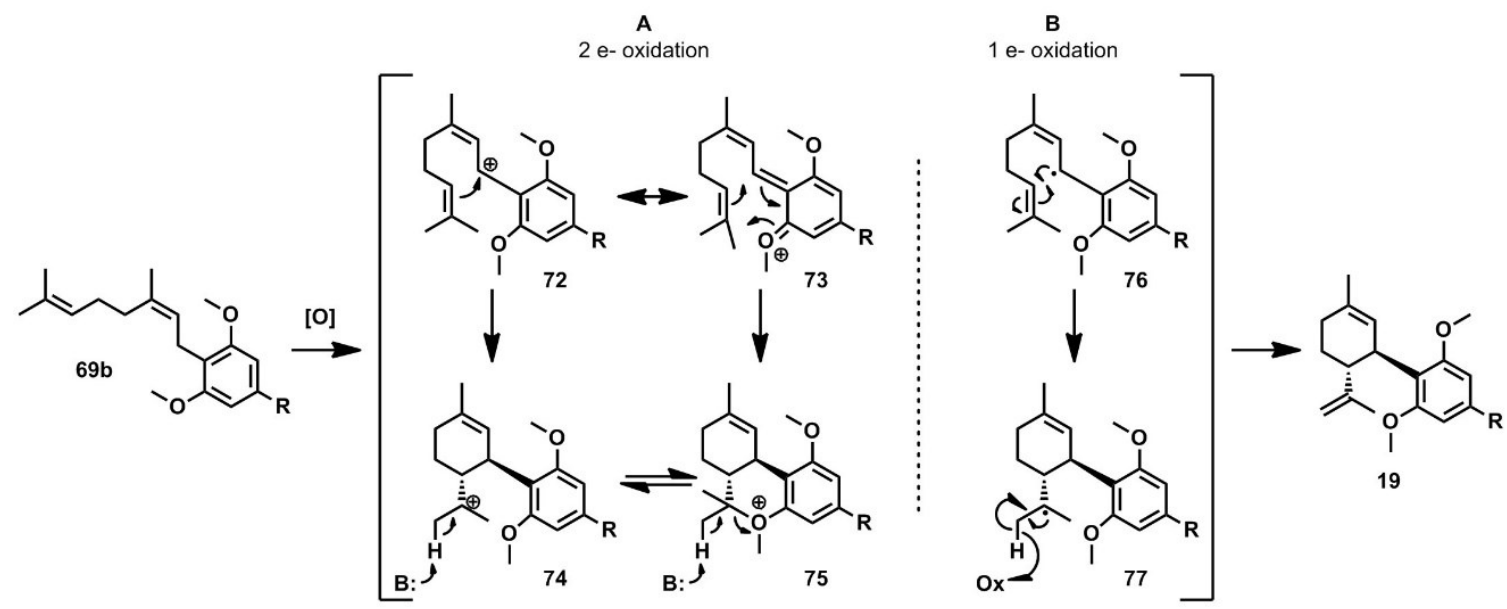

Scheme 2.14. Oxidative cyclization pathways: (A) cationic and (B) radical mechanisms

In an alternative process [Scheme 2.14.B], a one-electron oxidant must generate the benzylic radical 76, either by direct hydrogen abstraction, or by oxidation of the aryl ring to a radical cation $\mathbf{7 8}$, followed by deprotonation. A 6-exo-trig radical cyclization must ensue, followed by another equivalent oxidant effecting either another hydrogen abstraction, or a second oxidation followed by regiospecific deprotonation. While the radical mechanism is less likely to suffer from small ring formation and interference by nucleophiles, the electronic factors of the cyclization are unfavourable, allowing ample time for premature termination. The results of several attempted oxidations are summarized in Table 2.

\subsubsection{Oxidation: Reagents}

We first turned our attention to quinones as promising $2 \mathrm{e}^{-}$oxidants, well known for mild and neutral benzylic oxidations ${ }^{54-56}$. Quinones are available with a wide variety of substituents, making it possible to tune their reactivity ${ }^{57}$. Oxidation of $69 \mathbf{b}$ with 1 equivalent of tetrachlorobenzoquinone (chloranil) produced a complex mixture and no desired product. While oxidations with DDQ are often performed at high temperatures 
and lengthy reaction times, $69 \mathbf{b}$ consumed DDQ immediately at room temperature in a 1:2 ratio. Since80 was only isolated in trace yield from the complex mixture, it shows that premature deprotonation occurred followed by a second equivalent of DDQ acting as a dienophile [Scheme 2.15.]. This type of reaction (and even the associated colour changes) is known in the literature ${ }^{55}$.

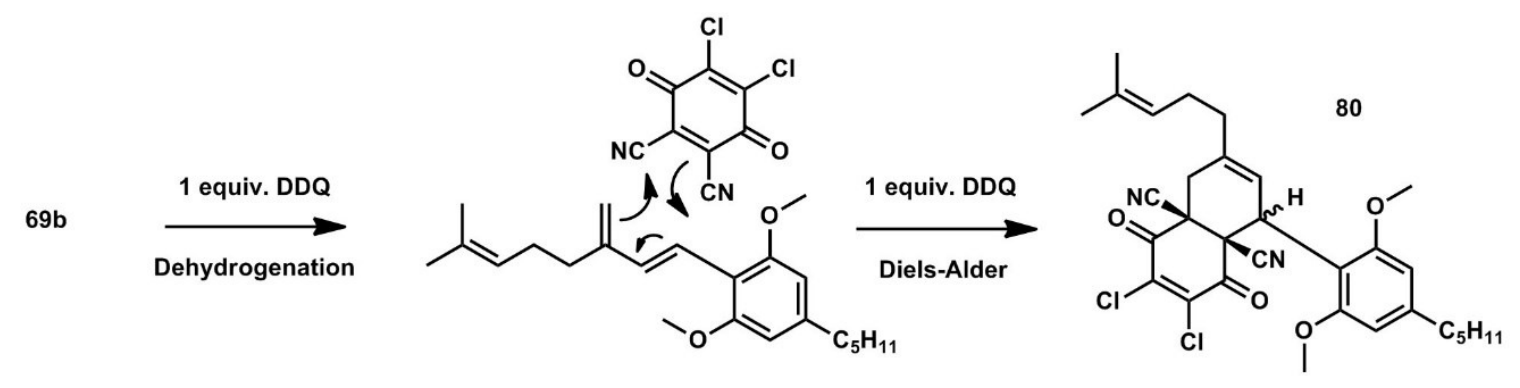

Scheme 2.15. Probable oxidation of $69 \mathrm{~b}$ with DDQ

Table 2 Screening of oxidants for the oxidative cyclization of $69 \mathrm{~b}$

\begin{tabular}{|c|c|c|c|c|c|}
\hline Entry & Oxidant & $e^{-}$ & Equiv & conditions & result (estimated by NMR) \\
\hline 1 & DDQ & 2 & 1.2 & $\mathrm{C}_{6} \mathrm{D}_{6}, \mathrm{RT}, 4 \mathrm{~min}$ & complex mixture, trace $\mathbf{8 0}$ isolated \\
\hline 2 & TCQ & 2 & 1.2 & $\mathrm{C}_{6} \mathrm{H}_{6}, 85^{\circ} \mathrm{C}, 7 \mathrm{~h}$ & complex mixture \\
\hline 4 & CAN & 1 & 2.0 & $\mathrm{MeOH}, \mathrm{RT}$, & unreacted $69 b+$ highly polar products \\
\hline 5 & NBS & 1 & 1.1 & $\begin{array}{l}\mathrm{CCl}_{4}, 0.02 \text { equiv } \mathrm{AIBN}, 75^{\circ} \mathrm{C}, 15 \\
\text { min }\end{array}$ & $\begin{array}{l}\text { unreacted } 69 \mathrm{~b}+\text { complex nonpolar } \\
\text { products }\end{array}$ \\
\hline 6 & $\begin{array}{l}\mathrm{Mn}(\mathrm{OAc})_{3} \\
\cdot 2 \mathrm{H}_{2} \mathrm{O}\end{array}$ & 1 & 2.0 & $\mathrm{HOAc}, \leq 100^{\circ} \mathrm{C}, 5 \mathrm{~h}$ & $\begin{array}{l}17 \mathbf{a}: 69 \mathbf{b}: 19=20: 74: 6.5, \text { few side } \\
\text { products }\end{array}$ \\
\hline 7 & $\begin{array}{l}\mathrm{Mn}(\mathrm{OAc})_{3} \\
\cdot 2 \mathrm{H}_{2} \mathrm{O}\end{array}$ & 1 & 2.0 & HOAc, microwaves, $100^{\circ} \mathrm{C}, 12 \mathrm{~h}$ & $\begin{array}{l}\text { 17a:69b:19 }=17: 74: 8.7, \text { few side } \\
\text { products }\end{array}$ \\
\hline 8 & $\begin{array}{l}\mathrm{Mn}(\mathrm{OAc})_{3} \\
\cdot 2 \mathrm{H}_{2} \mathrm{O}\end{array}$ & 1 & 4.0 & $\mathrm{HOAc}, \leq 100^{\circ} \mathrm{C}, 6.75 \mathrm{~h}$ & 17a:69b:19 = 25:63:13, few side products \\
\hline
\end{tabular}

Cerium(IV) salts are versatile $1 \mathrm{e}^{-}$strong oxidants in a variety of applications ${ }^{58-60}$. Oxidation of 69b with ceric ammonium nitrate [CAN, $\left.\mathrm{Ce}\left(\mathrm{NH}_{4}\right)_{2}\left(\mathrm{NO}_{3}\right)_{6}\right]$ was immediate 
and appeared to completely consume part of the starting material by subsequent oxidations, while leaving the rest of it unaffected.

N-bromosuccinimide (NBS) is a versatile brominating agent, but under certain conditions is useful for effecting allylic and benzylic brominations through a radical process. The advantage of NBS over other brominating agents is that oxidations occur in mild, neutral conditions. Cyclization of the intermediate radical76 [Scheme 2.16.] should give the bromide 81, which could produce 19 on elimination of $\mathrm{HBr}$. Oxidation of $69 \mathrm{~b}$ in standard allylic bromination conditions appeared to be very rapid, but again only produced starting material in a complex mixture of nonpolar compounds that blackened with time.

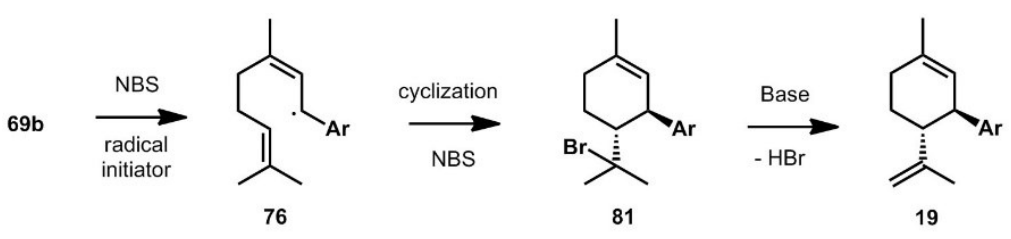

Scheme 2.16. Possible radical cyclization pathway with NBS

\subsubsection{Oxidation: Use of Mn(III)}

Manganese(III) acetate, a 1e` oxidant, is used overwhelmingly for radical oxidation of enolizable groups to generate $\alpha$-carbonyl radicals. Its rate of reaction is usually dependent on the rate of enolization of the substrate ${ }^{61,62}$. The low toxicity, low cost, and ease of preparation of manganese (III) acetate makes this oxidant particularly attractive.

Upon oxidation of $69 \mathbf{b}$ with 2 equivalents of $\mathrm{Mn}(\mathrm{OAc})_{3} \cdot 2 \mathrm{H}_{2} \mathrm{O}$ at $100{ }^{\circ} \mathrm{C}$ in acetic acid, several characteristic peaks of $\mathbf{1 9}$ appeared in the ${ }^{1} \mathrm{H}$ NMR spectrum of the crude mixture, though in very low intensity. Analytical TLC stained with $p$-anisaldehyde 
produced a TLC spot with matching $\mathrm{R}_{\mathrm{f}}$ and colour to 19 . Satisfyingly, the reaction appeared relatively clean by TLC and NMR, with only 69b, 19 and residual 17 (a contaminant in the starting material) as the main constituents of the reaction mixture, and little highly polar side products. Repeating the experiment with microwave heating in a sealed vessel, or by doubling the equivalents of oxidant gave similar results.

Purification of the crude reaction mixture in order to unambiguously confirm the identity of the product was not a trivial task, given the very high boiling point and UV absorbing properties of $o$-DCB. Preparatory TLC using 30:70 $o$-DCB:cyclohexane as eluent, followed by drying the TLC plate under high vacuum so it could be visualized under UV, and isolation of the bands resulted in incomplete separation of $69 \mathbf{b}$ and $\mathbf{1 9}$ (perhaps as a result of inconsistent plate loading). Material limitations precluded further purification. Nonetheless, one fraction was sufficiently enriched in $\mathbf{1 9}$ to allow resolution of most of the diagnostic ${ }^{1} \mathrm{H}$ NMR peaks matching those of the authentic standard [Figure A24. (Appendix)]. Importantly, the coupling constants of protons at C-1 and C-6 showed a trans-pseudo-diaxial relationship between them, indicative of trans-substitution on the cyclohexene ring, and congruent with literature values ${ }^{27}$. Finally, GCMS with electron impact ionization (EI) of the mixed fraction showed the presence of only $69 \mathbf{b}$ and $\mathbf{1 9}$, with both retention times and fragmentation patterns identical to the reference materials.

Due to the highly stable nature of the benzylic allylic radical 76, as well as the size of the ring, cyclization is slow. Calculations by Sadeghian, Seyedi, and co-workers ${ }^{63}$ predict that the $\mathrm{C}-\mathrm{H}$ bond dissociation energy leading to the $m$-dimethoxybenzyl allyl radical 76 is about $74 \mathrm{kcal} / \mathrm{mol}$, compared to about $85-90 \mathrm{kcal} / \mathrm{mol}$ for typical benzylic radicals, and about $98 \mathrm{kcal} / \mathrm{mol}$ for t-butyl radicals ${ }^{64,65}$. They have suggested that 
intramolecular $\mathrm{CH}-\mathrm{O}$ interactions are involved in stabilizing the planar conformation of the radical. They reported these radicals are so stable that they observed no reaction with air or water in the active site of a 15-lipo-oxygenase enzyme. This makes the cyclization of 76 to 77 thermodynamically uphill by about $24 \mathrm{kcal} / \mathrm{mol}$, resulting in a sluggish, and perhaps even reversible, reaction. The semi-isolated yield of $1.7 \%$ is comparable to those of other THT cyclization approaches to $\mathrm{CBD}^{7,24}$. Although slow and low-yielding, the clean conversion of $69 \mathrm{~b}$ to 19 makes this reaction remarkable in view of the complex mixtures of isomers typically obtained in concise syntheses of CBD.

\subsection{Future Work: Deprotection, Oxidation Optimization, Stereoselectivity, and}

\section{Protecting groups.}

The ultimate goal of this work is to develop this into a concise, selective and scalable synthesis of $\mathrm{CBD}$, from simple and readily available starting materials, and would lend itself readily to making modified CBD analogues.

Although the unoptimized yield in this reaction was only $1.7 \%$, there are a number of reasons to be optimistic that this could be developed into a synthetically useful method. The first is that the main productsare19and the unreacted starting material. Simply driving the reaction to complete consumption of $69 \mathrm{~b}$ should eliminate the challenge in purification. Without the need for prep TLC, losses in purification should be reduced, and the use of $o$-DCB eliminated. Qualitatively, colour changes during the reaction suggest the reaction time could be greatly reduced. Optimization of solvent, temperature and stoichiometry is yet to be done.

When an $\alpha$-carbonyl radical generated from the $\mathrm{Mn}$ (III) enolate is added to an 
olefin, the resulting radical can either propagate by abstracting $\mathrm{H}$ from eg. the solvent, or undergo elimination to form another alkene, sometimes producing a mixture of these two products. A co-oxidant commonly used in $\mathrm{Mn}(\mathrm{III})$ oxidations is $\mathrm{Cu}(\mathrm{OAc})_{2}$, often catalytically to control the fate of the this radical. $\mathrm{Cu}(\mathrm{II})$ is thought to rapidly reduce this radical to a $\mathrm{Cu}(\mathrm{III})$ alkyl species followed by $\beta$-hydride elimination to the corresponding alkene $^{61,62}$. Addition of $\mathrm{Cu}(\mathrm{II})$ is an area left to explore in the $\mathbf{6 9 b}$ oxidative cyclization.

Finally, in order to obtain CBD 1, 19 must be deprotected. Demethylation of 19 and similar compounds has been demonstrated in $40-80 \%$ yields by heating neat to 150 $210^{\circ} \mathrm{C}$, with methyl magnesium iodide ${ }^{7,27}$. Avoiding pyrophoric Grignard reagents, demethylation with NaSEt in DMF at $140{ }^{\circ} \mathrm{C}$ has been demonstrated for similar cannabinoids in high yield, but gives only the mono-deprotected product under these conditions ${ }^{34}$. However, without the complications brought by rearrangements of $46 \mathbf{a}$ or with ionic cyclizations, this potentially opens the door for other protecting groups that are easier to remove. With a variety of milder methods available for coupling 68 and 17 together, even chiral esters may be feasible protecting groups.

Obtaining the required (-)-enantiomer of CBD requires either resolution or asymmetric synthesis. Enantiomeric resolution of $\mathrm{CBD}$ has been shown with chiral chromatography on carbamated amylose stationary phase ${ }^{66}$, but it may be possible to resolve CBD by crystallization with a chiral base. Ideally, an asymmetric synthesis would be more efficient than resolution, and this may be achieved in the future by use of chiral protecting groups or a chiral catalyst during the key cyclization step. 


\subsection{Conclusion}

We report the first truly biomimetic approach to formal synthesis of CBD, via an oxidative cyclization mediated by $\mathrm{Mn}(\mathrm{OAc})_{3}$, a one-electron oxidant. These results could foster the use of biomimetic approaches to synthesize CBD as well as other cannabinoids and their analogues for pharmaceutical and research purposes. 


\section{Chapter: Experimental Methods}

\subsection{General Experimental:}

Reagents were purchased from commercial sources, and used as received, unless otherwise noted. Olivetol was obtained from Alicorn Chemical and CBD from Infinite CBD. Solvents and reagents used for moisture sensitive reactions were dried by the following methods: $\mathrm{Et}_{2} \mathrm{O}$ was distilled from $\mathrm{LiAlH}_{4}$; toluene and DCM distilled from $\mathrm{CaH}_{2}$; THF was either distilled from Na/benzophenone ketyl or used directly from a bottle of anhydrous solvent (Sigma); xylenesx, $\mathrm{CCl}_{4}, \mathrm{CDCl}_{3}, \mathrm{C}_{6} \mathrm{D}_{6}, \mathrm{TMEDA}$, cyclohexane, acetone, and DIPEA were dried over 4 Å molecular sieves; orcinol monohydrate was dried azeotropically by concentrating from toluene with a small amount of EtOAc three times. All reactions we performed under $\mathrm{N}_{2}$ or $\mathrm{Ar}$ atmosphere, and air- or moisture-sensitive ones done in flame- or oven-dried glassware. Reaction temperatures refer to the temperature of the appropriate heating or cooling bath ${ }^{1}$. Volatile solvents were removed under reduced pressure at $40-50{ }^{\circ} \mathrm{C}$ on a rotary evaporator (Heidolph Laborota 4011, or Buchi Rotovapor-R), unless otherwise noted. High vacuum refers to pressures on the order of $\sim 100$ mTorr, generated by a Maxima C Plus vacuum pump (Fisher). Kugelrohr distillations were carried out on a Buchi Glass Oven B-585. Molecular sieves, $4 \AA$ (Aldrich) were flame activated under vacuum. Brine refers to saturated aqueous $\mathrm{NaCl}$.

\footnotetext{
${ }^{1}$ Toward the end of this project, it was discovered that one hotplate gave unreliable temperature readings that were sometimes up to $\sim 30^{\circ} \mathrm{C}$ lower than the actual temperature.
} 
Reactions were monitored by analytical TLC on $4-5 \mathrm{~cm}$ long, $250 \mu \mathrm{m}$ thick, GlassBacked Extra Hard Layer60 Å TLC plates, with F-254 indicator (Silicycle), and visualized by fluorescence quenching with UV light ( $254 \mathrm{~nm})$, and/orone of the following stains: $\mathrm{I}_{2}$ adsorbed on silica gel, ceric ammonium molybdate, or $p$-anisaldehyde.

Flash column chromatography (FCC) was performed either using forced flow on SiliaFlash P60, 40-63 $\mu \mathrm{m}$ silica gel (Silicycle) by the method of Still et al. ${ }^{67}$, or on a Biotage Isolera One automated chromatography system equipped with UV detector. Dry Column Vacuum Chromatography (DCVC) was performed on SiliaFlash E60, 15-40 $\mu \mathrm{m}$ silica gel (Silicycle), as per the method of Pedersen and Rosenbohm ${ }^{68}$. Preparative thin layer chromatography (PTLC) was performed on $20 \mathrm{~cm}$ x $10 \mathrm{~cm}$ TLC plates (same type as for analytical TLC), and visualized by fluorescence quenching with UV light (254 $\mathrm{nm})$.

Yields refer to spectroscopically pure compounds (or to one component of a multi-component known mixture, as quantified by ${ }^{1} \mathrm{H}$ NMR), unless noted as crude. NMR spectra were recorded on a Bruker Avance 300 spectrometer at $300 \mathrm{MHz}$ for ${ }^{1} \mathrm{H}$, and $75 \mathrm{MHz}$ for ${ }^{13} \mathrm{C}$. Chemical shifts are given in parts per million (ppm) referenced to tetramethylsilane (TMS, $\delta=0.00 \mathrm{ppm}$ ) as internal standard in $\mathrm{CDCl}_{3}$, or the residual solvent peaks in $\mathrm{C}_{6} \mathrm{D}_{6}\left(\delta\left({ }^{1} \mathrm{H}\right)=7.16 \mathrm{ppm}, \delta\left({ }^{13} \mathrm{C}\right)=128.06 \mathrm{ppm}\right)$ and in $\left(\mathrm{CD}_{3}\right)_{2} \mathrm{CO}\left(\delta\left({ }^{1} \mathrm{H}\right)\right.$ $=2.05 \mathrm{ppm}) . \mathrm{CDCl}_{3}$ and $\mathrm{C}_{6} \mathrm{D}_{6}$ were stored over activated $4 \AA$ molecular sieves. Coupling constants $(J)$ are reported in $\mathrm{Hz}$, and the multiplicity abbreviations used are: s, singlet; $\mathrm{d}$, 
doublet; t, triplet; q, quartet; m, multiplet; br, broad. Other multiplicities are not abbreviated.

Fourier transform infrared (FTIR) absorption spectra were recorded on an ABB Bomem MB series spectrometer, as thin films on $\mathrm{NaCl}$ plates and are reported in units of wavenumbers $\left(\mathrm{cm}^{-1}\right)$.

Electrospray ionization (ESI) high resolution mass spectrometry (HRMS) was performed on a QSTAR XL spectrometer. Gas chromatography - mass spectrometry (GCMS) - was performed on an Agilent 7820A gas chromatograph connected to an Agilent 5977E MSD spectrometer.

Melting points were determined on an Electrothermal brand melting point apparatus.

\subsection{Protecting Groups}

\subsubsection{1,3-dimethoxy-5-methylbenzene (49a)}
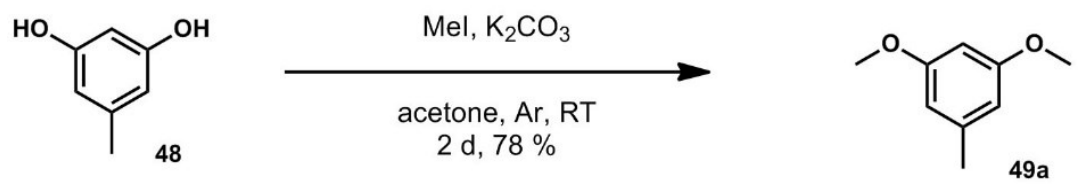

A round-bottom flask was charged with orcinol 48 (4.78 g, $38.6 \mathrm{mmol}, 1.0$ equiv.), and anhydrous $\mathrm{K}_{2} \mathrm{CO}_{3}(16.42 \mathrm{~g}, 118 \mathrm{mmol}, 3.1$ equiv.) before being flushed with argon. To this acetone ( $96 \mathrm{~mL}, 0.4 \mathrm{M}$ w.r.t.48) was added, and the flask sealed with a septum after a brief buildup of pressure had ceased. The suspension was stirred vigorously, MeI (6.5 $\mathrm{mL}, 105 \mathrm{mmol}, 2.7$ equiv.) was added, and the mixture stirred at $\mathrm{RT}$ for $24 \mathrm{~h}$. More MeI (3.0 $\mathrm{mL}, 49 \mathrm{mmol}, 1.3$ equiv.) was added, and the mixture stirred for another $24 \mathrm{~h}$. The 
reaction mixture was filtered, concentrated in vacuo, and resuspended in $60 \mathrm{~mL}$ of $0.5 \mathrm{M}$ $\mathrm{NaOH}$. This aqueous phase was extracted with $3 \times 30 \mathrm{~mL}$ toluene, and the combined organic layers washed with $3 \mathrm{M} \mathrm{NaOH}_{(\mathrm{aq})}(10 \mathrm{~mL})$ and brine $(30 \mathrm{~mL})$, before being dried over anhydrous $\mathrm{MgSO}_{4}$, filtered, and evaporated under high vacuum to give nearly pure (by ${ }^{1} \mathrm{H}$ NMR) 49a (4.60 g, 78\% yield) as a yellow oil. This was used without further purification in some cases, or distilled at $165-170{ }^{\circ} \mathrm{C}, 73-75$ mbar in a kugelrohr to yield a clear colourless liquid with high optical dispersion.

$\mathbf{R}_{\mathbf{f}} 0.73$ (25\% EtOAc/hexanes; UV, I $\left.2, \mathrm{CAM}\right) .{ }^{1} \mathbf{H}$ NMR $\left(\mathrm{CDCl}_{3} 300 \mathrm{MHz}\right): \delta 6.34$ (dd, J $=2.3,0.6 \mathrm{~Hz}, 2 \mathrm{H}), 6.29(\mathrm{t}, \mathrm{J}=2.3 \mathrm{~Hz}, 1 \mathrm{H}), 3.77(\mathrm{~s}, 6 \mathrm{H}), 2.31(\mathrm{~d}, \mathrm{~J}=0.6 \mathrm{~Hz}, 3 \mathrm{H})$. Spectroscopic data was in good agreement with literature ${ }^{69}$.

\subsubsection{1,3-dimethoxy-5-pentylbenzene (17a)}

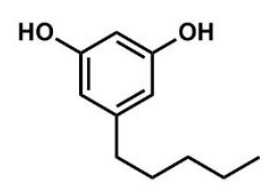

10

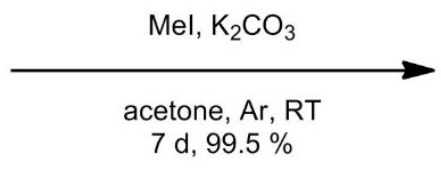

$7 \mathrm{~d}, 99.5 \%$

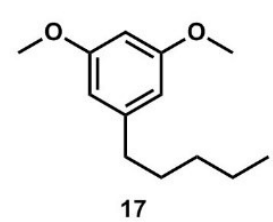

A round-bottom flask equipped with a heavy magnetic stir bar, was charged with olivetol 10 (9.00 g, 49.9 mmol, 1.0 equiv.), and anhydrous $\mathrm{K}_{2} \mathrm{CO}_{3}(20.99 \mathrm{~g}, 151 \mathrm{mmol}, 3.0$ equiv.) before being flushed with argon. To this was added acetone [dried over $4 \AA$ molecular sieves] (195 mL, 0.26 M w.r.t. 10), and the flask capped with a septum after a brief evolution of gas had ceased. To the mixture was added MeI (8.5 mL, $136 \mathrm{mmol}, 2.7$ equiv.), and the suspension stirred vigorously at RT for 7 days, with additional MeI (6.2 mL, 100 mmol, 2.0 equiv.) and $\mathrm{K}_{2} \mathrm{CO}_{3}$ (13.86 g, 100 mmol, 2.0 equiv.) being added after 
3 days. The reaction mixture was filtered, concentrated in vacuo, and resuspended in 100 $\mathrm{mL}$ water. This aqueous phase was extracted with $3 \times 50 \mathrm{~mL}$ toluene, and the combined organic layers washed with brine, dried over anhydrous $\mathrm{Na}_{2} \mathrm{SO}_{4}$, filtered overCelite, and evaporated to give a yellow oil, consisting 84\%17 and 15.5\% toluene by NMR (12.32 g, 99.5\% yield). This was used without further purification, however distillation at 150-165 ${ }^{\circ} \mathrm{C},>100$ mTorr pressure in a kugelrohr yielded pure 17 as a clear colourless liquid with high optical dispersion.

$\mathbf{R}_{\mathbf{f}} 0.29$ (50\% PhH/CyH; UV, anisaldehyde bright pink). ${ }^{1} \mathbf{H} \mathbf{N M R}\left(\mathrm{CDCl}_{3}, 300 \mathrm{MHz}\right): \delta$ $6.35\left(\mathrm{ABB}^{\prime}, \mathrm{J}=2.2 \mathrm{~Hz}, 2 \mathrm{H}\right), 6.30$ (ABB', J = 2.2 Hz, 1H), $3.78(\mathrm{~s}, 6 \mathrm{H}), 2.54$ (t, J = 7.8 $\mathrm{Hz}, 2 \mathrm{H}), 1.66-1.56$ (m, 2H), 1.38-1.28 (m, 4H), 0.91-0.87 (m, 3H). Spectroscopic data was in good agreement with literature ${ }^{69}$.

3.2.3. (1R,2R)-2',6'-dimethoxy-5-methyl-4'-pentyl-2-(prop-1-en-2-yl)-1,2,3,4tetrahydro-1,1'-biphenyl (dimethyl CBD) (19)
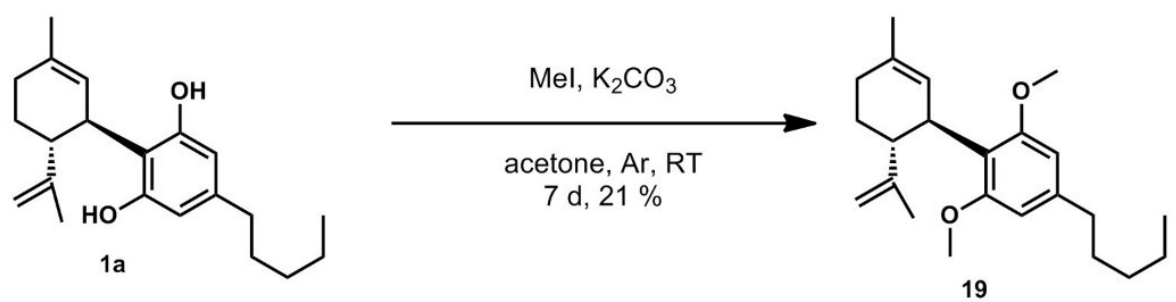

In a small vial fitted with a septum and magnetic stir bar was added cannabidiol 1 (21.2 $\mathrm{mg}, 67 \mu \mathrm{mol}, 1.0$ equiv) and finely powdered $\mathrm{K}_{2} \mathrm{CO}_{3}(96.1 \mathrm{mg}, 695 \mu \mathrm{mol}, 10.3$ equiv.). After flushing with Ar, acetone (0.68 mL, 0.1 M w.r.t. 1), and MeI (approx. $40 \mu \mathrm{L}$, $670 \mu \mathrm{mol}, 10$ equiv.) were added, and the suspension stirred for $7 \mathrm{~d}$ at RT. The mixture was evaporated with a stream of $\mathrm{N}_{2}$ gas, resuspended in $5 \mathrm{~mL} \mathrm{H} \mathrm{H}_{2} \mathrm{O}$, and extracted with 3 
x $5 \mathrm{~mL}$ toluene. The combined organic layers were washed with $5 \mathrm{~mL}$ brine, dried over anhydrous $\mathrm{Na}_{2} \mathrm{SO}_{4}$, filtered, and evaporated to give $12.4 \mathrm{mg}$ yellowish oil, that was almost entirely 19 by crude ${ }^{1} \mathrm{H}$ NMR. Preparative TLC $\left(\mathrm{SiO}_{2}, 2: 98 \mathrm{Et}_{2} \mathrm{O}:\right.$ n-hexane $)$ gave 19 (5.1 mg, 21\% yield) as a slightly yellowish oil.

Rf $0.77 ; 0.47\left(50 \% \mathrm{PhH} / \mathrm{CyH} ; 50 \% o-\mathrm{C}_{6} \mathrm{H}_{4} \mathrm{Cl}_{2} / \mathrm{CyH} ; \mathrm{UV}, \mathrm{I}_{2}\right.$ brown, CAM blue, anisaldehyde light blue). ${ }^{1} \mathbf{H}$ NMR $\left(\mathrm{CDCl}_{3}, 300 \mathrm{MHz}\right): \delta 6.32$ (s, 2H), 5.20 (br s, 1H), 4.44-4.41 (m, 2H), 4.01-3.96 (m, J $\approx 10-11 \mathrm{~Hz}, 1 \mathrm{H}), 3.73(\mathrm{~s}, 6 \mathrm{H}), 2.89(\mathrm{td}, \mathrm{J}=10.5,4.8$ Hz, 1H), 2.53 (t, J = 8.0 Hz, 2H), 2.21-2.11 (m, 2H), 1.97 (br d, J = 14.4 Hz, 1H), 1.77$1.72(\mathrm{~m}, 2 \mathrm{H}), 1.66$ (br s, 3H), 1.64-1.56 (m, 5H), 1.36-1.29 (m, 4H), 0.92-0.87 (m, 3H). FTIR ( $\mathrm{NaCl}$ plate, neat, $\left.\mathrm{cm}^{-1}\right): 3070,2957,2927,2856,1608,1581,1454,1419,1233$, $1196,1159,1119,884$.

Spectroscopic data was in good agreement with literature ${ }^{27}$.

\subsection{4. methyl THC (71)}
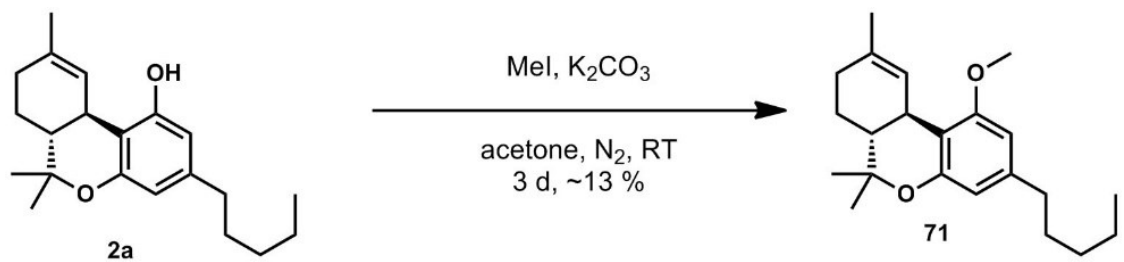

In a small vial fitted with septum and magnetic stir bar was added of an 80:20 mixture of $\Delta^{9}$-THC: $\Delta^{8}$-THC 2a and 3a (22.9 mg, $73 \mu \mathrm{mol}$ total, 1.0 equiv. total) and finely powdered $\mathrm{K}_{2} \mathrm{CO}_{3}\left(54.5 \mathrm{mg}, 390 \mu \mathrm{mol}, 5.4\right.$ equiv.). After flushing with $\mathrm{N}_{2}, 0.8 \mathrm{~mL}$ acetone (0.1 M w.r.t. 2a), and about 23-40 $\mu \mathrm{L} \operatorname{MeI}(23-40 \mu \mathrm{L}, 360-660 \mu \mathrm{mol}, 5-9$ equiv.)were added, and the suspension stirred for $3 \mathrm{~d}$ at RT. Volatile materials were 
evaporated using a stream of $\mathrm{N}_{2}$ gas. The residue was then resuspended in $5 \mathrm{~mL} \mathrm{H}_{2} \mathrm{O}$, and extracted with $3 \times 5 \mathrm{~mL}$ hexanes. The combined organic layers were washed with $5 \mathrm{~mL}$ brine, dried over anhydrous $\mathrm{Na}_{2} \mathrm{SO}_{4}$, filtered, and evaporated to give $17.6 \mathrm{mg}$ of a brownish oil. PTLC $\left(\mathrm{SiO}_{2}, 2: 98 \mathrm{Et}_{2} \mathrm{O}:\right.$ n-hexane) provideda yellowish oil consisting of impure 71(3.1 mg, $\sim 10 \%$ yield) by ${ }^{1} \mathrm{H}$ NMR. This produced only 1 spot on analytical TLC, so it was used without further purification.

Rf 0.66 (50\% PhH/CyH; UV, I 2 brown, anisaldehyde grey). ${ }^{1} \mathbf{H} \mathbf{~ N M R}\left(\mathrm{CDCl}_{3}, 300 \mathrm{MHz}\right)$ : $\delta 6.30(\mathrm{~d}, \mathrm{~J}=1.8 \mathrm{~Hz}, 1 \mathrm{H}), 6.26(\mathrm{~d}, \mathrm{~J}=1.5 \mathrm{~Hz}, 1 \mathrm{H}), 6.22$ (apparent quintet, $\mathrm{J}=1.5 \mathrm{~Hz}$, 1H), $3.84(\mathrm{~s}, 3 \mathrm{H}), 3.17$ (br d, J = 10.8 Hz, 1H), 2.49 (t, J = 7.8 Hz, 2H), 2.18-2.11 (m, 2H), $1.94-1.86(\mathrm{~m}, 1 \mathrm{H}), 1.68-1.65(\mathrm{~m}, 3 \mathrm{H}), 1.65-1.53(\mathrm{~m}, 5 \mathrm{H})^{\dagger}, 1.41(\mathrm{~s}, 3 \mathrm{H}), 1.38-1.25$ $(\mathrm{m}, 11 \mathrm{H})^{\dagger}, 1.07(\mathrm{~s}, 3 \mathrm{H}), 0.92-0.85(\mathrm{~m}, 8 \mathrm{H})^{\dagger 2}$.

\subsubsection{5-methyl-1,3-phenylene bis(dimethylcarbamate) (49b)}

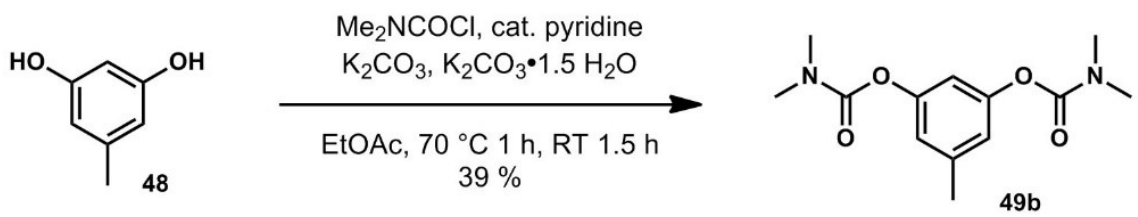

A round-bottom flask was loaded with 48 (0.3187 g, 2.57 mmol, 1.0 equiv.), $\mathrm{K}_{2} \mathrm{CO}_{3} .1 .5$ $\mathrm{H}_{2} \mathrm{O}$ (0.6655 g, $4.03 \mathrm{mmol}, 1.57$ equiv.), and anhydrous $\mathrm{K}_{2} \mathrm{CO}_{3}(0.1579 \mathrm{~g}, 1.13 \mathrm{mmol}$, 0.44 equiv.), then flushed with Ar. To this was added $3.2 \mathrm{~mL}$ EtOAc (0.8 M w.r.t. 48), pyridine (16 $\mu \mathrm{L}, 0.20 \mathrm{mmol}, 0.08$ equiv.), and dimethylcarbamoyl chloride $(0.68 \mathrm{~mL}, 7.4$ mmol, 2.9 equiv.) dropwise, turning the light pink mixture a dark red-purple colour, which faded over time. A reflux condenser was attached. The reaction mixture was

\footnotetext{
${ }^{2 \dagger}$ These peaks could not be fully resolved or correctly integrated due to impurities.
} 
stirred at $70{ }^{\circ} \mathrm{C}$ for about $1 \mathrm{~h}$, then at RT $1.5 \mathrm{~h}$ (instead of the intended $70{ }^{\circ} \mathrm{C}$ for the whole $2.5 \mathrm{~h}$, due to a failure of the hot plate). To this, $2.4 \mathrm{~mL} \mathrm{H}_{2} \mathrm{O}(2.4 \mathrm{~mL}, 130 \mathrm{mmol}$, 52 equiv.) was added, and the biphasic mixture stirred vigorously for another $2 \mathrm{~h}$ before the layers were separated. The organic layer was diluted with $10 \mathrm{~mL}$ EtOAc, and washed with $0.5 \mathrm{M} \mathrm{H}_{2} \mathrm{SO}_{4(\mathrm{aq})}\left(2 \times 20 \mathrm{~mL}, 20 \mathrm{mmol}, 8\right.$ equiv), dried over anhydrous $\mathrm{Na}_{2} \mathrm{SO}_{4}$, filtered and evaporated to give $0.5304 \mathrm{~g}$ amber oil. Flash chromatography on $\mathrm{SiO}_{2}$ with 50:50 EtOAc : hexanes gave 49b ( $0.2665 \mathrm{~g}, 39 \%$ yield $)$ as a viscous colourless oil:

Rf 0.24 (50\% EtOAc/hexanes; UV, $\mathrm{I}_{2}$ brown). ${ }^{1} \mathbf{H}$ NMR ( $\left.\mathrm{CDCl}_{3}, 300 \mathrm{MHz}\right): \delta 6.79$ (ABB', J = 2.2 Hz, 2H), $6.75\left(\mathrm{ABB}^{\prime}, \mathrm{J}=2.2,0.6 \mathrm{~Hz}, 1 \mathrm{H}\right), 3.06$ (s, 6H), 2.99 (s, 6H), 2.33 $(\mathrm{d}, \mathrm{J}=0.6 \mathrm{~Hz}, 3 \mathrm{H}) .{ }^{13} \mathbf{C} \mathbf{N M R}\left(\mathrm{CDCl}_{3}, 75 \mathrm{MHz}\right): \delta 154.4,151.5,139.5,119.0,112.5$, 36.41, 36.17, 21.2. FTIR (neat, $\mathrm{NaCl}$ plate, $\mathrm{cm}^{-1}$ ): 3584, 3522, 2931, 1725, 1619, 1463, 1382, 1300, 1267, 1160, 1046, 756. HRMS: $\left(\mathrm{C}_{13} \mathrm{H}_{18} \mathrm{~N}_{2} \mathrm{O}_{4} \cdot \mathrm{Na}^{+}\right) \mathrm{m} / \mathrm{z}$ calculated: 289.1159; found: 289.1167 .

From the reaction mixture was also isolated $0.0724 \mathrm{~g}$ yellow oil. Crystallization of this oil from toluene at $-15{ }^{\circ} \mathrm{C}$ provided pure $50 \mathrm{~b}(\sim 6 \%$ yield $)$ as white plates, insoluble in hexanes:

3-hydroxy-5-methylphenyl dimethylcarbamate (50b)

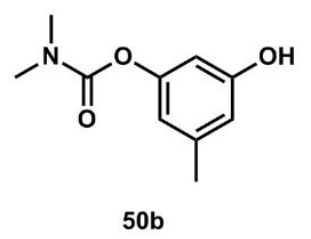

mp 98.4-99.5 ${ }^{\circ} \mathrm{C} . \mathbf{R}_{\mathbf{f}} 0.39$ (50\% EtOAc/hexanes; UV, $\mathrm{I}_{2}$ brown). ${ }^{1} \mathbf{H}$ NMR $\left(\mathrm{CDCl}_{3}, 300\right.$ MHz): $\delta$ 6.47-6.45 (m, 1H), 6.43-6.41 (m, 1H), 6.40-6.39 (m, 1H), 5.78 (br s, 1H), 3.08 (s, 3H), $3.02(\mathrm{~s}, 3 \mathrm{H}), 2.25(\mathrm{~d}, \mathrm{~J}=0.3 \mathrm{~Hz}, 3 \mathrm{H}) .{ }^{13} \mathbf{C} \mathbf{~ N M R}\left(\mathrm{CDCl}_{3}, 75 \mathrm{MHz}\right): \delta 157.1$, 155.7, 151.8, 140.2, 113.9, 106.8, 36.83, 36.58, 21.4. FTIR (neat, NaCl plate, $\mathrm{cm}^{-1}$ ): 
3327, 2927, 1698, 1609, 1397, 1320, 1187, 1156, 1043, 758.HRMS: $\left(\mathrm{C}_{10} \mathrm{H}_{13} \mathrm{NO}_{3} \cdot \mathrm{Na}^{+}\right)$

m/z calculated: 218.0788 ; found: 218.0769 .

\subsubsection{5-methyl-1,3-phenylene bis(diphenylcarbamate) (49c)}
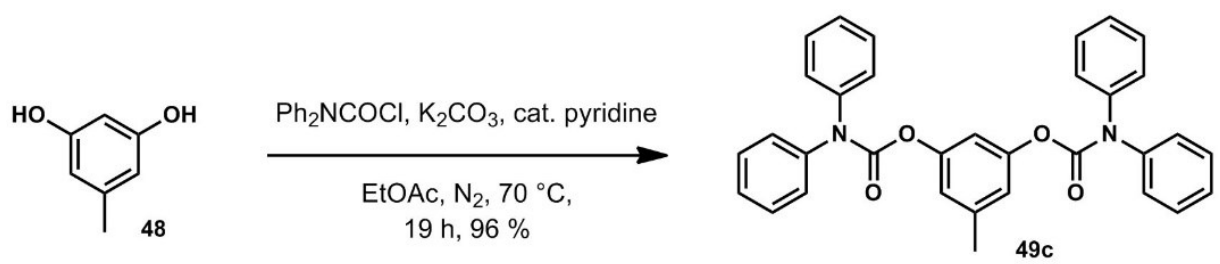

A round-bottom flask was loaded with $\mathbf{4 8} 97 \%$ with $3 \% \mathrm{H}_{2} \mathrm{O}(0.4052 \mathrm{~g}, 3.17 \mathrm{mmol}, 1.0$ equiv.), anhydrous $\mathrm{K}_{2} \mathrm{CO}_{3}(0.8777 \mathrm{~g}, 6.33 \mathrm{mmol}, 2.0$ equiv.), and EtOAc (14.0 mL), and stirred at RT for 30 min under $\mathrm{N}_{2}$. To this was added pyridine $(20 \mu \mathrm{L}, 0.25 \mathrm{mmol}, 0.08$ equiv.), and diphenylcarbamoyl chloride (2.0856 g, $8.99 \mathrm{mmol}, 2.84$ equiv.). A reflux condenser was attached, and the reaction mixture was stirred at $70{ }^{\circ} \mathrm{C}$ for $19 \mathrm{~h}$. To this, $\mathrm{H}_{2} \mathrm{O}$ (5.0 mL, $280 \mathrm{mmol}, 87$ equiv.) was added, and the red-brown biphasic mixture stirred vigorously for another $2 \mathrm{~h}$ at $70{ }^{\circ} \mathrm{C}$ before the layers were separated. The organic layer was diluted witrh $20 \mathrm{~mL}$ EtOAc, and washed with saturated $\mathrm{Na}_{2} \mathrm{CO}_{3(\mathrm{aq})}(30 \mathrm{~mL})$, $0.5 \mathrm{M} \mathrm{H}_{2} \mathrm{SO}_{4(\mathrm{aq})}(3 \times 30 \mathrm{~mL}), 30 \mathrm{~mL}$ brine, dried over anhydrous $\mathrm{Na}_{2} \mathrm{SO}_{4}$, filtered and evaporated to give $2.0277 \mathrm{~g}$ of a red tar that solidified overnight. This was dissolved in a small amount of DCM and subjected to flash chromatography on $\mathrm{SiO}_{2}$ with 25:75 EtOAc : hexanes, to afford $49 \mathrm{c}$ (1.6206 g, 96\% yield) as white needle-like crystals insoluble in the elution solvent. Recrystallization of a small amount from acetone/hexane gave a pure analytical sample of $49 \mathrm{c}$ :

mp 161.9-165.3 ${ }^{\circ} \mathrm{C} . \mathbf{R}_{\mathbf{f}} 0.45$ (25\% EtOAc/hexanes; UV strong, $\mathrm{I}_{2}$ faint brown). ${ }^{1} \mathbf{H}$ NMR ((CD $\left.)_{2} \mathrm{CO}, 300 \mathrm{MHz}\right): \delta$ 7.46-7.38 (m, $\left.16 \mathrm{H}\right), 7.30-7.25(\mathrm{~m}, 4 \mathrm{H}), 6.91\left(\mathrm{ABB}^{\prime}, \mathrm{J}=2.0\right.$ 
$\mathrm{Hz}, 1 \mathrm{H}), 6.86\left(\mathrm{ABB}^{\prime}, \mathrm{J}=2.0 \mathrm{~Hz}, 2 \mathrm{H}\right), 2.31$ (br s, 3H). ${ }^{13} \mathbf{C} \mathbf{N M R}\left(\mathrm{CDCl}_{3}, 75 \mathrm{MHz}\right): \delta$

152.8, 151.2, 142.7, 140.0, 129.1, 126.9 (broad), 126.6, 119.3, 112.3, 21.4. FTIR (NaCl

plate, $\left.\mathrm{cm}^{-1}\right)$ : 1731, 1593, 1491, 1335, 1301, 1278, 1197, 1125, 757. HRMS:

$\left(\mathrm{C}_{33} \mathrm{H}_{26} \mathrm{~N}_{2} \mathrm{O}_{4} \cdot \mathrm{Na}^{+}\right) \mathrm{m} / \mathrm{z}$ calculated: 537.1785; found: 537.1796 .

\subsubsection{1,3-bis(methoxymethoxy)-5-methylbenzene (49d)}
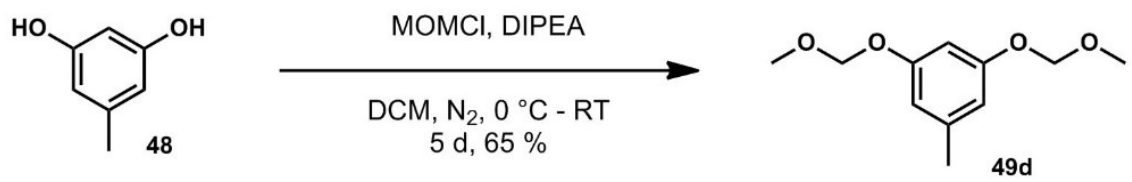

A three-necked flask was fitted with a septum, a vacuum take-off adapter, and a pressureequalizing addition funnel. The flask was loaded with orcinol $48(3.4803 \mathrm{~g}, 28 \mathrm{mmol}, 1.0$ equiv) and DIPEA ( $29 \mathrm{~mL}, 165 \mathrm{mmol}, 5.9$ equiv), under $\mathrm{N}_{2}$, stirred, and then suspended in dry DCM (110 mL). A solution of MOMCl $(12.75 \mathrm{~mL}, 168 \mathrm{mmol}, 6.0$ equiv) in dry DCM $(54 \mathrm{~mL})$ was added dropwise via the addition funnel in 5 equal portions over 5 days, cooling the flask to $0^{\circ} \mathrm{C}$ at each addition, and then allowing it to warm to RT. Another portion of DIPEA ( $14.5 \mathrm{~mL}, 83 \mathrm{mmol}, 3.0$ equiv) was added $4 \mathrm{~d}$ after the start of the reaction. The solvent and other volatile components were removed under vacuum, and the residue partitioned between $\mathrm{CHCl}_{3}(100 \mathrm{~mL})$ and water $(100 \mathrm{~mL})$. The organic layer was washed with saturated $\mathrm{NaHCO}_{3(\mathrm{aq})}(100 \mathrm{~mL})$, brine $(100 \mathrm{~mL})$, dried over anhydrous $\mathrm{Na}_{2} \mathrm{SO}_{4}$, filtered, and evaporated to provide brown oil (6.06 g). Purification by DCVC (5\% EtOAc / hexanes) gave 49d as a clear colourless liquid with high optical dispersion (4.0063 g, 65\% yield): 
$\mathbf{R}_{\mathbf{f}} 0.50\left(15 \%\right.$ EtOAc/hexanes; UV, $\left.\mathrm{I}_{2}\right) .{ }^{1} \mathbf{H}$ NMR $\left(\mathrm{CDCl}_{3}, 300 \mathrm{MHz}\right): \delta 6.55-6.53(\mathrm{~m}, 3 \mathrm{H})$, $5.14(\mathrm{~s}, 4 \mathrm{H}), 3.47(\mathrm{~s}, 6 \mathrm{H}), 2.30(\mathrm{~d}, \mathrm{~J}=0.3 \mathrm{~Hz}, 3 \mathrm{H}) .{ }^{13} \mathbf{C ~ N M R}\left(\mathrm{CDCl}_{3}, 75 \mathrm{MHz}\right): \delta 158.2$, $140.3,110.4,102.0,94.4,55.9,21.7$.

Spectroscopic data was in good agreement with literature ${ }^{70}$.

Compounds 50d and $\mathbf{5 1}$ were also identified as major side products.

3-(methoxymethoxy)-5-methylphenol (50d):

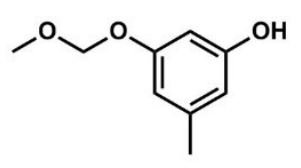

$50 d$

Colourless oil, that turned orange with time. $\mathbf{R}_{\mathbf{f}} 0.17$ (15\% EtOAc/hexanes; UV, $\mathrm{I}_{2}$ brown). ${ }^{1} \mathbf{H}$ NMR $\left(\mathrm{CDCl}_{3}, 300 \mathrm{MHz}\right): \delta 6.46-6.44(\mathrm{~m}, 1 \mathrm{H}), 6.36$ (apparent t, $\mathrm{J}=2.1 \mathrm{~Hz}$, $1 \mathrm{H}), 6.32-6.31(\mathrm{~m}, 1 \mathrm{H}), 5.13(\mathrm{~s}, 2 \mathrm{H}), 4.74\left(\mathrm{~s}, 1 \mathrm{H}\right.$, exchanges with $\left.\mathrm{D}_{2} \mathrm{O}\right), 3.47(\mathrm{~s}, 3 \mathrm{H})$, $2.27(\mathrm{~d}, \mathrm{~J}=0.6 \mathrm{~Hz}, 3 \mathrm{H}) .{ }^{13} \mathbf{C} \mathbf{N M R}\left(\mathrm{CDCl}_{3}, 75 \mathrm{MHz}\right): \delta 158.3,156.7,140.8,110.0$, 109.4, 101.0, 94.4, 56.1, 21.7. FTIR (neat, $\mathrm{NaCl}$ plate, $\mathrm{cm}^{-1}$ ): 3382, 2955, 2828, 1598 , 1467, 1330, 1212, 1146, 1082, 1040. HRMS: $\left(\mathrm{C}_{9} \mathrm{H}_{12} \mathrm{O}_{3} \cdot \mathrm{Na}^{+}\right) \mathrm{m} / \mathrm{z}$ calculated: 191.0679; found: 191.0768 .

1,5-bis(methoxymethoxy)-2-(methoxymethyl)-3-methylbenzene (51):

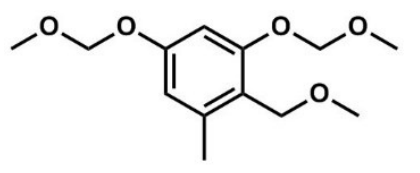

51

Colourless oil. Rf 0.27 (15\% EtOAc/hexanes; UV, I $).{ }^{1} \mathbf{H}$ NMR ( $\left.\mathrm{CDCl}_{3}, 300 \mathrm{MHz}\right): \delta$ $6.65(\mathrm{~d}, \mathrm{~J}=2.4 \mathrm{~Hz}, 1 \mathrm{H}), 6.57(\mathrm{~d}, \mathrm{~J}=2.1 \mathrm{~Hz}, 1 \mathrm{H}), 5.18(\mathrm{~s}, 2 \mathrm{H}), 5.14(\mathrm{~s}, 2 \mathrm{H}), 4.50(\mathrm{~s}, 2 \mathrm{H})$, 3.482 (s, 3H), 3.465 (s, 3H), $3.36(\mathrm{~s}, 3 \mathrm{H}), 2.36$ ( s, 3H). ${ }^{13} \mathbf{C ~ N M R}\left(\mathrm{CDCl}_{3}, 75 \mathrm{MHz}\right): \delta$ 157.6, 156.9, 140.9, 119.1, 111.1, 101.0, 94.96, 94.33, 65.2, 57.8, 56.14, 56.03, 19.5. 
FTIR (neat, $\mathrm{NaCl}$ plate, $\mathrm{cm}^{-1}$ ): 2924, 2825, 1608, 1591, 1486, 1449, 1293, 1214, 1154, 1140, 1057, 1031, 1000, 923. HRMS: $\left(\mathrm{C}_{13} \mathrm{H}_{20} \mathrm{O}_{5} \cdot \mathrm{Na}^{+}\right) \mathrm{m} / \mathrm{z}$ calculated: 279.1203; found: 279.1182.

\subsection{First Approach}

\subsubsection{1-(2,6-dimethoxy-4-methylphenyl)-3,7-dimethyloct-6-en-1-ol (58)}

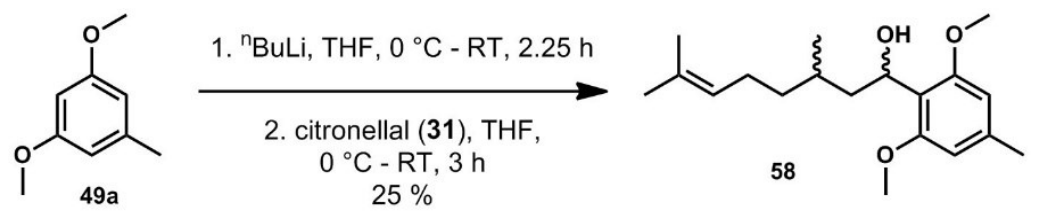

To a solution of $49 \mathrm{a}$ [0.1481 $\mathrm{g}(67 \%$, with $33 \%$ toluene $), 0.81 \mathrm{mmol}, 1.0$ equiv] in dry THF (7.5 mL, $0.11 \mathrm{M}$ w.r.t. 49a) was added $\mathrm{nBuLi}$ solution $(0.42 \mathrm{~mL}, 2.15 \mathrm{M}$ in hexanes, $0.91 \mathrm{mmol}, 1.12$ equiv) dropwiseat $0{ }^{\circ} \mathrm{C}$ under argon. The yellow mixture was stirred at RT for $2.25 \mathrm{~h}$, then cooled to $0{ }^{\circ} \mathrm{C}$ again and a solution of citronellal $(0.1647 \mathrm{~g}$, 1.06mmol, 1.32 equiv) in dry THF ( $1.3 \mathrm{~mL}, 0.8 \mathrm{M}$ w.r.t. citronellal) was added dropwise. The mixture was stirred at $\mathrm{RT}$ for $3 \mathrm{~h}$, then quenched with saturated $\mathrm{NH}_{4} \mathrm{Cl}_{(\mathrm{aq})}(10 \mathrm{~mL})$, extracted with $\mathrm{Et}_{2} \mathrm{O}(3 \times 5 \mathrm{~mL})$, dried over anhydrous $\mathrm{MgSO}_{4}$, filtered, and evaporated to give an amber oil (0.2698 g). Flash chromatography $\left(\mathrm{SiO}_{2}, 5-15 \% \mathrm{EtOAc} /\right.$ hexanes $)$ of the mixture provided a 50:50 mixture of two diasereomers of $\mathbf{5 8}$ as a yellow oil $(61.8 \mathrm{mg}$, $25 \%$ yield):

$\mathbf{R}_{\mathbf{f}} 0.38$ (15\% EtOAc/hexanes; UV, $\left.\mathrm{I}_{2}, \mathrm{CAM}\right) .{ }^{1} \mathbf{H}$ NMR ( $\left.\mathrm{CDCl}_{3}, 300 \mathrm{MHz}\right): \delta 6.37$ (s, 4H), 5.24-5.15 (m, 2H), 5.11 (tqq, J = 7.2, 1.5, $1.5 \mathrm{~Hz}, 1 \mathrm{H}), 5.06$ (tqq, J = 7.2, 1.5, 1.5 $\mathrm{Hz}, 1 \mathrm{H}), 3.81(\mathrm{~s}, 12 \mathrm{H}), 3.57\left(\mathrm{~d}, \mathrm{~J}=0.9 \mathrm{~Hz}, 1 \mathrm{H}\right.$, exchanges with $\left.\mathrm{D}_{2} \mathrm{O}\right), 3.53(\mathrm{~d}, \mathrm{~J}=0.6 \mathrm{~Hz}$, $1 \mathrm{H}$, exchanges with $\left.\mathrm{D}_{2} \mathrm{O}\right), 2.32(\mathrm{~s}, 6 \mathrm{H}), 2.05-1.87(\mathrm{~m}, 4 \mathrm{H}), 1.75-1.70(\mathrm{~m}, 2 \mathrm{H}), 1.68(\mathrm{~s}$, 
3H), $1.65(\mathrm{~s}, 3 \mathrm{H}), 1.61(\mathrm{~s}, 3 \mathrm{H}), 1.57(\mathrm{~s}, 3 \mathrm{H}), 1.52-1.08(\mathrm{~m}, 8 \mathrm{H}), 0.94(\mathrm{t}, \mathrm{J}=6.5 \mathrm{~Hz}$,

6H). ${ }^{13}$ C NMR (DEPT 135) $\left(\mathrm{CDCl}_{3}, 75 \mathrm{MHz}\right): \delta 157.55$ (0), 157.41 (0), $138.24(0)$,

$138.18(0), 130.77(0), 130.74(0), 125.17(+), 117.80(0), 117.44(0), 105.13(+), 105.12$

$(+), 66.12(+), 65.77(+), 55.62(+), 55.58(+), 44.95(-), 44.85(-), 37.71(-), 36.80(-)$,

$29.75(+), 29.33(+), 25.77(+), 25.71(+), 25.62(-), 25.23(-), 21.99(+), 20.34(+), 19.22$

$(+), 17.65(+), 17.59(+)$. FTIR (neat, $\mathrm{NaCl}$ plate, $\mathrm{cm}^{-1}$ ): 3566, 2959, 2928, 2851, 1611,

1585, 1464, 1414, 1225, 1119, 815. HRMS: $\left(\mathrm{C}_{19} \mathrm{H}_{30} \mathrm{O}_{3} \cdot \mathrm{Na}^{+}\right) \mathrm{m} / \mathrm{z}$ calculated: 329.2087;

found: 329.2115 .

\subsubsection{1-(2,6-dimethoxy-4-methylphenyl)-3,7-dimethylocta-2,6-dien-1-ol (46a and}

\section{6b)}
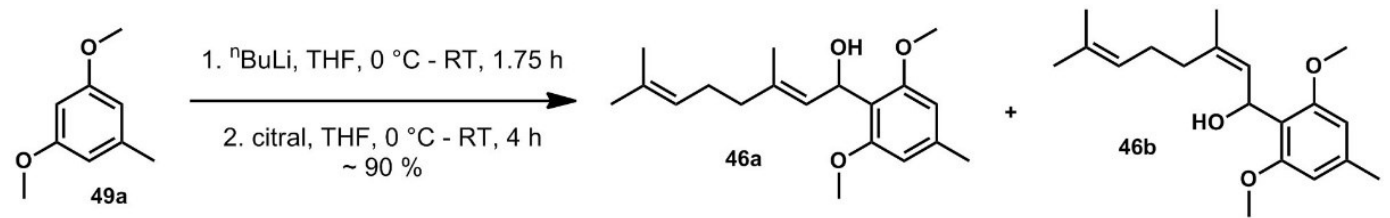

A solution of 49a (1.9984 g, $13.1 \mathrm{mmol}, 1.0$ equiv. ) in dry THF was dried over $4 \AA$ molecular sieves overnight under argon. The solution was transferred by syringe to a dry Schlenk flask under argon and diluted in dry THF (to $122 \mathrm{~mL}, 0.11 \mathrm{M}$ w.r.t.49a). The flask was cooled to $0{ }^{\circ} \mathrm{C}$ and ${ }^{n} \mathrm{BuLi}$ in hexanes $(7.00 \mathrm{~mL}, 2.10 \mathrm{M}, 14.7 \mathrm{mmol}, 1.12$ equiv) was added dropwise over $30 \mathrm{~min}$. After warming and stirring at RT for $1.75 \mathrm{~h}$, the amber mixture was again cooled to $0{ }^{\circ} \mathrm{C}$ and a solution of citral13 $(2.54 \mathrm{~mL}, 14.8$ mmol,1.13equiv.) in dry THF (18.5 mL, $0.8 \mathrm{M}$ w.r.t.13) was added over $30 \mathrm{~min}$ via syringe pump, then stirred at RT for an additional $3.75 \mathrm{~h}^{3}$. To the dark brown reaction

\footnotetext{
${ }^{3} \mathrm{TLC}$ of the reaction mixture $2 \mathrm{~h}$ after addition of citral showed most of the starting material had been consumed.
} 
mixture was added saturated $\mathrm{NaHCO}_{3(\mathrm{aq})}(12 \mathrm{~mL})$ and water $(150 \mathrm{~mL})$, the layers separated, and the vivid yellow aqueous layer extracted with $4 \times 50 \mathrm{~mL}$ ether. The combined organic layers were washed with $50 \mathrm{~mL}$ brine, dried over anhydrous $\mathrm{MgSO}_{4}$, filtered, and evaporated to give an orange oil. This material proved unstable toward purification, so it was not fully characterized. The ${ }^{1} \mathrm{H}$ NMR spectrum of the crude reaction products showed mostly a 50:50 mixture of $46 \mathbf{a}$ and $46 \mathbf{b}(3.9784 \mathrm{~g}, \leq 95 \%$ pure, $\sim 90 \%$ yield):

${ }^{1} \mathbf{H}$ NMR $\left(\mathrm{CDCl}_{3}, 300 \mathrm{MHz}\right): \delta 6.37(\mathrm{~s}, 4 \mathrm{H}), 5.90-5.83(\mathrm{~m}, 2 \mathrm{H}), 5.62-5.68(\mathrm{~m}, 2 \mathrm{H}), 5.18-$ $5.13(\mathrm{tqq}, \mathrm{J}=6.9,1.4,1.4 \mathrm{~Hz}, 1 \mathrm{H}), 5.09-5.04(\mathrm{tqq}, \mathrm{J}=7.0,1.4,1.4 \mathrm{~Hz}, 1 \mathrm{H}), 3.83(\mathrm{~s}, 6 \mathrm{H})$, 3.82 (s, 6H), 3.66 (apparent dd, J = 11.1, $2.1 \mathrm{~Hz}, 2 \mathrm{H}), 2.32$ (s, 6H), 2.30-1.95 (m), 1.77 (d, J = 1.2 Hz, 3H), $1.695(\mathrm{~d}, \mathrm{~J}=1.5 \mathrm{~Hz}, 3 \mathrm{H}), 1.688$ (br s, 3H), 1.63 (br s, 3H), 1.62 (br s, 3H), 1.56 (br s, 3H), 1.63 (br s, 3H), 1.62 (br s, 3H), 1.56 (br s, 3H).

\subsection{3. (E)-1-(2,6-dimethoxy-4-methylphenyl)-3,7-dimethylocta-1,6-dien-3-ol (46c)}

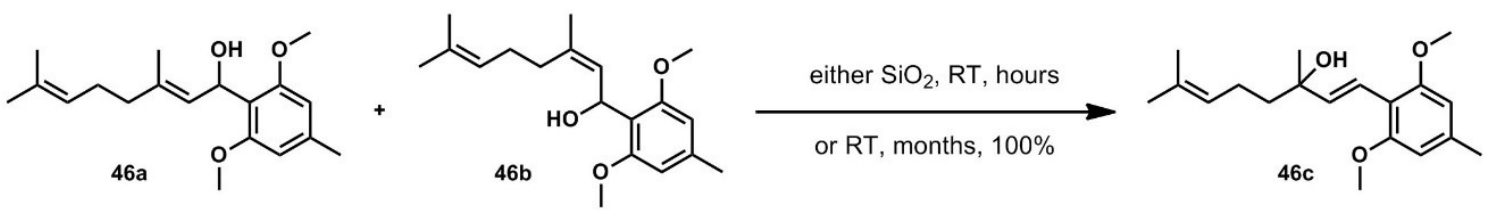

Method 1: Flash chromatography of a portion of crude $46 \mathbf{a} / \mathbf{4 6 \mathbf { b }}$ on $40-63 \mu \mathrm{m} \mathrm{SiO}{ }_{2}$, eluted with 15:85 EtOAc : hexanes over a few hours gave $\mathbf{4 6 c}$ as a yellow oil. If eluted from the column in less than an hour, incomplete conversion resulted.

Method 2: addingSiO 2 to $46 \mathbf{a} / \mathbf{4 6 b}$ gave $46 \mathbf{c}$ mixed with small amounts of side products after several hours. 
Method 3: Crude concentrated $\mathbf{4 6 a / 4 6 b}$, after storage for several months at RT, was almost completely isomerized cleanly to $\mathbf{4 6 c}$ :

$\mathbf{R}_{\mathbf{f}} 0.27$ (15\% EtOAc/hexanes; UV, $\left.\mathrm{I}_{2}, \mathrm{CAM}\right) .{ }^{1} \mathbf{H}$ NMR $\left(\mathrm{C}_{6} \mathrm{D}_{6}, 300 \mathrm{MHz}\right): \delta 7.37$ (d, J = $16.5 \mathrm{~Hz}, 1 \mathrm{H}), 7.01(\mathrm{~d}, \mathrm{~J}=16.5 \mathrm{~Hz}, 1 \mathrm{H}), 6.25(\mathrm{~s}, 2 \mathrm{H}), 5.25$ (tqq, J = 7.4, 1.4, $1.4 \mathrm{~Hz}, 1 \mathrm{H})$, $3.38(\mathrm{~s}, 6 \mathrm{H}), 2.35-2.25(\mathrm{~m}, 2 \mathrm{H}), 2.18(\mathrm{~s}, 3 \mathrm{H}), 1.77-1.12(\mathrm{~m}, 2 \mathrm{H}), 1.64(\mathrm{~d}, \mathrm{~J}=1.2 \mathrm{~Hz}, 3 \mathrm{H})$, $1.56($ br s, $3 \mathrm{H}), 1.39(\mathrm{~s}, 3 \mathrm{H}), 1.30\left(\mathrm{~s}, 1 \mathrm{H}\right.$, exchanges with $\left.\mathrm{D}_{2} \mathrm{O}\right) \cdot{ }^{13} \mathbf{C}$ NMR $\left(\mathrm{C}_{6} \mathrm{D}_{6}+1\right.$ drop $\left.\mathrm{D}_{2} \mathrm{O}, 75 \mathrm{MHz}\right): \delta 159.3,140.7,138.0,131.4,126.0,118.3,113.1,105.6,73.9,55.6,43.9$, 29.4, 26.2, 23.9, 22.5, 18.1. FTIR (neat, $\mathrm{NaCl}$ plate, $\mathrm{cm}^{-1}$ ): 3445, 2966, 2922, 2855, 1607, 1575, 1463, 1413, 1239, 1201, 1118.HRMS: $\left(\mathrm{C}_{19} \mathrm{H}_{28} \mathrm{O}_{3} \cdot \mathrm{Na}^{+}\right) \mathrm{m} / \mathrm{z}$ calculated: 327.1931; found: 327.1952 .

\subsubsection{Attempted cyclization of $\mathbf{4 6 c}$}
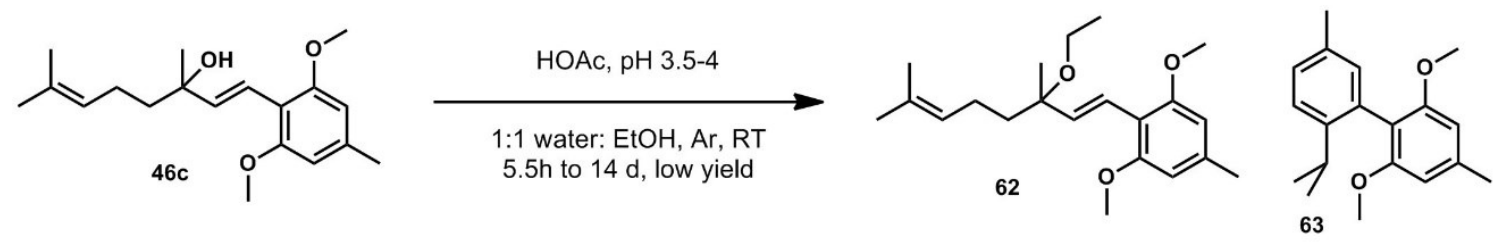

A flask was loaded with water ( $(8.2 \mathrm{~mL})$, ethanol $(8.2 \mathrm{~mL}), \mathrm{HOAc}(48 \mu \mathrm{L}, 0.82 \mathrm{mmol}, 2.5$ equiv, $\mathrm{pH}$ tested at about $3.5-4.0)$, and $\mathbf{4 6 c}(0.1001 \mathrm{~g}, 0.33 \mathrm{mmol}, 1.0$ equiv, $0.02 \mathrm{M})$ under argon, and the suspension was stirred vigorously at RT. TLC analysis showed the appearance of many new products after just $15 \mathrm{~min}$. After $5.5 \mathrm{~h}$, an $8 \mathrm{~mL}$ portion of this mixture was extracted and analyzed, showing a complex mixture of products. Flash chromatography (1-10\% EtOAc/hexanes) followed by PTLC (2\% EtOAc/hexanes) yielded only trace amounts of impure $\mathbf{6 2}$ and $\mathbf{6 3}$. After stirring 14 days at RT, the 
remaining mixture was extracted with $3 \times 10 \mathrm{~mL}$ hexanes, and the combined organic layers were evaporated to afford a yellow oil $(71 \mathrm{mg})$. After standing for 8 months in storage at RT under $\mathrm{N}_{2}$, a portion $(35.6 \mathrm{mg})$ of this mixture was separated by flash chromatography on $\mathrm{SiO}_{2}$ eluted with $2 \% \mathrm{Et}_{2} \mathrm{O} / \mathrm{n}$-hexane to yield pure $63(2.1 \mathrm{mg}, 6.3 \%$ yield).

\section{2'-isopropyl-2,6-dimethoxy-4,5'-dimethyl-1,1'-biphenyl (63):}

mp 129.6-130.7 ${ }^{\circ} \mathrm{C}$. $\mathbf{R}_{\mathbf{f}} 0.22$ (2.5\% EtOAc/hexanes; UV strong, $\mathrm{I}_{2}$ faint brown). ${ }^{1} \mathbf{H}$ NMR $\left(\mathrm{CDCl}_{3}, 300 \mathrm{MHz}\right): \delta 7.26\left(\mathrm{~d}, \mathrm{~J}=8.1 \mathrm{~Hz}, 1 \mathrm{H}\right.$ (overlaps with $\left.\left.\mathrm{CHCl}_{3}\right), \mathrm{Ar}-\mathrm{H}\right), 7.14(\mathrm{dd}, \mathrm{J}=$ 7.8, 1.8 Hz, 1H, Ar-H), 6.89 (d, J = 1.8 Hz, 1H, Ar-H), 6.46 (s, 2H, Ar'-H), 3.69 (s, 6H, OCH3), 2.63 (septet, J = 6.9 Hz, 1H, Me2-CH), 2.42 (s, 3H, Ar-CH3), 2.32 (s, 3H, Ar'CH3), $1.08(\mathrm{~d}, \mathrm{~J}=6.9 \mathrm{~Hz}, 6 \mathrm{H}, \mathrm{CH}-(\mathrm{CH} 3) 2) .{ }^{13} \mathbf{C ~ N M R}\left(\mathrm{CDCl}_{3}, 75 \mathrm{MHz}\right): \delta 157.7,145.0$ $138.5,134.3,132.8,131.5,128.6,124.7,116.1,104.6,55.7,30.0,23.9,22.2,21.1$. FTIR (neat, $\mathrm{NaCl}$ plate, $\mathrm{cm}^{-1}$ ): 2957, 2866, 1609, 1578, 1488, 1462, 1409, 1318, 1233, 1126 , 813. HRMS: $\left(\mathrm{C}_{19} \mathrm{H}_{24} \mathrm{O}_{2} \cdot \mathrm{H}^{+}\right) \mathrm{m} / \mathrm{z}$ calculated: 285.1849; found: 285.1840 .

A number of other products obtained from this reaction could not be fully isolated. Some of these products are thought to be:

Impure (E)-2-(3-ethoxy-3,7-dimethylocta-1,6-dien-1-yl)-1,3-dimethoxy-5methylbenzene (62) : yield $\sim 0.4 \mathrm{mg} ; \sim 1 \% .{ }^{1} \mathbf{H}$ NMR $\left(\mathrm{CDCl}_{3}, 300 \mathrm{MHz}\right): \delta 6.65(\mathrm{~d}, \mathrm{~J}=16.8 \mathrm{~Hz}, 1 \mathrm{H}), 6.49(\mathrm{~d}, \mathrm{~J}$ $=17.1 \mathrm{~Hz}, 1 \mathrm{H}), 6.37(\mathrm{~s}, 2 \mathrm{H}), 5.14(\mathrm{tm}, \mathrm{J}=7.2 \mathrm{~Hz}, 1 \mathrm{H}), 3.81(\mathrm{~s}, 6 \mathrm{H}), 3.42(\mathrm{q}, \mathrm{J}=7.0 \mathrm{~Hz}$ 2H), 2.33 (s 3H), 2.09-2.02 (m, 2H), 1.67 (s, 3H), 1.67-1.60 (m, 2H), $1.60(\mathrm{~s}, 3 \mathrm{H}), 1.34$ $(\mathrm{s}, 3 \mathrm{H}), 1.17(\mathrm{t}, \mathrm{J}=6.9 \mathrm{~Hz}, 3 \mathrm{H})$.

A 67:33 mixture of 64:65: 

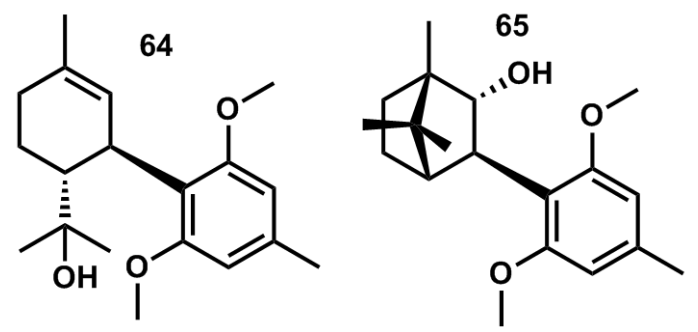

Yield $5.3 \mathrm{mg}$; $10 \% \mathbf{6 4}$ (denoted a), 5\% 65 (denoted b). Rf 0.36 (15\% EtOAc/hexanes;

UV, $\left.\mathrm{I}_{2}\right) .{ }^{1} \mathrm{H}$ NMR $\left(\mathrm{CDCl}_{3}, 300 \mathrm{MHz}\right): \delta 6.39(\mathrm{br} \mathrm{s}, 2 \mathrm{Hb}), 6.36(\mathrm{~s}, 2 \mathrm{Ha}), 5.22-5.21(\mathrm{~m}$, 1Hb), 4.98 (br s, 1Ha), 4.16-4.11 (m, 1Hb), 3.97-3.93 (m, J $\approx 9.3 \mathrm{~Hz}, 1 \mathrm{Ha}), 3.86$ (s, 3Hb),

3.77 (br s, 6Ha), 3.666 (s, 3Hb), 3.658 (br s, 1Hb), 2.37 (ddd, J = 12.6, 9.7, $2.8 \mathrm{~Hz}, 1 \mathrm{Ha}$ ), $2.32(\mathrm{~s}, 3 \mathrm{Hb}), 2.30(\mathrm{~s}, 3 \mathrm{Ha}), 2.25-1.89(\mathrm{~m}, 3 \mathrm{Ha}+5 \mathrm{Hb}), 1.83(\mathrm{~s}, 1 \mathrm{Ha}), 1.68(\mathrm{~s}, 3 \mathrm{Hb}), 1.64$ (s, 3Ha), $1.42(\mathrm{td}, \mathrm{J}=12.2,4.6 \mathrm{~Hz}, 1 \mathrm{Ha}), 1.15$ (s, 3Hb), 1.11 (s, 3Ha), 1.09 (s, 3Ha), 0.65 (s, 3Hb). GCMS: (EI) m/z, compound a: $304\left(\mathrm{M}^{+}\right.$, trace), 286, 255, 218, 203, 187 (100\%), 165; m/z, compound b: $304\left(\mathrm{M}^{+}\right.$, trace), 286, 246, 218, 203, 187 (100\%), 165. A 44:35:21 mixture of 66c:66a:66b :
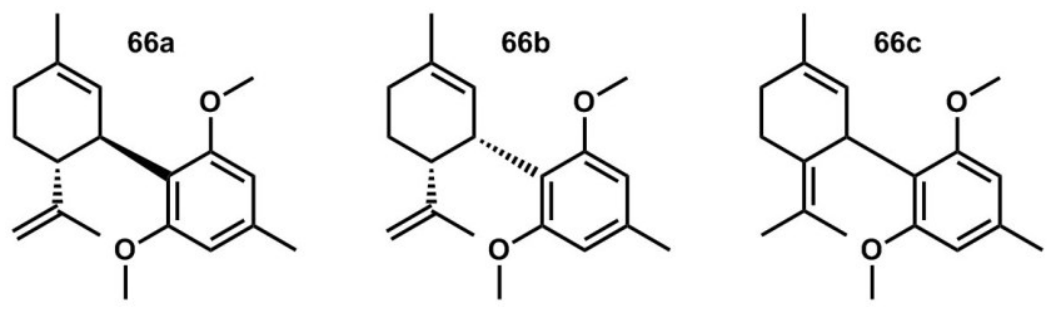

Yield $2.2 \mathrm{mg} ; 2.9 \%$ 66c, $2.3 \%$ 66a, $1.4 \%$ 66b. Rf 0.45 (5\% EtOAc/hexanes; $\mathrm{I}_{2}$ strong)

$.{ }^{1} \mathrm{H} \mathrm{NMR}\left(\mathrm{CDCl}_{3}, 300 \mathrm{MHz}\right): \delta 6.36(\mathrm{~s}, 2 \mathrm{Hb}), 6.33$ (s, 2Ha), $6.30(\mathrm{~s}, 2 \mathrm{Hc}), 5.35-5.31(\mathrm{~m}$, 1Hc), 5.18 (br s, $1 \mathrm{Ha}+1 \mathrm{Hb}), 4.69$ (br s, $1 \mathrm{Hb}), 4.49-4.47$ (m, 1Hc), 4.45-4.42 (m, 2Ha), $4.41(\mathrm{~s}, 1 \mathrm{Hc}), 4.32-4.27(\mathrm{~m}, 1 \mathrm{Hc}), 4.02-3.95(\mathrm{~m}, \mathrm{~J} \approx 12 \mathrm{~Hz}, 1 \mathrm{Ha}), 3.734(\mathrm{~s}, 6 \mathrm{Hb}), 3.725$ (s, 6Ha), 3.68 (s, 6Hc), 2.91 (td, J = 10.8, $4.5 \mathrm{~Hz}, 1 \mathrm{Ha}), 2.65$ (ddd, J = 13.8, 5.7, $3.3 \mathrm{~Hz}$, $1 \mathrm{Hb}), 2.60-2.44(\mathrm{~m}, 1 \mathrm{Hb}+1 \mathrm{Hc}), 2.30(\mathrm{~s}, 3 \mathrm{Hb}), 2.29(\mathrm{~s}, 3 \mathrm{Ha}), 2.28(\mathrm{~s}, 3 \mathrm{Hc}), 2.28-2.00(\mathrm{~m}$, $1 \mathrm{Ha}+2 \mathrm{Hb}+3 \mathrm{Hc}), 2.00-1.93(\mathrm{~m}, 1 \mathrm{Ha}+1 \mathrm{Hc}), 1.77-1.72(\mathrm{~m}, 2 \mathrm{Ha}), 1.70(\mathrm{~s}, 3 \mathrm{Hc}), 1.68$ (br s, 
3Ha+3Hc), $1.65(\mathrm{~s}, 6 \mathrm{Hb}), 1.60$ (s, 3Ha), $1.40(\mathrm{~d}, \mathrm{~J}=1.8 \mathrm{~Hz}, 3 \mathrm{Hb})$. GCMS: (EI) m/z, compound a: $286\left(\mathrm{M}^{+}\right), 218,203,187(100 \%), 165 ; \mathrm{m} / \mathrm{z}$, compound b: $286\left(\mathrm{M}^{+}\right), 218$, 203, 187 (100\%), 165; m/z, compound c: $286\left(\mathrm{M}^{+}, 100 \%\right), 271,243,228,179,165,105$.

\subsection{Second Approach}

\subsection{1. (Z)-1-chloro-3,7-dimethylocta-2,6-diene (neryl chloride)(68)}
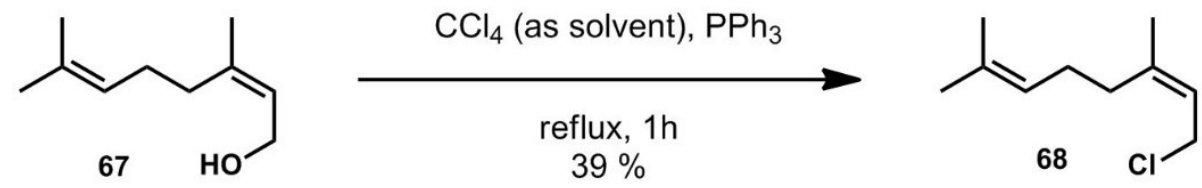

This procedure was based on that from reference ${ }^{71}$ for preparation of the $(E)$ isomer. To a solution of nerol (5.00 g, $32.4 \mathrm{mmol}, 1.0$ equiv) in dry $\mathrm{CCl}_{4}(30 \mathrm{~mL}, 300 \mathrm{mmol}, 9.3$ equiv) was added triphenylphosphine (11.08 g, $42.1 \mathrm{mmol}, 1.3$ equiv), and the mixture heated to reflux for $1 \mathrm{~h}$. After cooling, hexanes $(32 \mathrm{~mL})$ were added to precipitate the phosphine oxide, which was filtered off and washed with additional hexanes $(21 \mathrm{~mL})$. The filtrate was concentrated to yield a few colourless crystals in a yellowish liquid (5.31 g). A portion of this was partially distilled in a kugelrohr at $<105^{\circ} \mathrm{C}$ at $>100$ mTorr pressure to yield $\mathbf{6 8}$ as a clear colourless mobile liquid (2.27 g, 39\% yield [based on only material that was purified]):

Rf0.66-0.50 (100\%hexanes; $\left.\mathrm{I}_{2}\right) .{ }^{1} \mathbf{H}$ NMR $\left(\mathrm{CDCl}_{3}, 300 \mathrm{MHz}\right): \delta 5.45$ (apparent td, $\mathrm{J}=8.1$, $1.5 \mathrm{~Hz}, 1 \mathrm{H}), 5.08-5.14(\mathrm{~m}, 1 \mathrm{H}), 4.08$ (apparent dd, J = 8.1, 0.6 Hz, 2H), 2.06-2.15 (m, 4H), 1.78-1.77 (m, 3H), 1.69 (br s, 3H), $1.61(\mathrm{~d}, \mathrm{~J}=0.6 \mathrm{~Hz}, 3 \mathrm{H})$. FTIR (NaCl plate, $\mathrm{cm}^{-}$ $\left.{ }^{1}\right): 2969,2859,1661,1448,1377,1251,1110,1089,836,669$.

${ }^{1}$ H NMR data was in approximate agreement with literature ${ }^{53,72}$. 
3.4.2. (Z)-2-(3,7-dimethylocta-2,6-dien-1-yl)-1,3-dimethoxy-5methylbenzene $(\mathbf{6 9 a})$
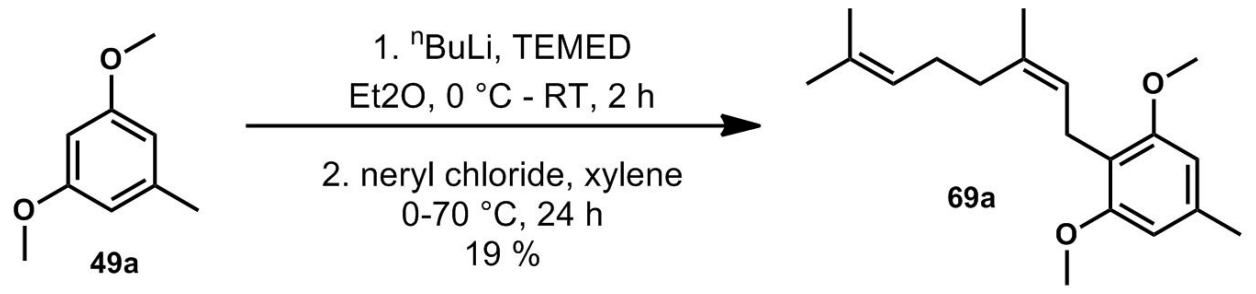

Following the procedure for $69 \mathrm{~b}, \mathrm{LiBr}(0 \mathrm{~g}, 0 \mathrm{mmol}, 0$ equiv $), 49 \mathrm{a}(0.149 \mathrm{~g}, 0.98 \mathrm{mmol}$, 1.0 equiv), $N, N, N^{\prime}, N^{\prime}$-tetramethylethylenediamine ( $0.288 \mathrm{~g}, 2.48 \mathrm{mmol}, 2.52$ equiv), $\mathrm{Et}_{2} \mathrm{O}(2.0 \mathrm{~mL}),{ }^{\mathrm{n}} \mathrm{BuLi}$ in hexanes $(1.20 \mathrm{mmol}, 1.22$ equiv), RT $2 \mathrm{~h}$, then $\mathbf{6 8}(0.206 \mathrm{~g}, 1.19$ mmol, 1.21 equiv), and xylenes $(2.0 \mathrm{~mL})$, then ice water quench $(5 \mathrm{~mL})$, yielded 69a (55.4 mg, 19\% yield) as a mobile colourless oil after two rounds of flash chromatography (0-5\% Et $2 \mathrm{O} /$ hexanes):

Rf $0.25(2.5 \%$ EtOAc/hexanes; UV, I $2, \mathrm{CAM}) .{ }^{1} \mathbf{H}$ NMR $\left(\mathrm{C}_{6} \mathrm{D}_{6}, 300 \mathrm{MHz}\right): \delta 6.26(\mathrm{~s}, 2 \mathrm{H})$, $5.66(\mathrm{tm}, \mathrm{J}=7.1 \mathrm{~Hz}, 1 \mathrm{H}), 5.37$ (tqq, $\mathrm{J}=7.1,1.4,1.4 \mathrm{~Hz}, 1 \mathrm{H}), 3.81($ br d, J = 7.2 Hz, 2H), $3.42(\mathrm{~s}, 6 \mathrm{H}), 2.50-2.45(\mathrm{~m}, 2 \mathrm{H}), 2.28$ (apparent br q, J 7.7 Hz, 2H), $2.22(\mathrm{~s}, 3 \mathrm{H}), 1.74$ (dt, ${ }^{4} \mathrm{~J}=1.2 \mathrm{~Hz},{ }^{5} \mathrm{~J}=1.2 \mathrm{~Hz}, 3 \mathrm{H}$ ), 1.70 (apparent d, J = 0.9 Hz, 3H), 1.62 (br s, 3H). ${ }^{13} \mathbf{C}$ NMR (DEPT 135) (C $\left.\mathrm{C}_{6} \mathrm{D}_{6}, 75 \mathrm{MHz}\right): \delta 158.9(0), 136.9(0), 134.6(0), 131.4(0), 125.9$ $(+), 125.5(+), 116.1(0), 105.3(+), 55.6(+), 32.9(-), 27.6(-), 26.3(+), 24.1(+), 22.8(-)$, $22.4(+), 18.1(+)$. FTIR (neat, $\mathrm{NaCl}$ plate, $\mathrm{cm}^{-1}$ ): 2961, 2855, 1609, 1589, 1464, 1414, 1376, 1317, 1234, 1185, 1172, 1118, 971, 813. HRMS: $\left(\mathrm{C}_{19} \mathrm{H}_{28} \mathrm{O}_{2} \cdot \mathrm{Na}^{+}\right) \mathrm{m} / \mathrm{z}$ calculated: 311.1982; found: 311.1969 . 


\subsection{3. (Z)-2-(3,7-dimethylocta-2,6-dien-1-yl)-1,3-dimethoxy-5-pentylbenzene}

(69b)
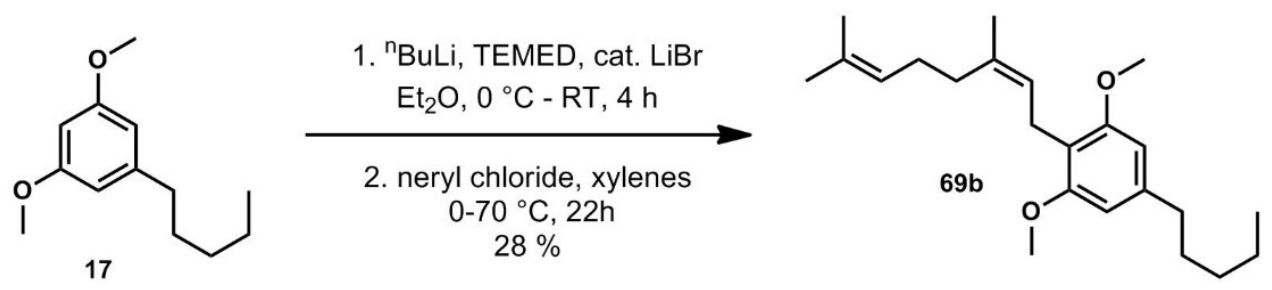

In a flame-dried $250 \mathrm{~mL}$ 3-neck flask fitted with a condenser, septum, and magnetic stir bar, was added $\mathrm{LiBr}(0.0613 \mathrm{~g}, 0.72 \mathrm{mmol}, 0.1$ equiv), 17 (1.7805 g [85\% in 15\%

toluene],7.20mmol, 1.0 equiv), and dry $N, N, N^{\prime}, N^{\prime}$-tetramethylethylenediamine $(2.0141 \mathrm{~g}$, $17.4 \mathrm{mmol}, 2.41$ equiv). The flask was flushed with $\mathrm{N}_{2}$, and dry $\mathrm{Et}_{2} \mathrm{O}(20 \mathrm{~mL}, 0.35 \mathrm{M}$ w.r.t.17) was added. The mixture was cooled to $0{ }^{\circ} \mathrm{C}$, and $\mathrm{nBuLi}$ in hexanes $(4.20 \mathrm{~mL}$ of $2.14 \mathrm{M}, 9.00 \mathrm{mmol}, 1.25$ equiv) was added dropwise over $15 \mathrm{~min}$. The mixture was stirred at $0{ }^{\circ} \mathrm{C}$ for an additional $15 \mathrm{~min}$, at $\mathrm{RT}$ for $4 \mathrm{~h}$, and then again cooled to $0{ }^{\circ} \mathrm{C}$. To this, a solution of neryl chloride $\mathbf{6 8}(1.5202 \mathrm{~g}, 8.78 \mathrm{mmol}, 1.22$ equiv) in dry xylenes (14 $\mathrm{mL}, 0.6 \mathrm{M}$ w.r.t.68), was added dropwise over $20 \mathrm{~min}$. The mixture was stirred at $0{ }^{\circ} \mathrm{C}$ for $10 \mathrm{~min}$, then gradually and carefully heated (to avoid bumping of $\mathrm{Et}_{2} \mathrm{O}$ ) and stirred for $22 \mathrm{~h}$ at $70{ }^{\circ} \mathrm{C}$, and $85^{\circ} \mathrm{C}$ for $2 \mathrm{~h}$. The reaction mixture was cooled to RT and stirred with $10 \mathrm{~mL}$ of ice water for $1 \mathrm{~h}$, diluted with $40 \mathrm{~mL}$ more water, and extracted with $3 \times 50 \mathrm{~mL}$ $\mathrm{Et}_{2} \mathrm{O}$. The combined organic layers were washed with $50 \mathrm{~mL}$ water, $50 \mathrm{~mL}$ brine, and evaporated to give $3.33 \mathrm{~g}$ brown liquid. Two iterative purifications by DCVC (2-3\% $\mathrm{Et}_{2} \mathrm{O} /$ hexanes $)$ provided a clear colourless oil $(0.7619 \mathrm{~g}$ consisting of $92 \% \mathbf{6 9 b}$ and $8 \%$ $17,28 \%$ yield) that was used without further purification. Preparative TLC ( $5 \%$ EtOAc/hexanes) provided an analytically pure sample: 
$\mathbf{R}_{\mathbf{f}} 0.79(50 \% \mathrm{PhH} / \mathrm{CyH}) ; 0.52\left(50 \% o-\mathrm{C}_{6} \mathrm{H}_{4} \mathrm{Cl}_{2} / \mathrm{CyH} ; \mathrm{UV}\right.$, anisaldehyde dull orange to dull purple). ${ }^{1} \mathbf{H}$ NMR $\left(\mathrm{C}_{6} \mathrm{D}_{6}, 300 \mathrm{MHz}\right): \delta 6.35(\mathrm{~s}, 2 \mathrm{H}), 5.68(\mathrm{br} \mathrm{t}, \mathrm{J}=7.1 \mathrm{~Hz}, 1 \mathrm{H}), 5.38$

$($ tqq, $\mathrm{J}=7.0,1.4,1.4 \mathrm{~Hz}, 1 \mathrm{H}), 3.82($ broad d, $\mathrm{J}=6.6 \mathrm{~Hz}, 2 \mathrm{H}), 3.45(\mathrm{~s}, 6 \mathrm{H}), 2.57(\mathrm{t}, \mathrm{J}=7.8$ $\mathrm{Hz}, 2 \mathrm{H}), 2.51-2.46(\mathrm{~m}, 2 \mathrm{H}), 2.33-2.26(\mathrm{~m}, 2 \mathrm{H}), 1.74$ (apparent q, J = 1.2 Hz, 3H), 1.71 $(\mathrm{d}, \mathrm{J}=0.9 \mathrm{~Hz}, 3 \mathrm{H}), 1.62(\mathrm{~s}, 3 \mathrm{H}), 1.75-1.55(\mathrm{~m}, 2 \mathrm{H}), 1.36-1.29(\mathrm{~m}, 4 \mathrm{H}), 0.92-0.88(\mathrm{~m}$, $3 \mathrm{H}) .{ }^{13} \mathrm{C}$ NMR $\left(\mathrm{CDCl}_{3}, 75 \mathrm{MHz}\right): \delta 158.0,142.0,134.7 .131 .3,125.0 .124 .0,115.5$. 104.1, 55.7. 36.7, 32.1. 31.8, 31.4. 26.9, 25.9. 23.6, 22.7. 21.9, 17.8. 14.2. FTIR $(\mathrm{NaCl}$ plate, neat, $\mathrm{cm}^{-1}$ ): 2957, 2927, 2856, 1608, 1587, 1455, 1419, 1118, 822. HRMS: $\left(\mathrm{C}_{23} \mathrm{H}_{36} \mathrm{O}_{2} \cdot \mathrm{Na}^{+}\right) \mathrm{m} / \mathrm{z}$ calculated: 367.2608 ; found: 367.2596 . Spectroscopic data was comparable to but distinct from that of the corresponding cisisomer in the literature ${ }^{73}$.

3.4.4. $\mathrm{Mn}(\mathrm{OAc})_{3} \cdot 2 \mathrm{H}_{2} \mathrm{O}$

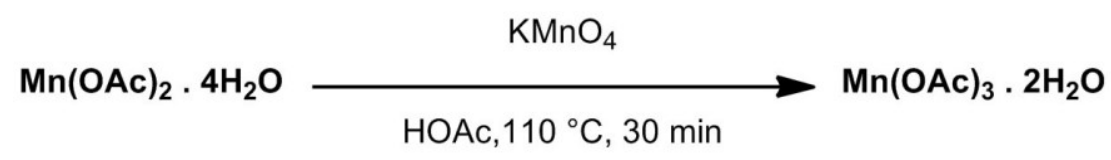

$\mathrm{Mn}(\mathrm{OAc})_{3} \cdot 2 \mathrm{H}_{2} \mathrm{O}$ was prepared according to the literature ${ }^{74}$, from $\mathrm{Mn}(\mathrm{OAc})_{2} \cdot 4 \mathrm{H}_{2} \mathrm{O}$ (0.439 g, 1.79 mmol, 4 equiv) and $\mathrm{KMnO} 4$ (0.0722 g, $0.46 \mathrm{mmol}, 1$ equiv). The product $(0.8 \mathrm{~g})$ was dissolved in hot 5:1 HOAc: $\mathrm{H}_{2} \mathrm{O}$, filtered hot, then concentrated, cooled, and left to crystallize overnight. The solids were filtered, washed with $\mathrm{Et}_{2} \mathrm{O}$ and dried under vacuum to yield a very voluminous cinnamon-brown powder $(0.303 \mathrm{~g}, 50 \% \text { yield })^{4}$.

\footnotetext{
${ }^{4}$ Note: The substantial residual manganese deposits were removed from the glassware via cleaning with aqueaous oxalic acid.
} 
3.4.5. Oxidative cyclization of $\mathbf{6 9 b}$ : (dimethyl CBD) (19).
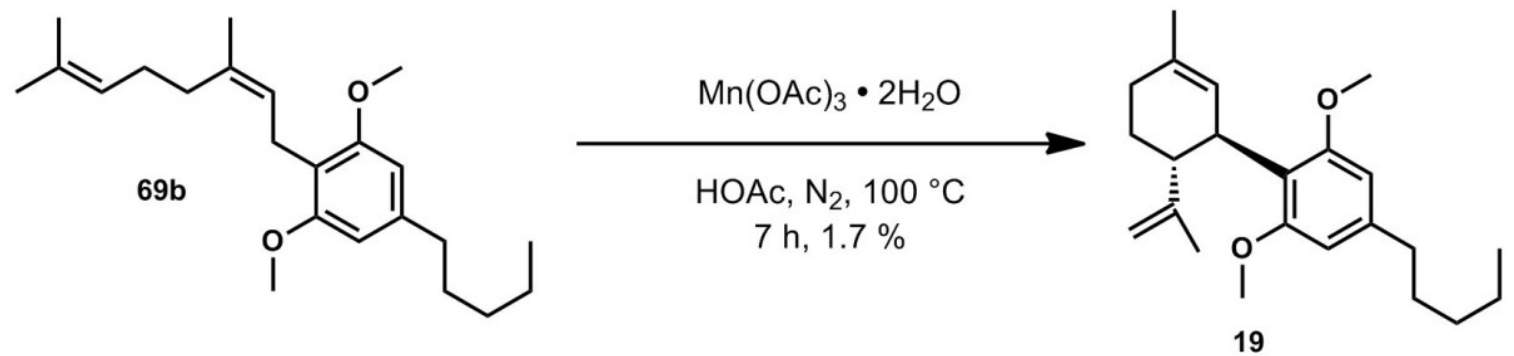

To a solution of $\mathbf{6 9 b}$ [ $20.8 \mathrm{mg}$ ( $92 \%$, with $8 \% \mathbf{1 7}$ impurity), $56 \mu \mathrm{mol}, 1.0$ equiv] in degassed HOAc (1.5 mL, $0.037 \mathrm{M}$ w.r.t. 69b, degassed by 3 cycles of freezing, evacuating, and thawing) was added $\mathrm{Mn}(\mathrm{OAc})_{3} \cdot 2 \mathrm{H}_{2} \mathrm{O}(58.3 \mathrm{mg}, 217 \mu \mathrm{mol}, 3.9$ equiv), and the brown suspension stirred at $100^{\circ} \mathrm{C}$ for $7 \mathrm{~h}$ under $\mathrm{N}_{2}$. The reaction mixture was cooled to RT, filtered, and the colourless solids washed with $\mathrm{Et}_{2} \mathrm{O}(5 \mathrm{~mL})$. The combined organic layers were washed with water $(3 \times 5 \mathrm{~mL})$, filtered through anhydrous $\mathrm{Na}_{2} \mathrm{SO}_{4}$, and evaporated to yield adark brown oil (28.3mg). This was pooled together with the result of another attempt of this reaction on similar scale $(26.5 \mathrm{mg} \mathrm{69b})$ and similar conditions, and the mixture partially separated by preparative TLC (30:70odichlorobenzene : cyclohexane) to afford a pure admixture of $69 \mathrm{~b}$ and $19(5.1 \mathrm{mg}, 16 \%$ 19 / $84 \%$ 69b, $1.7 \%$ yield of 19 ) as confirmed by ${ }^{1} \mathrm{H}$ NMR and GCMS. Spectroscopic data was in good agreement with both literature ${ }^{27}$, and material synthesized by a different route.

3.4.6. 2,3-dichloro-5-(2,6-dimethoxy-4-pentylphenyl)-7-(4-methylpent-3-en-1-yl)1,4-dioxo-1,4,4a,5,8,8a-hexahydronaphthalene-4a,8a-dicarbonitrile (80) 


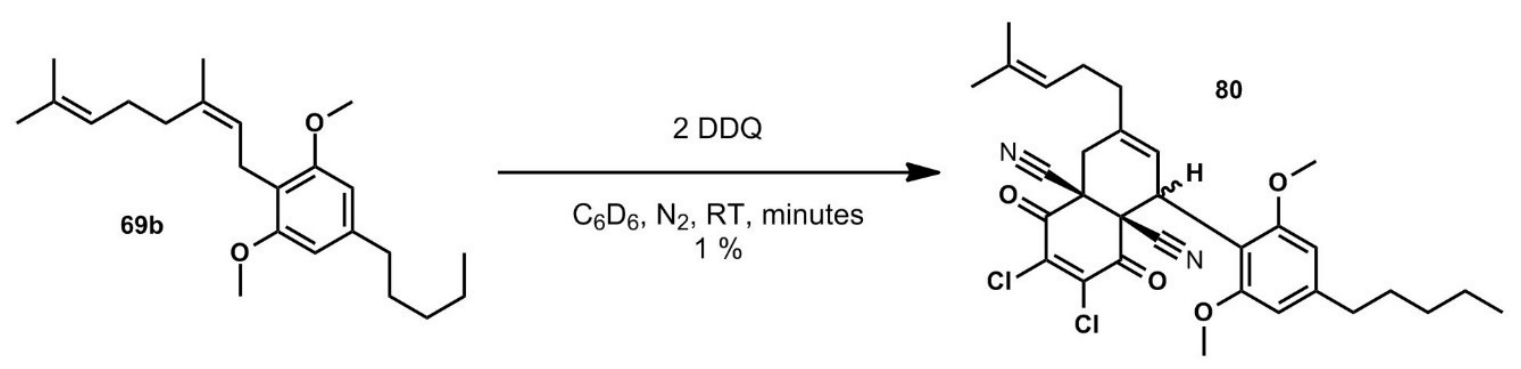

In an NMR tube fitted with a septum and flushed with $\mathrm{N}_{2}$, was added $69 \mathrm{~b}(9.7 \mathrm{mg}$, $28 \mu \mathrm{mol}, 1.0$ equiv $)$ and $\mathrm{C}_{6} \mathrm{D}_{6}(1000 \mu \mathrm{L}, 0.024 \mathrm{M}$ w.r.t.69b) dried over $4 \AA$ molecular sieves. After thorough mixing, an orange solution of DDQ in $\mathrm{C}_{6} \mathrm{D}_{6}(150 \mu \mathrm{L}, 0.23 \mathrm{M}$ stock, $34 \mu \mathrm{mol}, 1.2$ equiv) was added at RT and the deep green mixture shaken thoroughly. Though NMR proved the reaction had ceased within 4 min, the mixture was left at RT for $20 \mathrm{~h}$, then heated to $85^{\circ} \mathrm{C}$ for $7 \mathrm{~h}$. Another portion of DDQ in $\mathrm{C}_{6} \mathrm{D}_{6}(150 \mu \mathrm{L}, 0.23 \mathrm{M}$ stock, $34 \mu \mathrm{mol}, 1.2$ equiv) was added, and shaken for $5 \mathrm{~min}$ at RT. The amber supernatant was decanted, evaporated, and purified by preparative TLC ( $\mathrm{SiO}_{2}, 10: 90 \mathrm{EtOAc} /$ hexanes $)$ to afford what is believed to be $\mathbf{8 0}(\sim 0.2 \mathrm{mg}, 1 \%$ yield) as a bright yellow oil (material limitations meant not all NMR peaks could be resolved):

$\mathbf{R}_{\mathbf{f}} 0.30$ (5\% EtOAc/hexanes; yellow colour, UV, $\left.\mathrm{I}_{2}\right){ }^{1} \mathbf{H}$ NMR $\left(\mathrm{CDCl}_{3}, 300 \mathrm{MHz}\right): \delta 6.32$ (s, 1H), $6.16(\mathrm{~s}, 1 \mathrm{H}), 5.37(\mathrm{t}, \mathrm{J}=3.8 \mathrm{~Hz}, 1 \mathrm{H}), 5.12(\mathrm{~m}, 1 \mathrm{H}), 4.96(\mathrm{br} \mathrm{s}, 1 \mathrm{H}), 3.84(\mathrm{~s}, 3 \mathrm{H})$, 3.49 (s, 3H), 3.39 (d, J = 17.1 Hz, 1H), 2.79 (dt, J = 17.1, $2.8 \mathrm{~Hz}, 1 \mathrm{H}), 2.52(\mathrm{dd}, \mathrm{J}=8.2$, $6.5 \mathrm{~Hz}, 2 \mathrm{H}), 2.25-2.05(\mathrm{~m}, 1.71(\mathrm{~s}, 3 \mathrm{H}), 1.64(\mathrm{~s}, 3 \mathrm{H}), 1.54(\mathrm{~m}), 1.30(\mathrm{~m}), 0.90(\mathrm{t}, \mathrm{J}=6.8$ $\mathrm{Hz}, 3 \mathrm{H}) .{ }^{13} \mathbf{C}$ NMR ( $\left.\mathrm{CDCl}_{3}, 75 \mathrm{MHz}\right): \delta 123.2,120.7,104.2,103.9,55.9,54.2,38.1$, 37.3, 36.6, 31.3, 31, 30.4, 29.7, 26, 25.7, 22.5, 17.8, 14.1. FTIR ( $\mathrm{NaCl}$ plate, neat, $\left.\mathrm{cm}^{-1}\right)$ : 2923, 2851, 1720, 1609, 1580, 1559, 1461, 1422, 1238, 1143, 1124, 794. HRMS: $\left(\mathrm{C}_{31} \mathrm{H}_{34} \mathrm{Cl}_{2} \mathrm{~N}_{2} \mathrm{O}_{4} \cdot \mathrm{Na}^{+}\right) \mathrm{m} / \mathrm{z}$ calculated: 591.1788; found: 591.1794 . 


\section{References}

(1) ElSohly, M. A.; Slade, D. Life Sci. 2005, 78 (5), 539-548.

(2) Snider, B. B.; Lobera, M. Tetrahedron Lett. 2004, 45, 5015-5018.

(3) Park, B. H.; Lee, Y. R. Bull. Korean Chem. Soc. 2010, 31 (9), 2712-2714.

(4) Pertwee, R. G. Br. J. Pharmacol. 2006, 147, S163-S171.

(5) Grotenhermen, F.; Müller-Vahl, K. CRC. Crit. Rev. Plant Sci. 2016, 35 (5-6), 378-405.

(6) Mechoulam, R.; Hanuš, L. Chem. Phys. Lipids 2000, 108, 1-13.

(7) Mechoulam, R.; Gaoni, Y. J. Am. Chem. Soc. 1965, 87 (14), 3273-3275.

(8) Mechoulam, R.; Braun, P.; Gaoni, Y.; Mechoulam, R.; Braun, P.; Gaoni, Y.; Mechoulam, R. J. Am. Chem. Soc. 1972, 94 (17), 6159-6165.

(9) Yamaori, S.; Okushima, Y.; Masuda, K.; Kushihara, M.; Katsu, T.; Narimatsu, S.; Yamamoto, I.; Watanabe, K. Biol. Pharm. Bull. 2013, 36 (7), 1197-1203.

(10) Devinsky, O.; Cilio, M. R.; Cross, H.; Fernandez-Ruiz, J.; French, J.; Hill, C.; Katz, R.; Di Marzo, V.; Jutras-Aswad, D.; Notcutt, W. G.; Martinez-Orgado, J.; Robson, P. J.; Rohrback, B. G.; Thiele, E.; Whalley, B.; Friedman, D. Epilepsia 2014, 55 (6), 791-802.

(11) Di Marzo, V.; De Petrocellis, L. Annu. Rev. Med. 2006, 57, 553-574.

(12) Gagne, S. J.; Stout, J. M.; Liu, E.; Boubakir, Z.; Clark, S. M.; Page, J. E. Proc. Nat. Acad. Sci. 2012, 109 (31), 12811-12816.

(13) Fellermeier, M.; Eisenreich, W.; Bacher, A.; Zenk, M. H. Eur. J. Biochem. 2001, $268(6), 1596-1604$.

(14) Degenhardt, J.; Köllner, T. G.; Gershenzon, J. Phytochemistry 2009, 70 (15-16), $1621-1637$.

(15) Zhang, Q.; Tiefenbacher, K. Nat. Chem. 2015, 7 (3), 197-202.

(16) Fellermeier, M.; Zenk, M. H. FEBS Lett. 1998, 427 (2), 283-285.

(17) Carvalho, Â.; Hansen, E. H.; Kayser, O.; Carlsen, S.; Stehle, F. FEMS Yeast Res. 2017, 17 (4), 1-11.

(18) Taura, F.; Morimoto, S.; Shoyama, Y. Phytochemistry 1995, 39 (2), 457-458.

(19) Choi, Y. H.; Hazekamp, A.; Peltenburg-looman, A. M. G.; Frederich, M.; Erkelens, C.; Lefeber, A. W. M.; Verpoorte, R. Phytochem. Anal. 2004, 15, 345354.

(20) Taura, F.; Sirikantaramas, S.; Shoyama, Y.; Yoshikai, K.; Shoyama, Y.; Morimoto, S. FEBS Lett. 2007, 581 (16), 2929-2934.

(21) Shoyama, Y.; Tamada, T.; Kurihara, K.; Takeuchi, A.; Taura, F.; Arai, S.; Blaber, M.; Shoyama, Y.; Morimoto, S.; Kuroki, R. J. Mol. Biol. 2012, 423 (1), 96-105.

(22) Petrzilka, T.; Haefliger, W.; Sikemeier, C.; Ohloff, G.; Eschemmoser, A. Helv. Chim. Acta 1967, 50 (2), 719-723.

(23) Petrzilka, T.; Haefliger, W.; Sikemeier, G. Helv. Chim. Acta 1969, 52 (4), 1102 1134.

(24) Baek, S. H.; Srebnik, M.; Mechoulam, R. Tetrahedron Lett. 1985, 26 (8), 10831086.

(25) Razdan, R. K.; Handrick, R. Direct Synthesis of (-)-trans-delta9-

tetrahydrocannabinol from Olivetol and (+)-trans-delta2-carene oxide. 3,734,930, 
1973.

(26) Kinney, W. A.; McDonnell, M. E.; Zhong, H. M.; Liu, C.; Yang, L.; Ling, W.; Qian, T.; Chen, Y.; Cai, Z.; Petkanas, D.; Brenneman, D. E. ACS Med. Chem. Lett. 2016, 7 (4), 424-428.

(27) Hanuš, L. O.; Tchilibon, S.; Ponde, D. E.; Breuer, A.; Fride, E.; Mechoulam, R. Org. Biomol. Chem. 2005, 3 (6), 1116-1123.

(28) Rickards, R. W.; Röenneberg, H. J. Org. Chem. 1984, 49 (3), 572-573.

(29) Fahrenholtz, K. E.; Lurie, M.; Kierstead, R. W. J. Am. Chem. Soc. 1967, 89 (23), 5934-5941.

(30) ApSimon, J, W.; Holmes, A, M.; Johnson, I. Can. J. Chem. 1982, 38 (18), 31933194.

(31) Evans, D. A.; Shaughnessy, E. A.; Barnes, D. M. Tetrahedron Lett. 1997, 38, 3193-3194.

(32) Childers, W. E.; Pinnick, H. W. J. Org. Chem. 1984, 49, 5276-5277.

(33) Kobayashi, Y.; Takeuchi, A.; Wang, Y. G. Org. Lett. 2006, 8 (13), 2699-2702.

(34) Trost, B. M.; Dogra, K. Org. Lett. 2007, 9 (8), 861-863.

(35) Lee, Y. R.; Xia, L. Tet. Lett. 2008, 49 (20), 3283-3287.

(36) Saimoto, H.; Yoshida, K.; Murakami, T.; Morimoto, M.; Sashiwa, H.; Shigemasa, Y. J. Org. Chem. 1996, 61 (20), 6768-6769.

(37) Chauder, B. a.; Kalinin, A. V.; Snieckus, V. Synthesis (Stuttg). 2001, 140-144.

(38) Loumouamou, A. N.; Bikindou, K.; Bitemou, E.; Chalard, P.; Silou, T.; Figueredo, G. Food Sci Nutr 2017, 5, 784-792.

(39) Itoh, H.; Maeda, H.; Yamada, S.; Hori, Y.; Mino, T.; Sakamoto, M. Org. Chem. Front. 2014, 1 (9), 1107-1115.

(40) Itoh, H.; Maeda, H.; Yamada, S.; Hori, Y.; Mino, T.; Sakamoto, M. Org. Biomol. Chem. 2015, 13 (20), 5817-5825.

(41) Dioos, B. M. L.; Jacobs, P. A. Tetrahedron Lett. 2003, 44 (25), 4715-4717.

(42) Wuts, P.; Greene, T. Protective Groups in Organic Synthesis, 4th ed.; John Wiley \& Sons, 2003.

(43) Snieckus, V. Chem. Rev. 1990, 90 (6), 879-933.

(44) Gerstenberger, B. S.; Konopelski, J. P. J. Org. Chem. 2005, 70 (4), 1467-1470.

(45) Marsini, M. A.; Gowin, K. M.; Pettus, T. R. R. Org. Lett 2006, 8, 3481-3483.

(46) Armarego, W. L. F.; Chai, C. L. L. Purification of Laboratory Chemicals, 6th ed.; Butterworth-Heinemann: Burlington, 2009.

(47) Ortega, R.; Sanchez-Quesada, J.; Lorenz, C.; Dolega, G.; Karawajczyk, A.; Sanz, M.; Showell, G.; Giordanetto, F. Bioorg. Med. Chem. 2015, 23 (11), 2716-2720.

(48) Townsend, C. A.; Davis, S. G.; Christensen, S. B.; Link, J. C.; Lewis, C. P. J. Am. Chem. Soc. 1981, 103 (23), 6885-6888.

(49) Berkessel, A.; Sebastian-Ibarz, M. L.; Müller, T. N. Angew. Chem. Int. Ed. 2006, 45 (39), 6567-6570.

(50) Dounay, A. B.; Overman, L. E. Chem. Rev. 2003, 103 (8), 2945-2963.

(51) Schafroth, M. A.; Sarlah, D.; Krautwald, S.; Carreira, E. M. J. Am. Chem. Soc. 2012, 134 (50), 20276-20278.

(52) Johnson, W. S. Bioorg. Chem. 1976, 5, 51-98.

(53) Buxton, C. A.; Hachey, D. L.; Leresche, J.-P. J. Org. Chem. 1972, 37 (25), 40364039. 
(54) Buckle, D. R.; Ohkubo, K.; Fukuzumi, S. Encyclopedia of Reagents of Organic Synthesis; 2016.

(55) Asato, A. E.; Kiefer, E. F. Chem. Commun. 1968, No. 24, 1684-1685.

(56) Walker, D.; Hiebert, J. D. Chem. Rev. 1967, 67 (2), 153-195.

(57) Zhu, X. Q.; Wang, C. H.; Liang, H.; Cheng, J. P. J. Org. Chem. 2007, 72 (3), 945956.

(58) Ho, T.-L.; Wang, J.; Li, C. Encyclopedia of Reagents of Organic Synthesis.

(59) Terent'ev, A. O.; Krylov, I. B.; Sharipov, M. Y.; Kazanskaya, Z. M.; Nikishin, G. I. Tetrahedron 2012, 68, 10263-10271.

(60) Laing, S.; Sykes, P. J. Chem. Soc. 1968, 2915-2918.

(61) Zard, S. Radical Reactions in Organic Synthesis; Oxford University Press, 2003.

(62) Burton, J. W. Manganese (III) Acetate, CAN, and Fe (III) Salts in Oxidative Radical Chemistry; 2012.

(63) Jabbari, A.; Sadeghian, H.; Salimi, A.; Mousavian, M.; Seyedi, S. M.; Bakavoli, M. Chem. Biol. Drug Des. 2016, 88, 460-469.

(64) Forbes, M. Carbon-Centered Free Radicals and Radical Cations: Structure, Reactivity and Dynamics; John Wiley \& Sons: Hoboken.

(65) Zipse, H. Top. Curr. Chem. 2006, 263, 163-189.

(66) Abu-Lafi, S.; Sterin, M.; Levin, S. J. Chromatogr. A 1994, 679, 47-58.

(67) Still, W. C.; Kahn, M.; Mitra, A. J. Org. Chem. 1978, 43 (14), 2923-2925.

(68) Pedersen, D.; Rosenbohm, C. Synthesis (Stuttg). 2004, 2001 (16), 2431-2434.

(69) Poldy, J.; Peakall, R.; Barrow, R. A. Org. Biomol. Chem. 2009, 7 (20), 4296-4300.

(70) Banwell, M. G.; Chand, S. Org. Prep. Proced. Int. 2005, 37 (3), 275-279.

(71) Calzada, J. G.; Hooz, J.; Chan, K. K.; Specian, A.; Brossi, A. Org. Synth. 1974, 54 (63).

(72) Araki, S.; Ohmori, K.; Butsugan, Y. Synthesis (Stuttg). 1984, 841-842.

(73) Srebnik, M.; Lander, N.; Breuer, A.; Mechoulam, R. J. Chem. Soc., Perkin I 1984, 2881-2886.

(74) Heiba, E. A. I.; Dessau, R. M.; Koehl, W. J. J. J. Am. Chem. Soc. 1969, 91, 138145 . 


\section{$\underline{\text { 5. Appendix }}$}
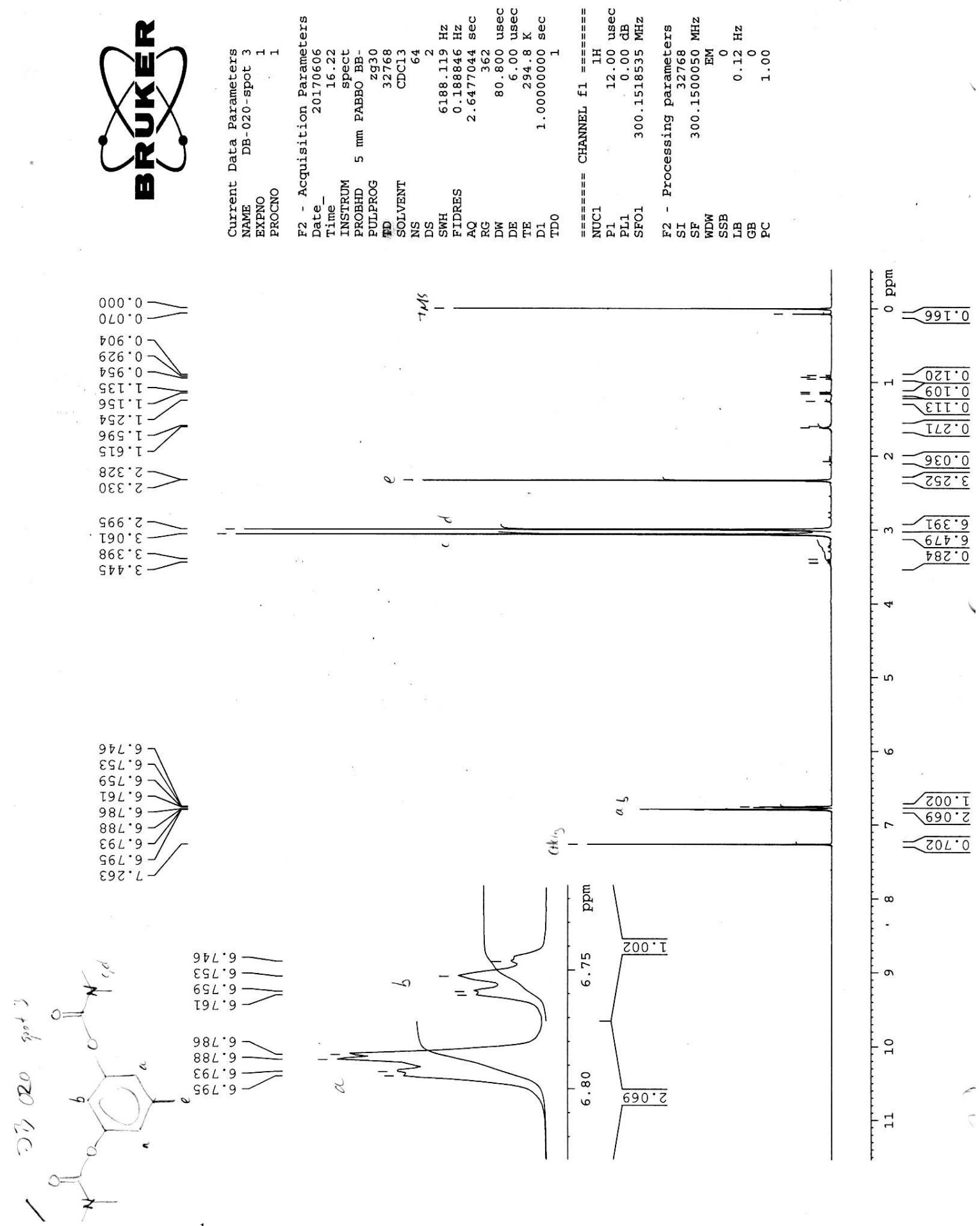

Figure A1. ${ }^{1} \mathrm{H}$ NMR of 5-methyl-1,3-phenylene bis(dimethylcarbamate) (49b) 

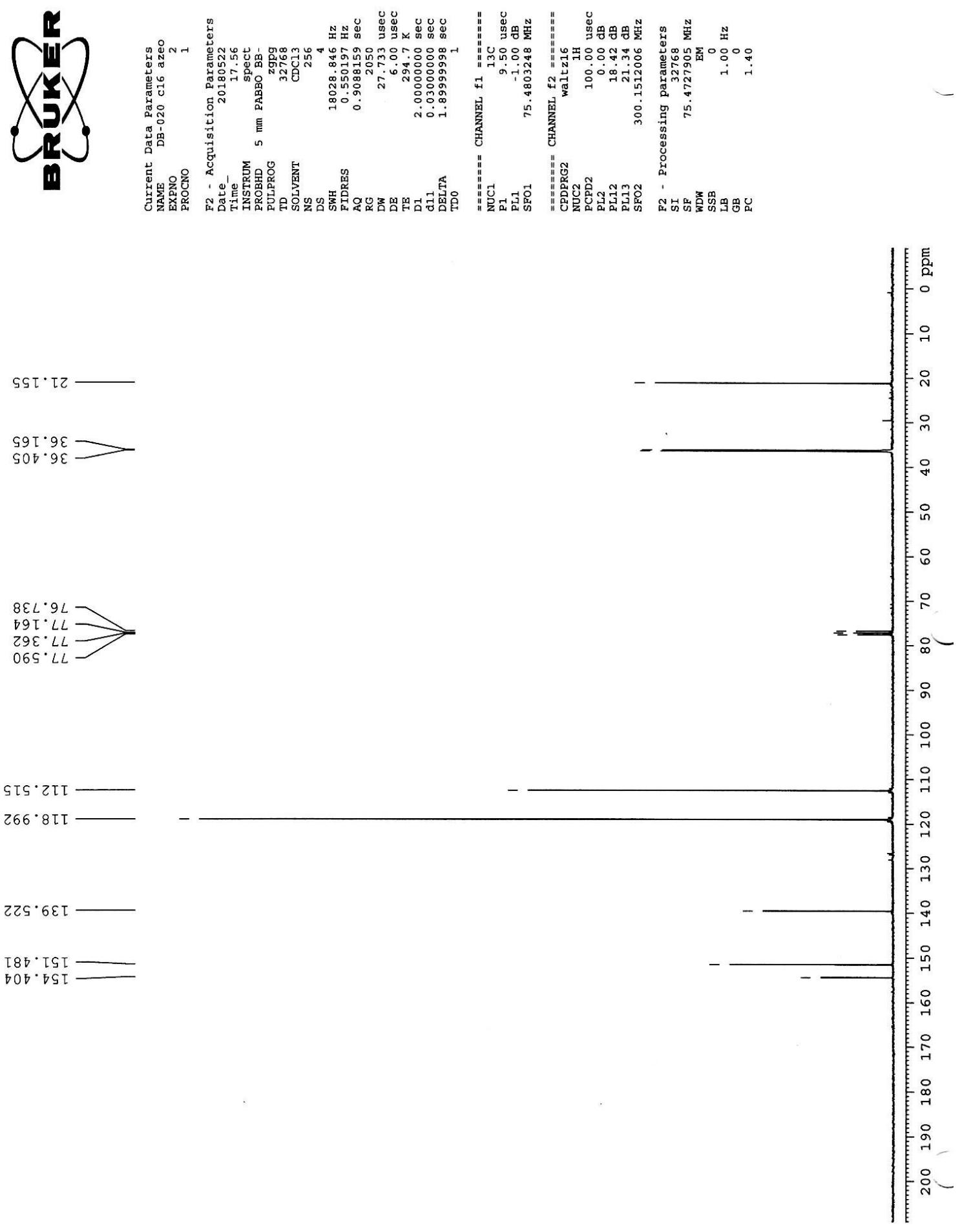

Figure A2. ${ }^{13} \mathrm{C}$ NMR of 5-methyl-1,3-phenylene bis(dimethylcarbamate) (49b) 

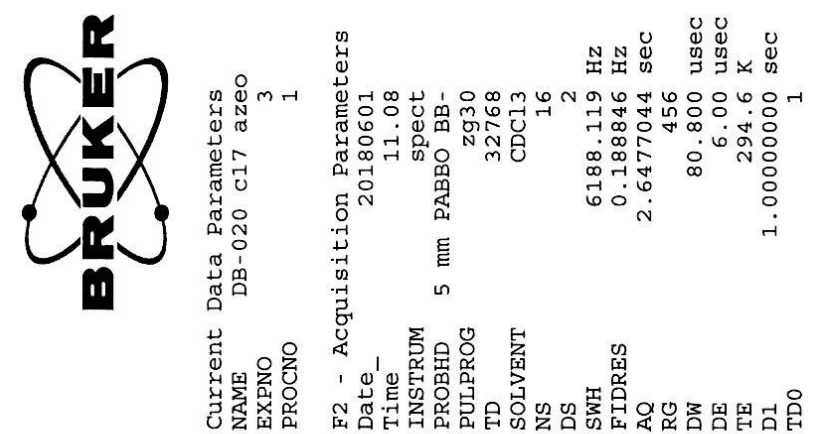

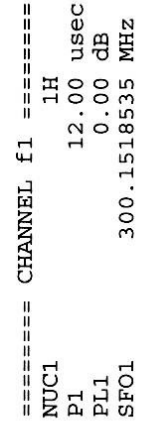
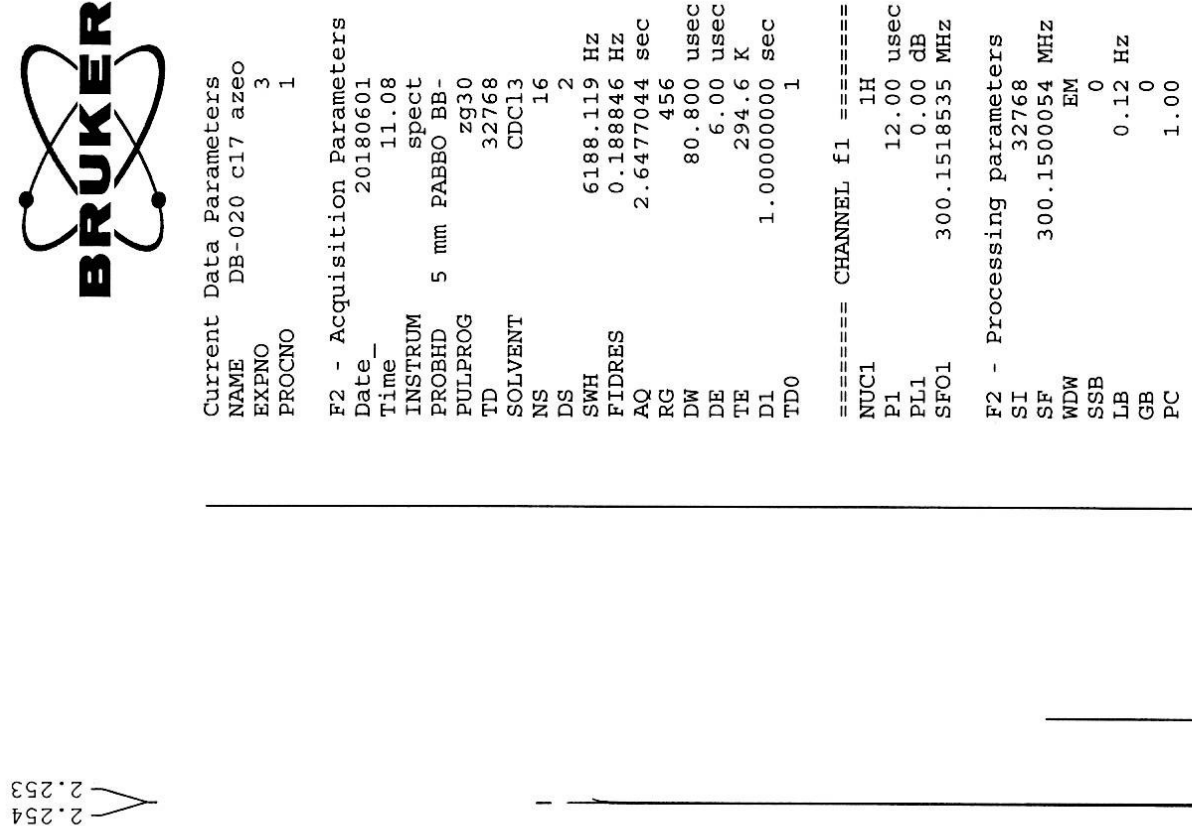

$\operatorname{si0}^{\circ} \varepsilon=$
$\varepsilon 80^{\circ} \varepsilon=$
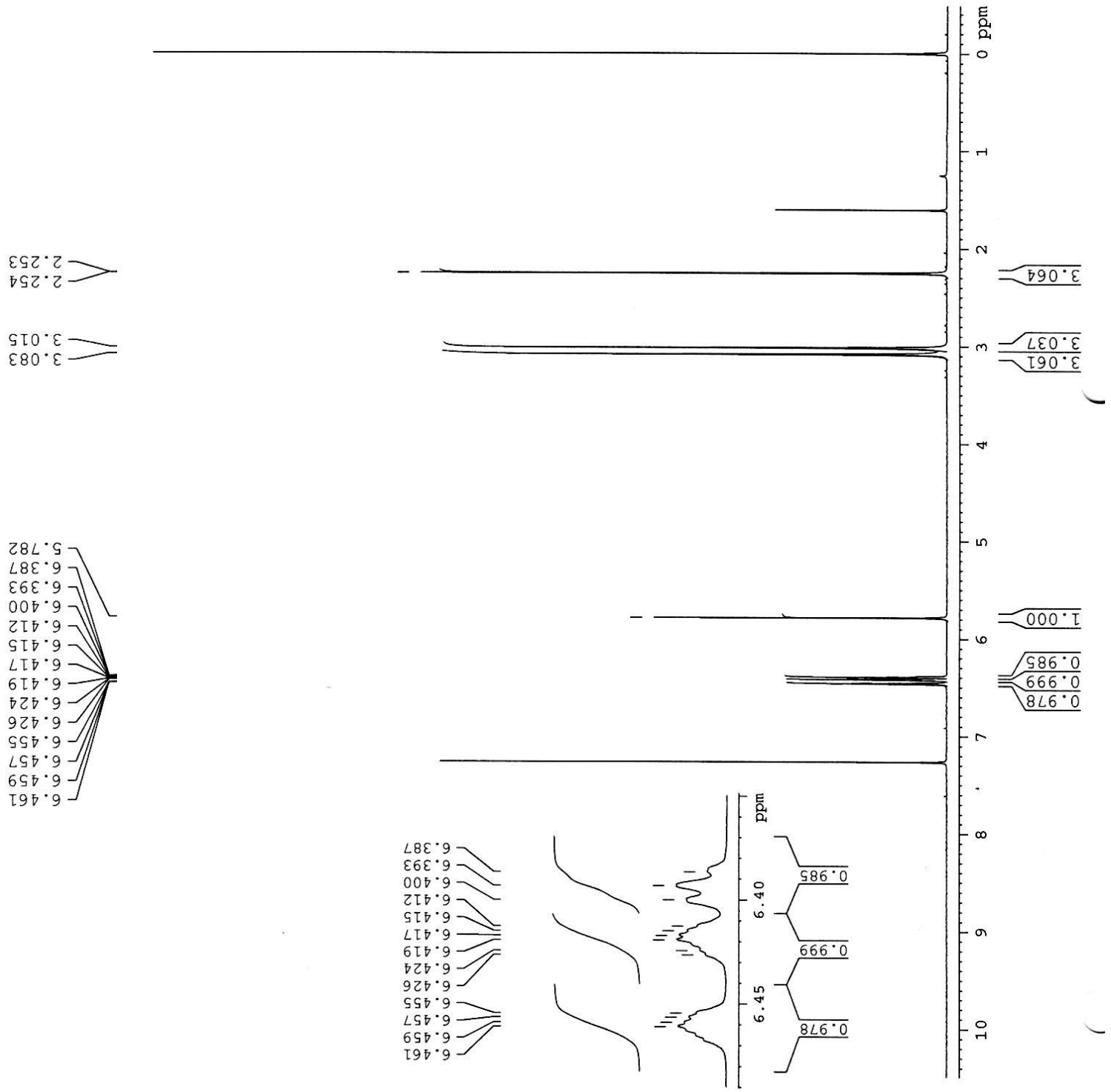

Figure A3. ${ }^{1} \mathrm{H}$ NMR of 3-hydroxy-5-methylphenyl dimethylcarbamate (50b) 

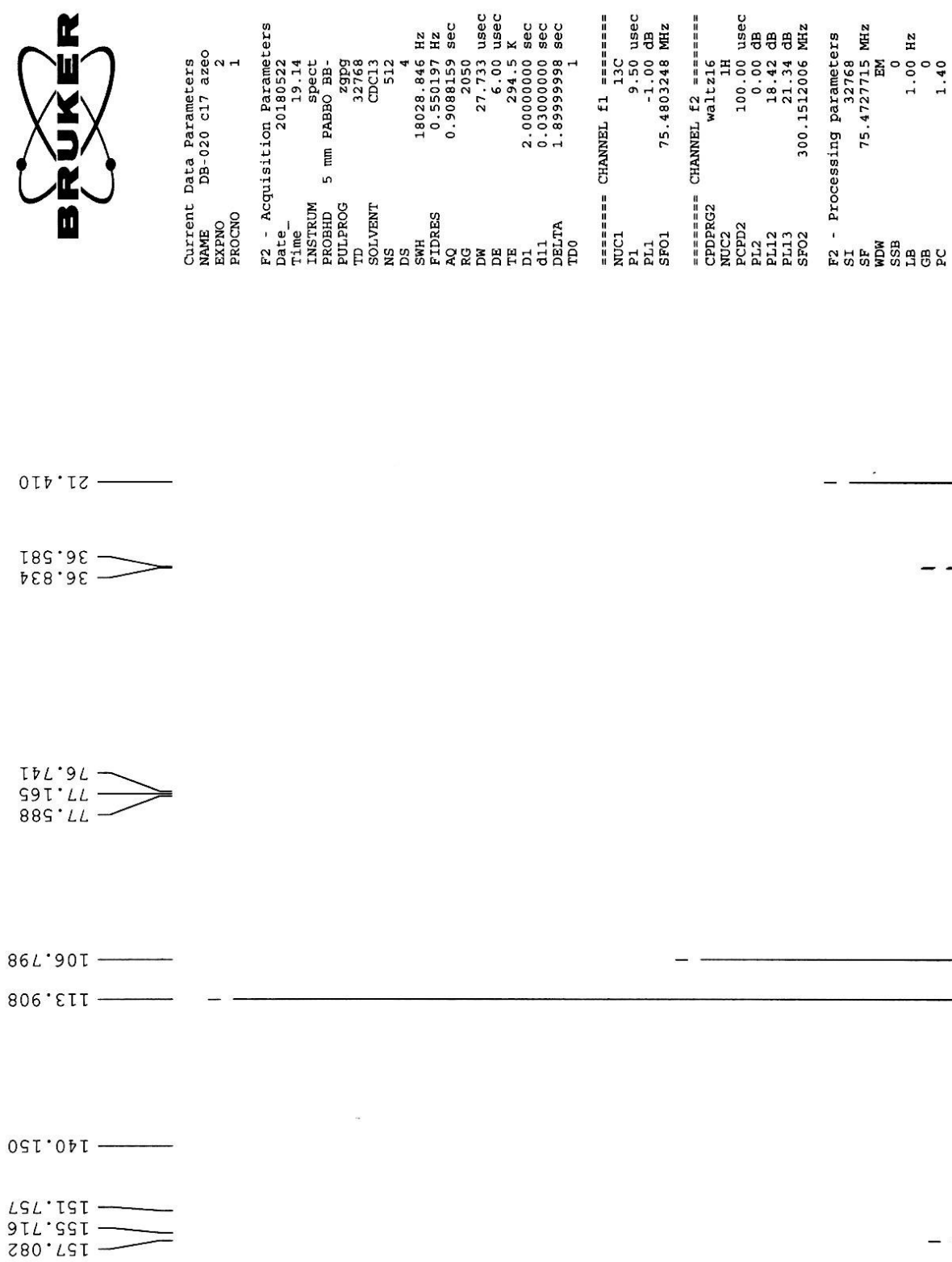

$86 L \cdot 90 \tau-$
$806 \cdot \varepsilon \tau \tau-$
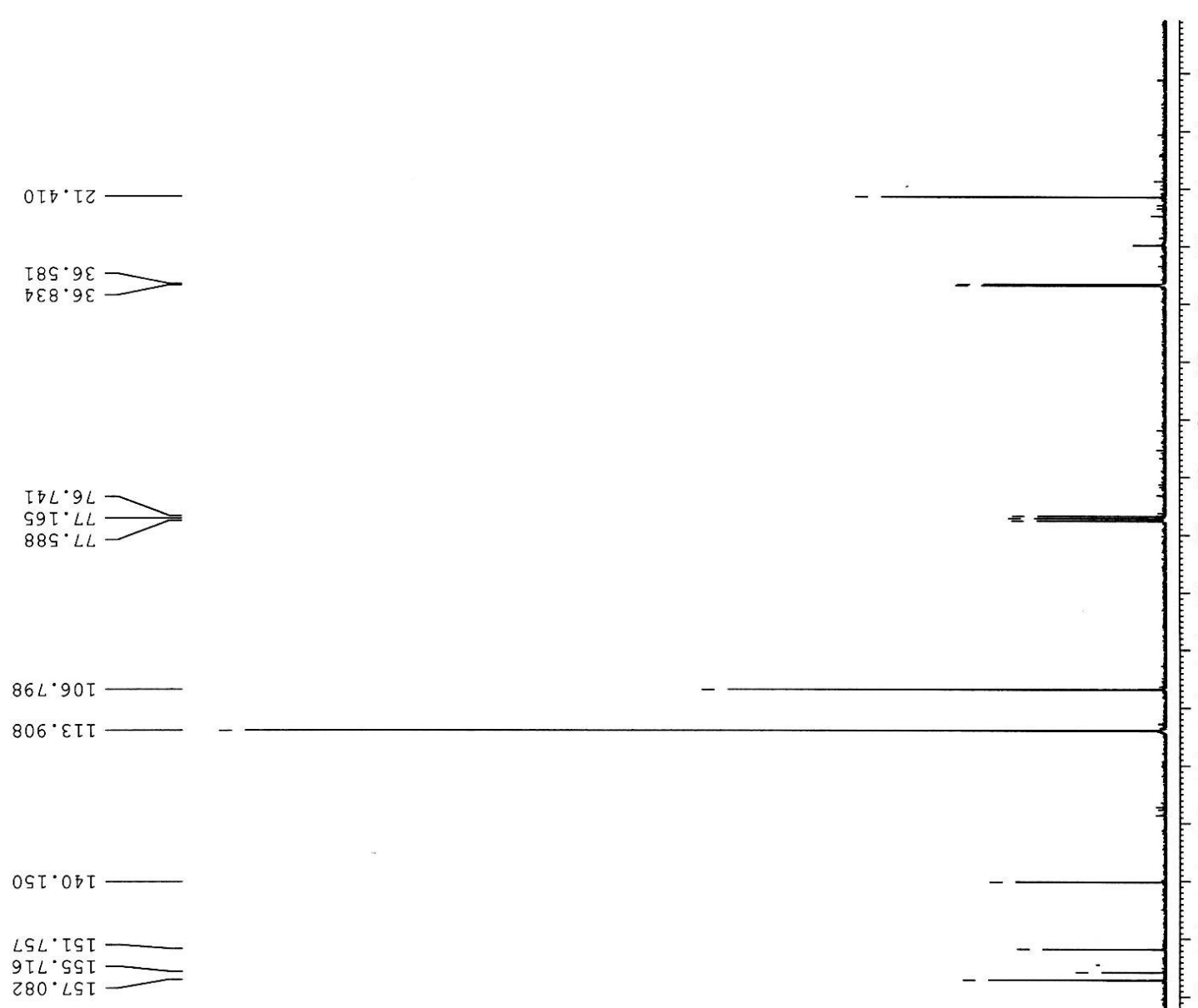


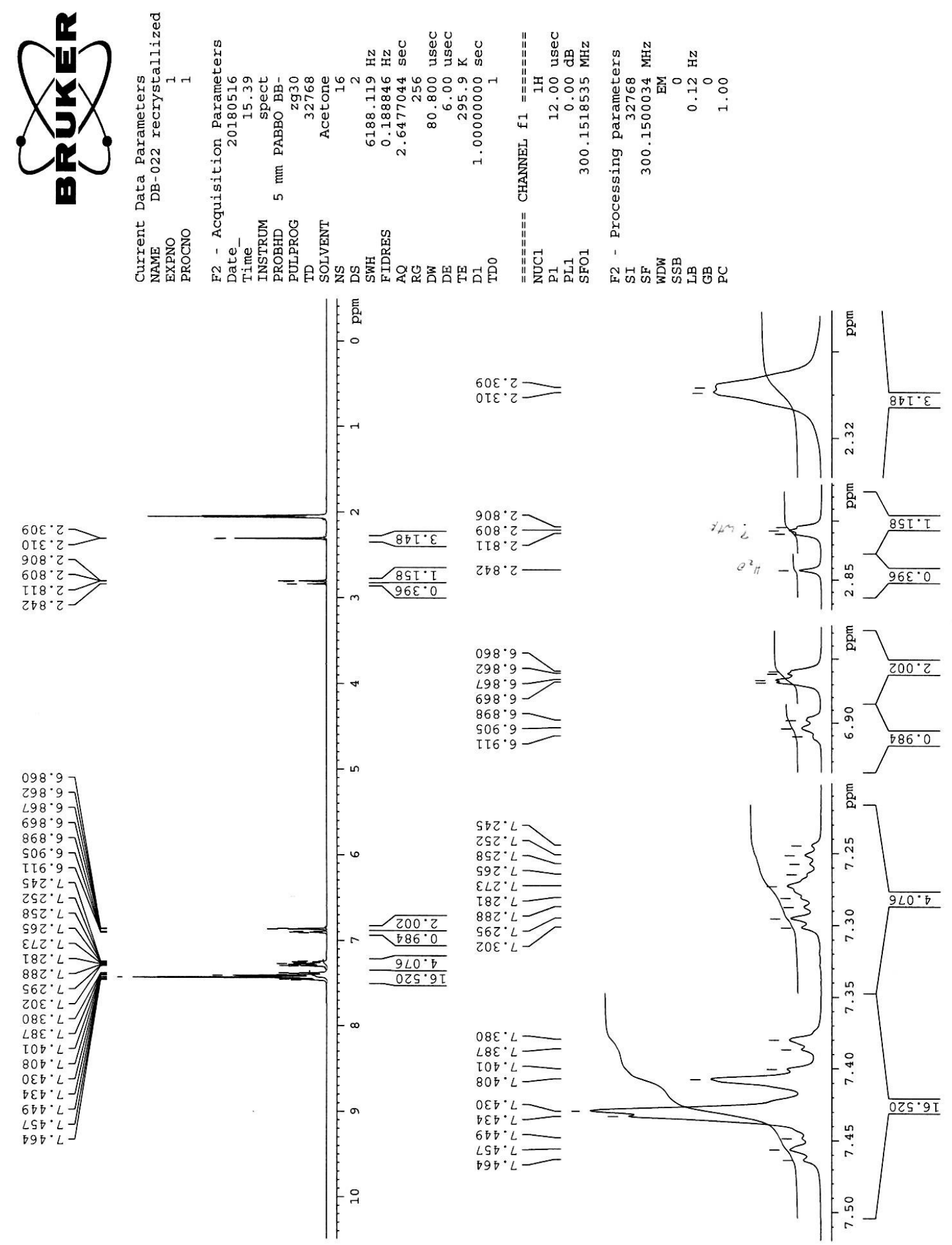

Figure A5. ${ }^{1} \mathrm{H}$ NMR of 5-methyl-1,3-phenylene bis(diphenylcarbamate) (49c) 

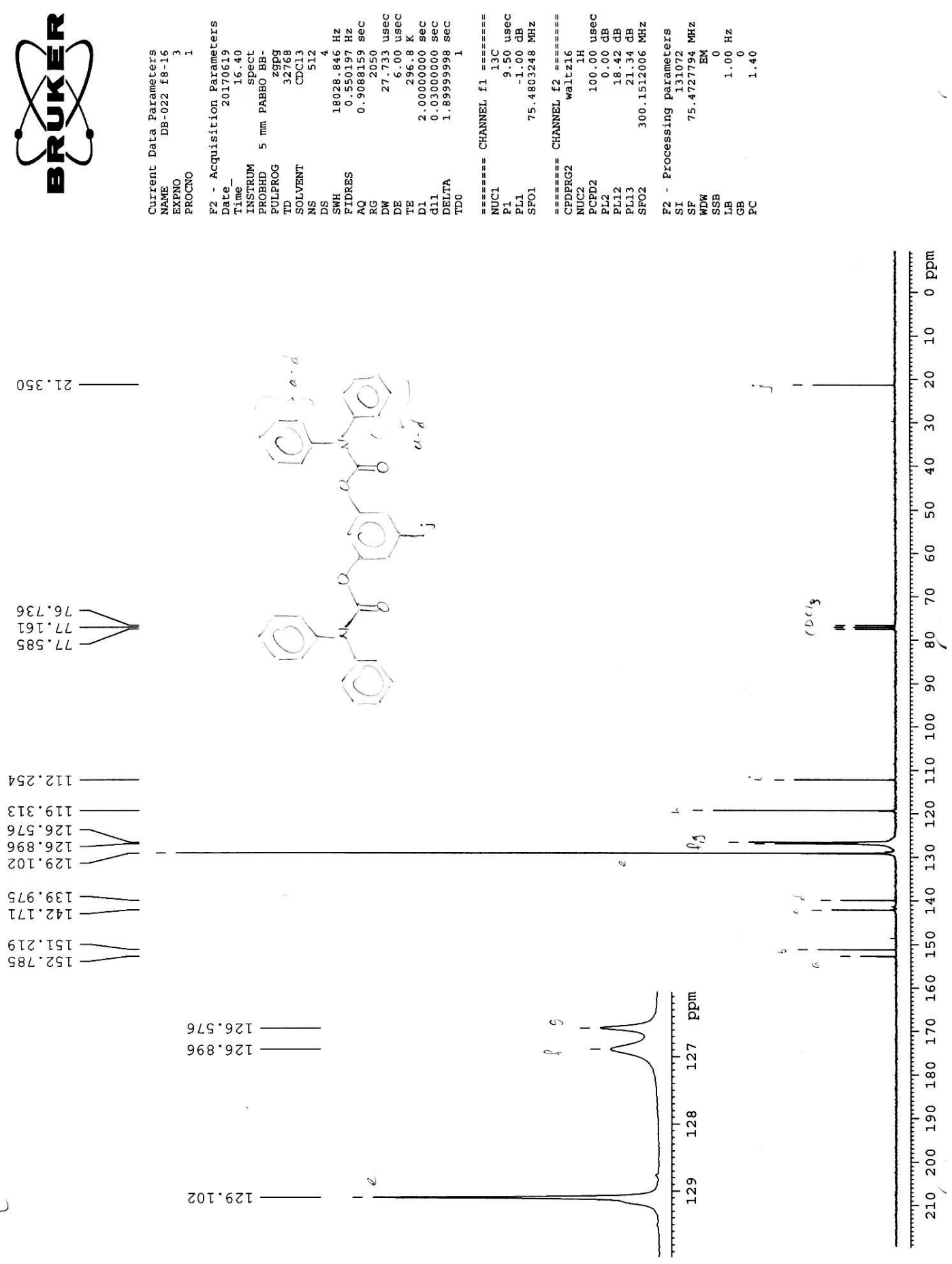

Figure A6. ${ }^{13} \mathrm{C}$ NMR of 5-methyl-1,3-phenylene bis(diphenylcarbamate) (49c) 

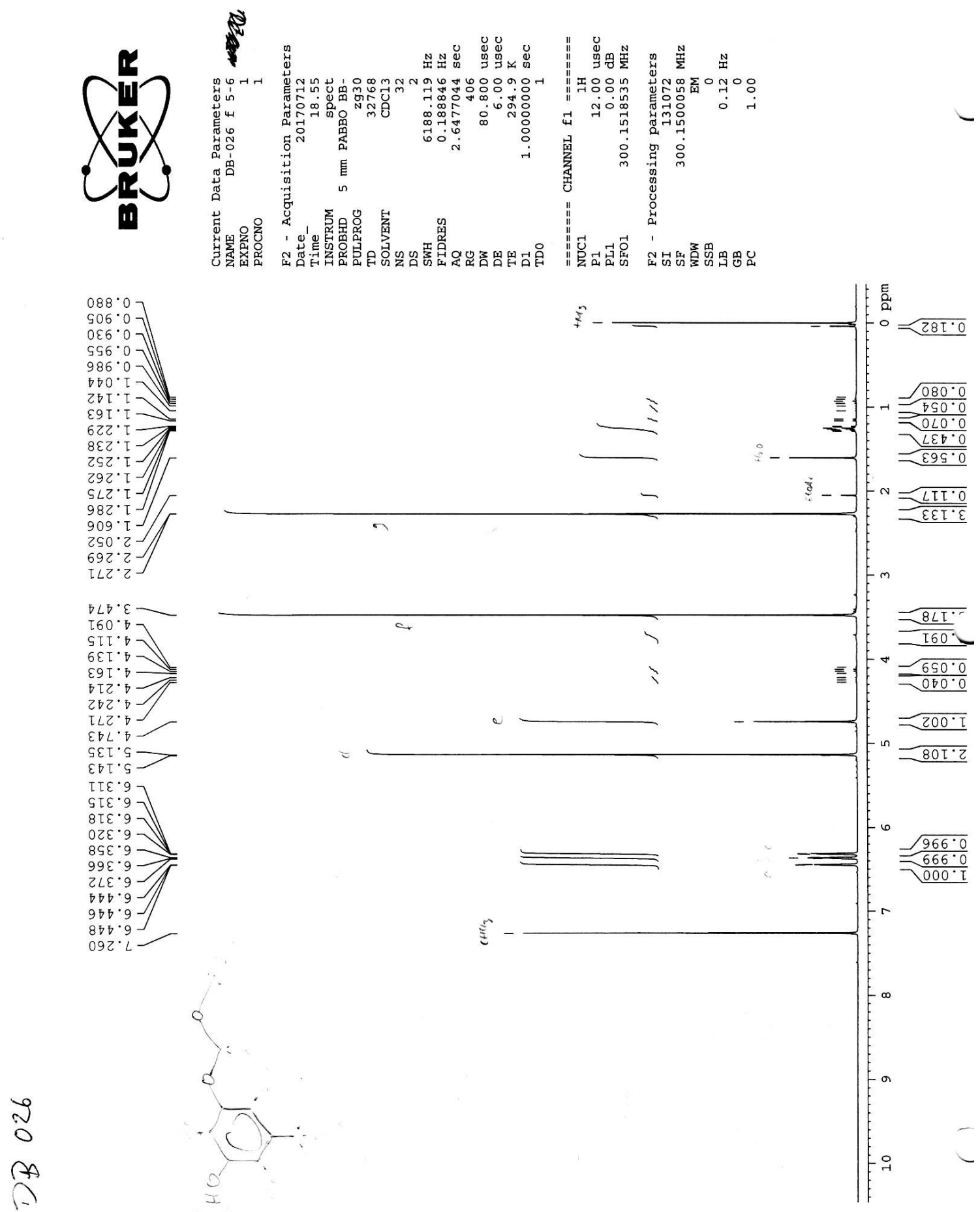

Figure A7. ${ }^{1}$ H NMR of 3-(methoxymethoxy)-5-methylphenol (50d) 

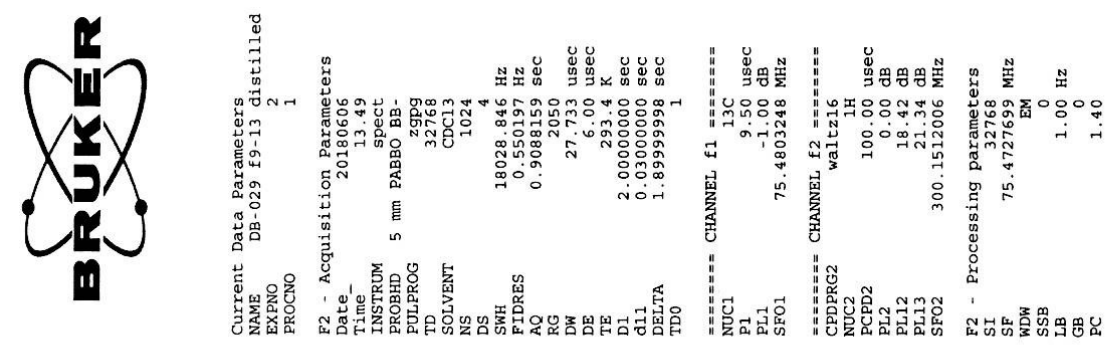

$\varepsilon 89 \cdot \tau 乙$

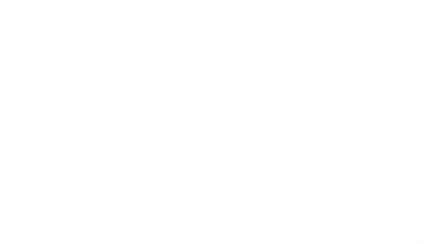

DII.9S

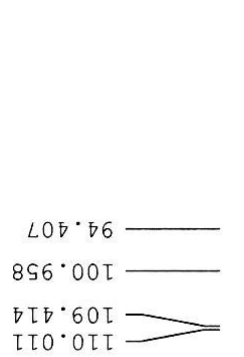

8 I8.0万T

8S9.9ST

โEย $8 \mathrm{SI}$

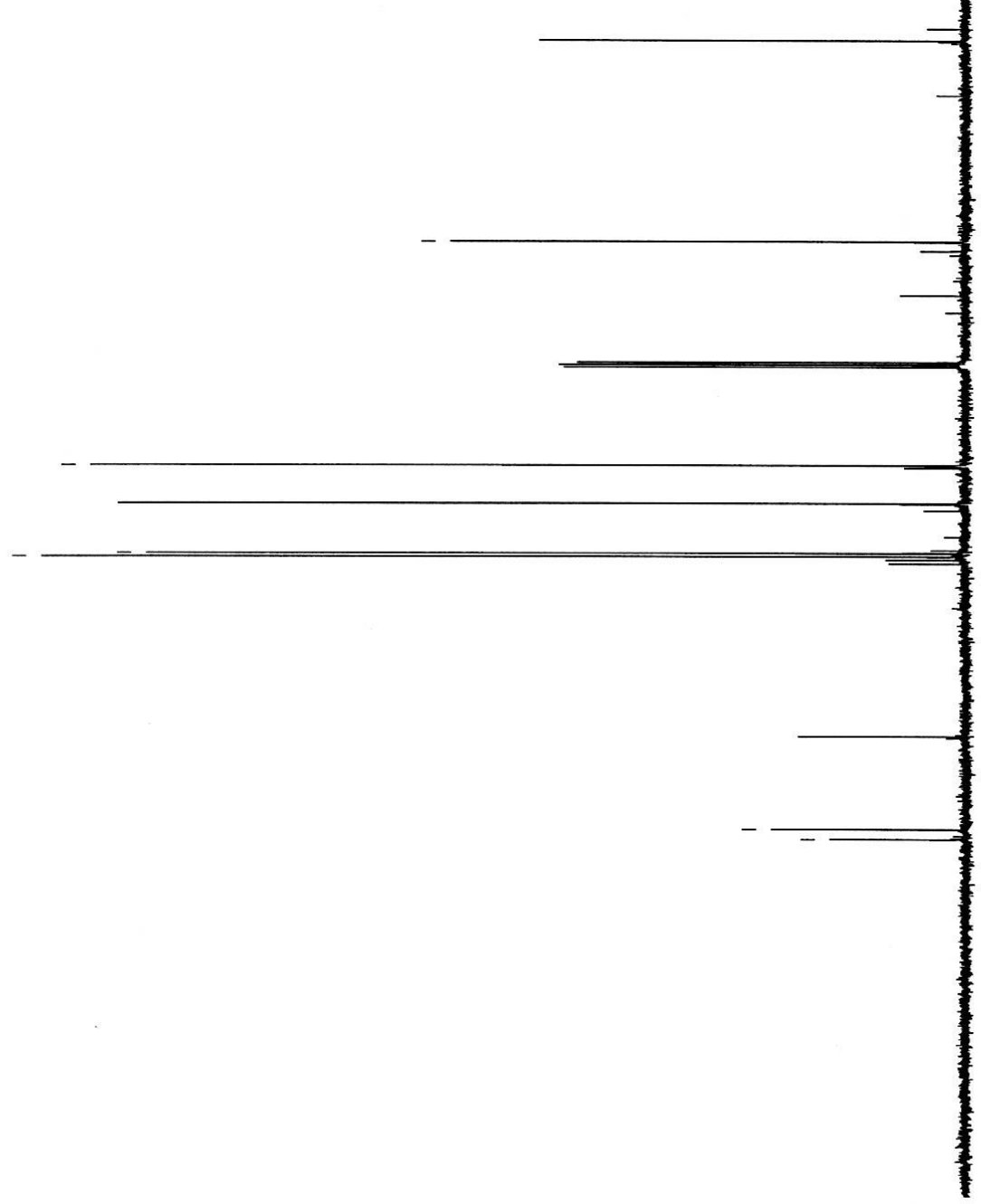

$-\stackrel{\text { N }}{2}$

-웅

$-8$

$-\infty$

-욱

$-\stackrel{4}{\circ}$

임

0
-0
-1

0
$-\infty$
-1
-1

- 웅

Figure A8. ${ }^{13} \mathrm{C}$ NMR of 3-(methoxymethoxy)-5-methylphenol (50d) 

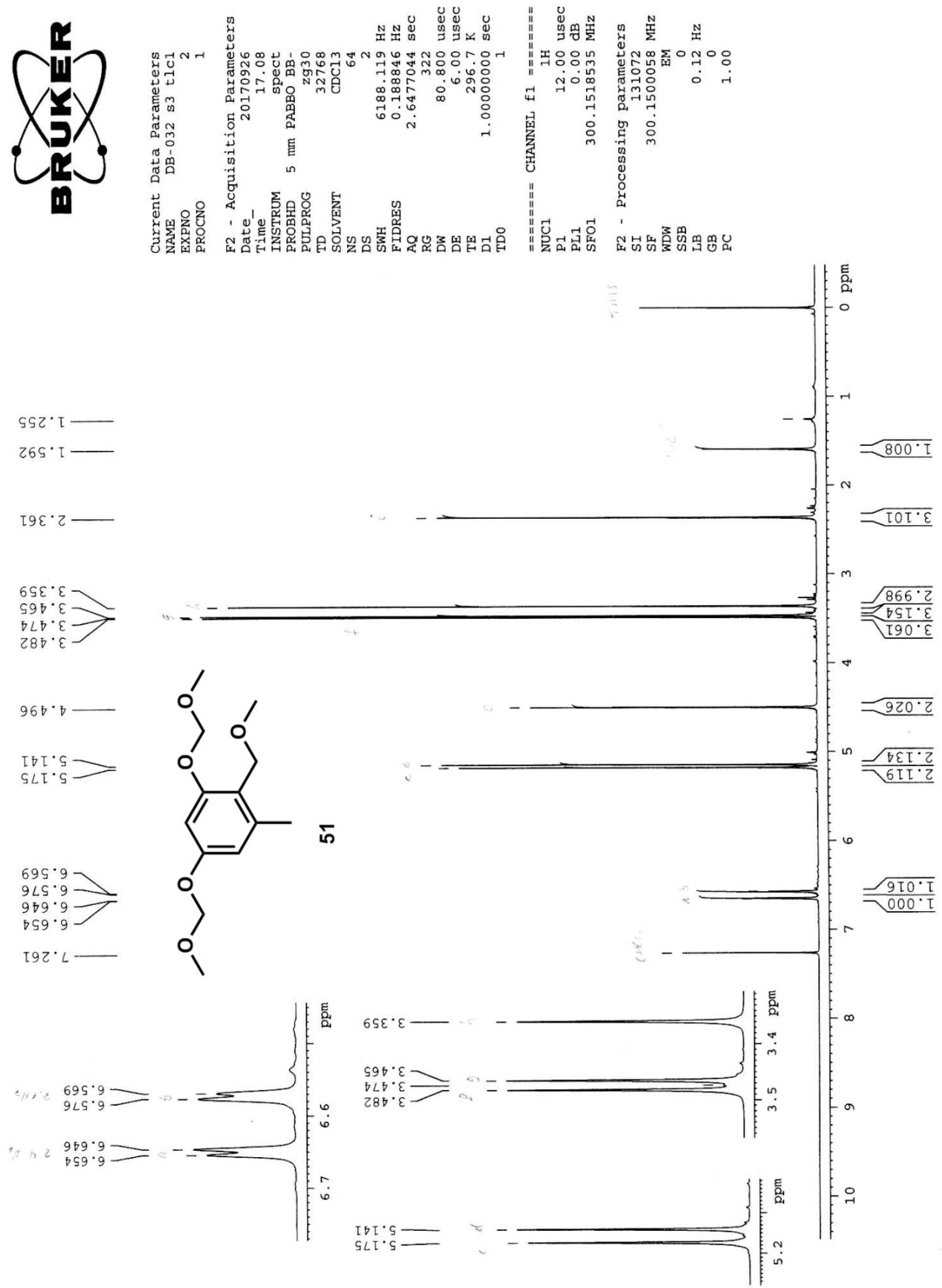

Figure A9. ${ }^{1} \mathrm{H}$ NMR of 1,5-bis(methoxymethoxy)-2-(methoxymethyl)-3-methylbenzene (51) 

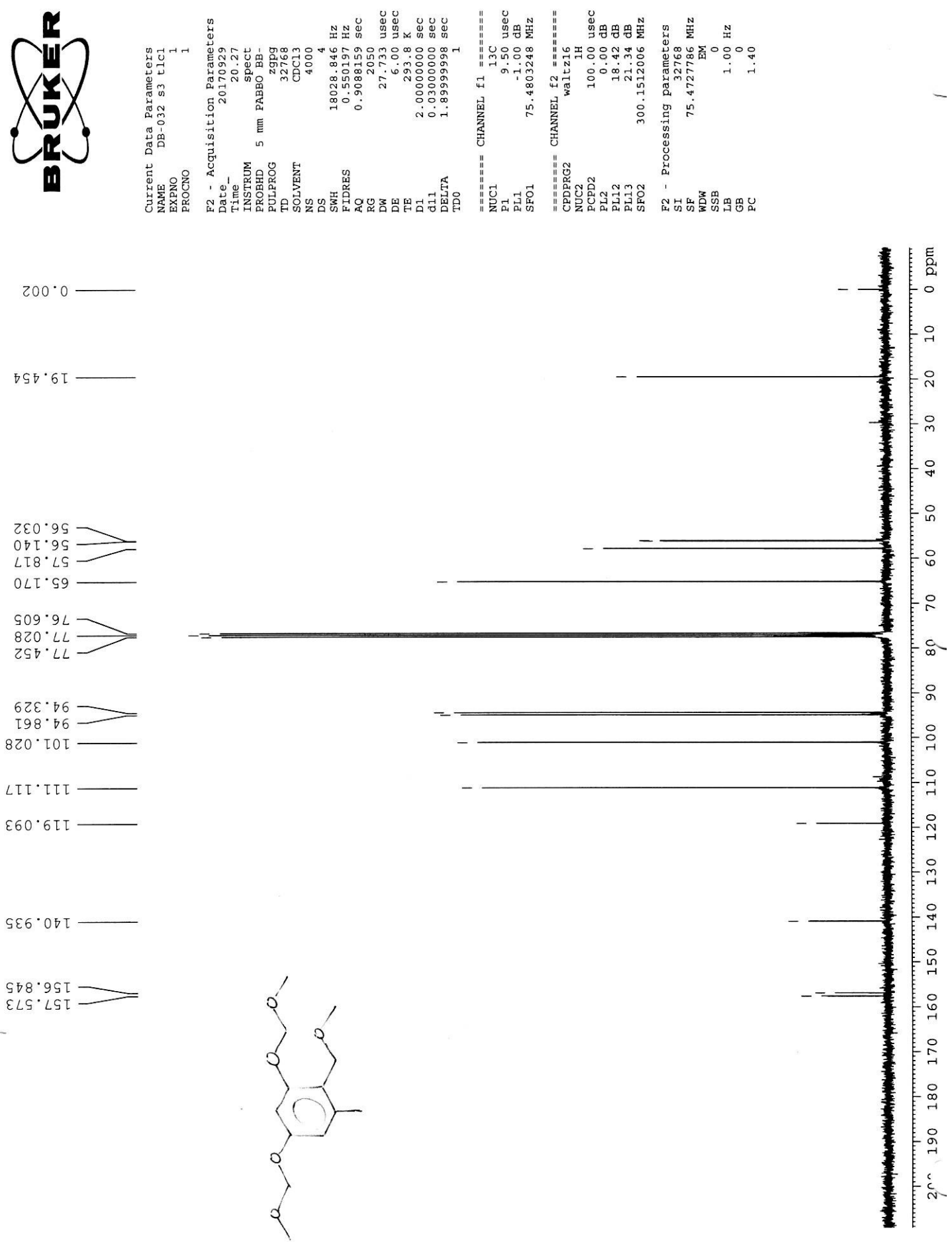

Figure A10. ${ }^{13} \mathrm{C}$ NMR of 1,5-bis(methoxymethoxy)-2-(methoxymethyl)-3methylbenzene (51) 

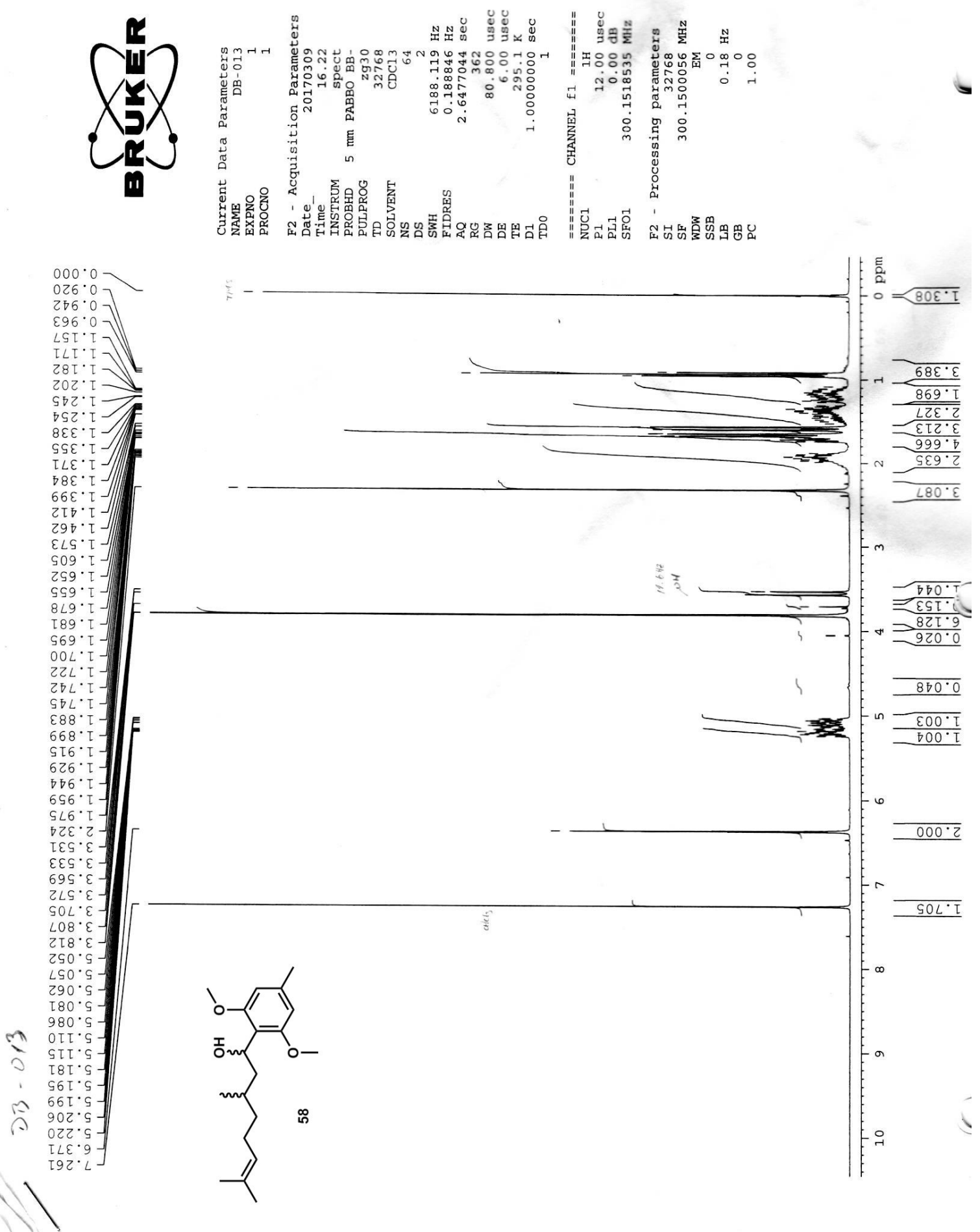

Figure A11. ${ }^{1} \mathrm{H}$ NMR of 1-(2,6-dimethoxy-4-methylphenyl)-3,7-dimethyloct-6-en-1-ol (58) 

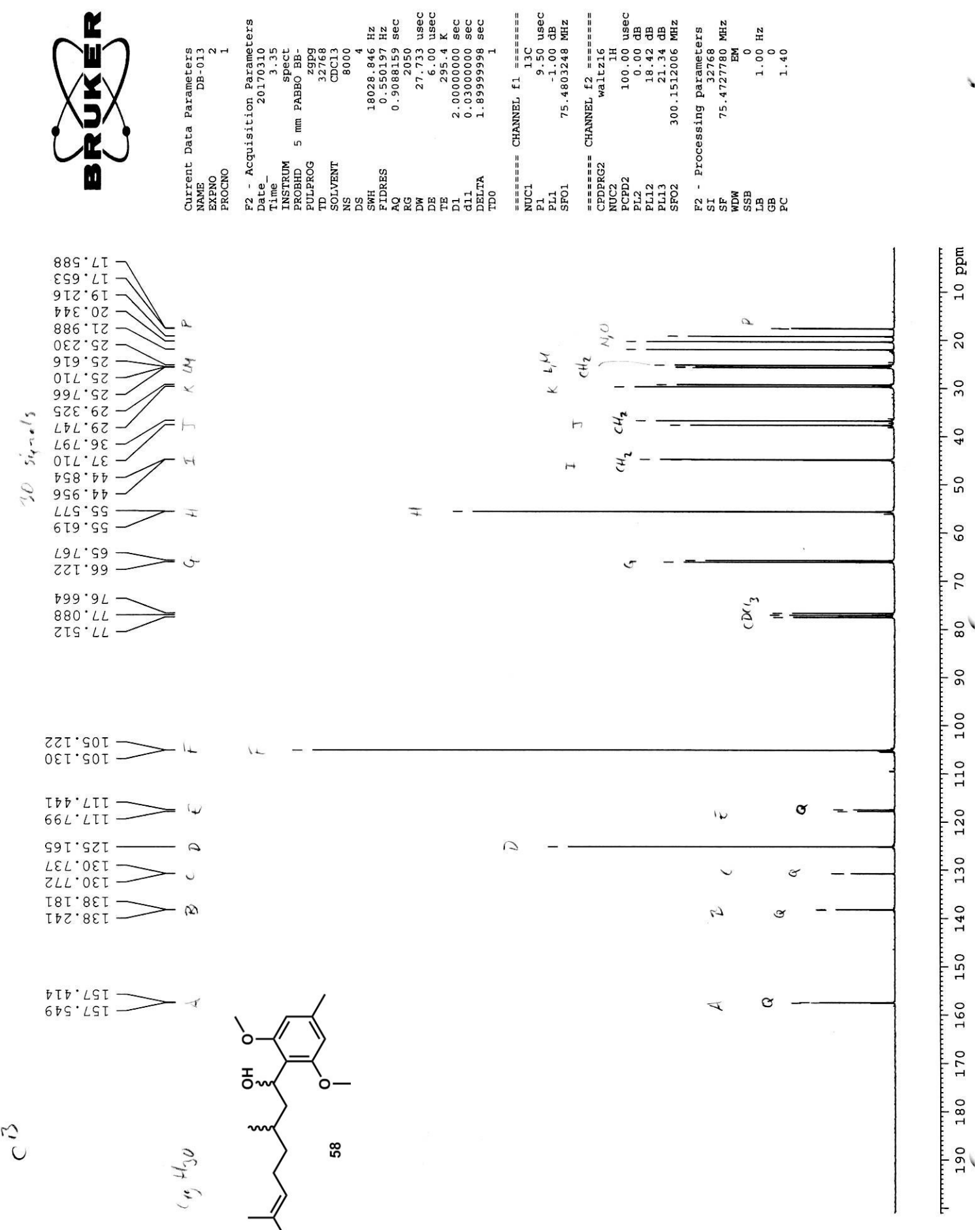

11
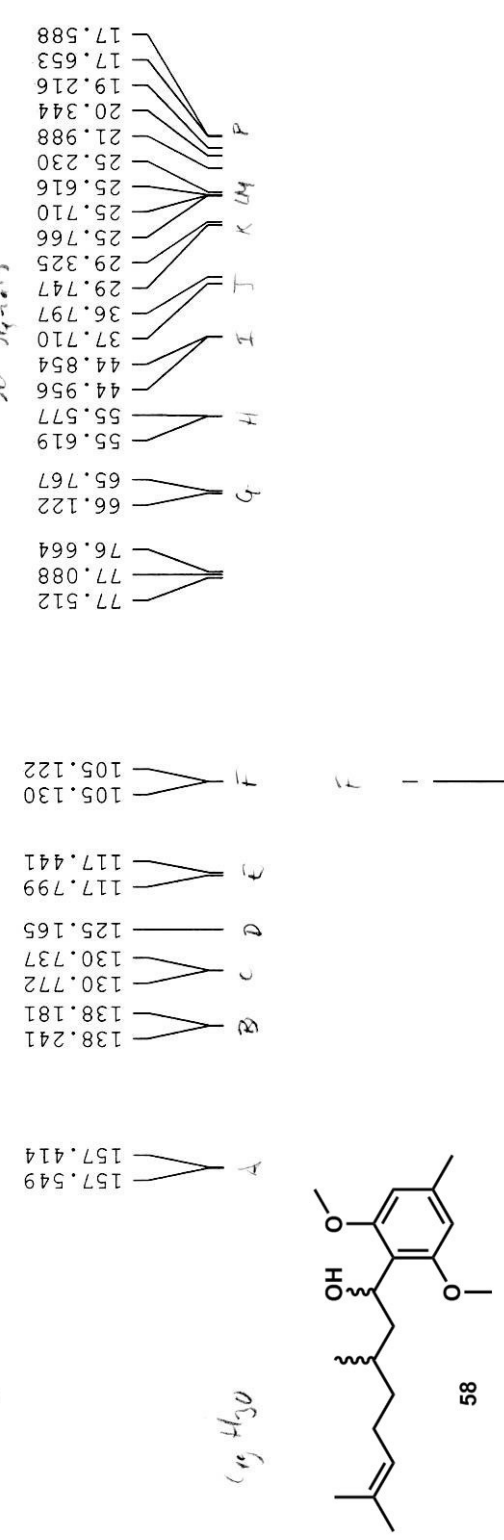

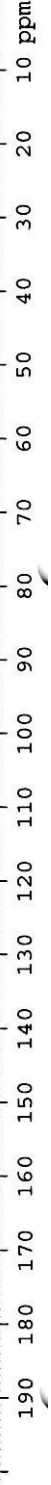

Figure A12. ${ }^{13} \mathrm{C}$ NMR of 1-(2,6-dimethoxy-4-methylphenyl)-3,7-dimethyloct-6-en-1-ol

(58) 

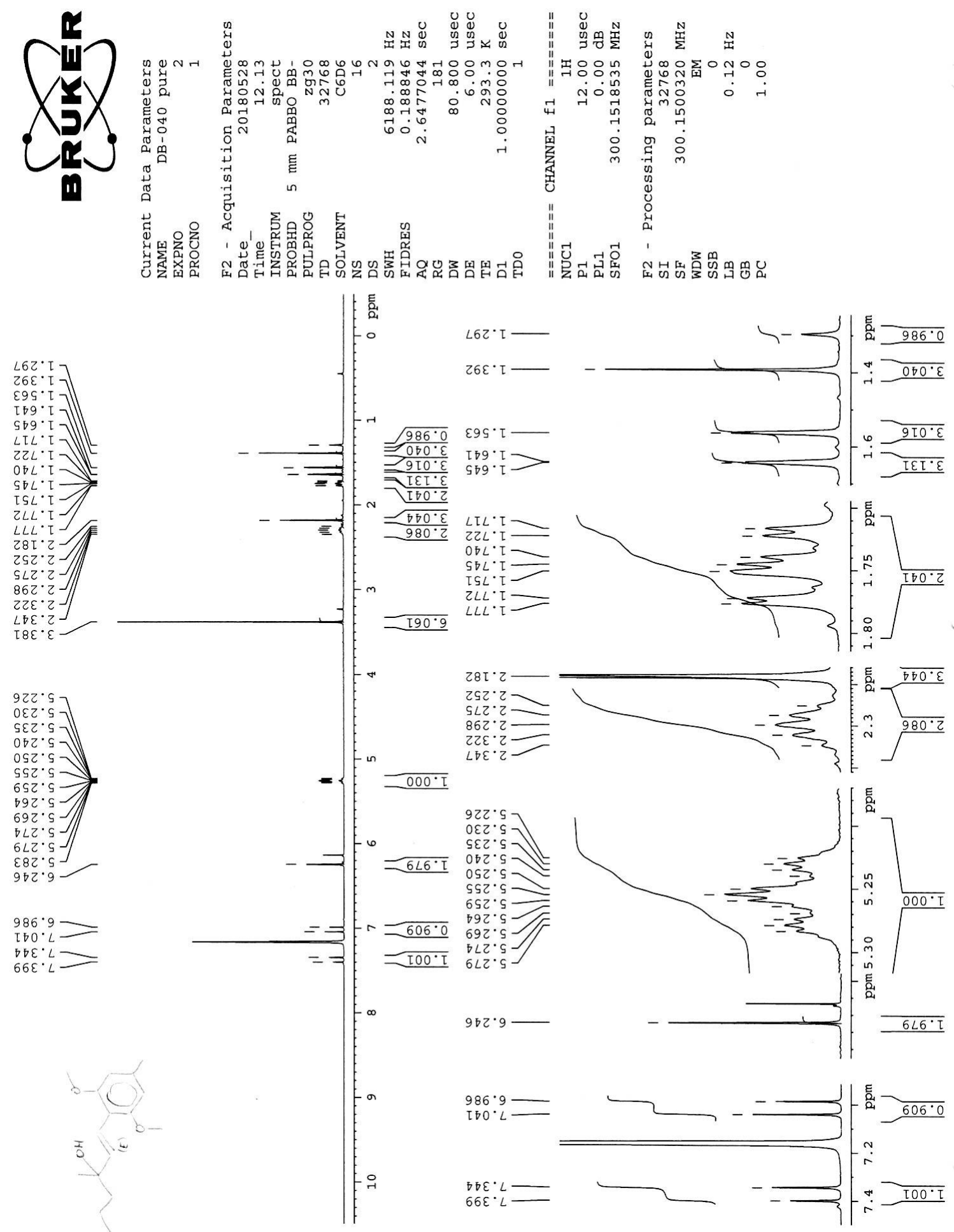

Figure A13. ${ }^{1} \mathrm{H}$ NMR of (E)-1-(2,6-dimethoxy-4-methylphenyl)-3,7-dimethylocta-1,6dien-3-ol (46c) 

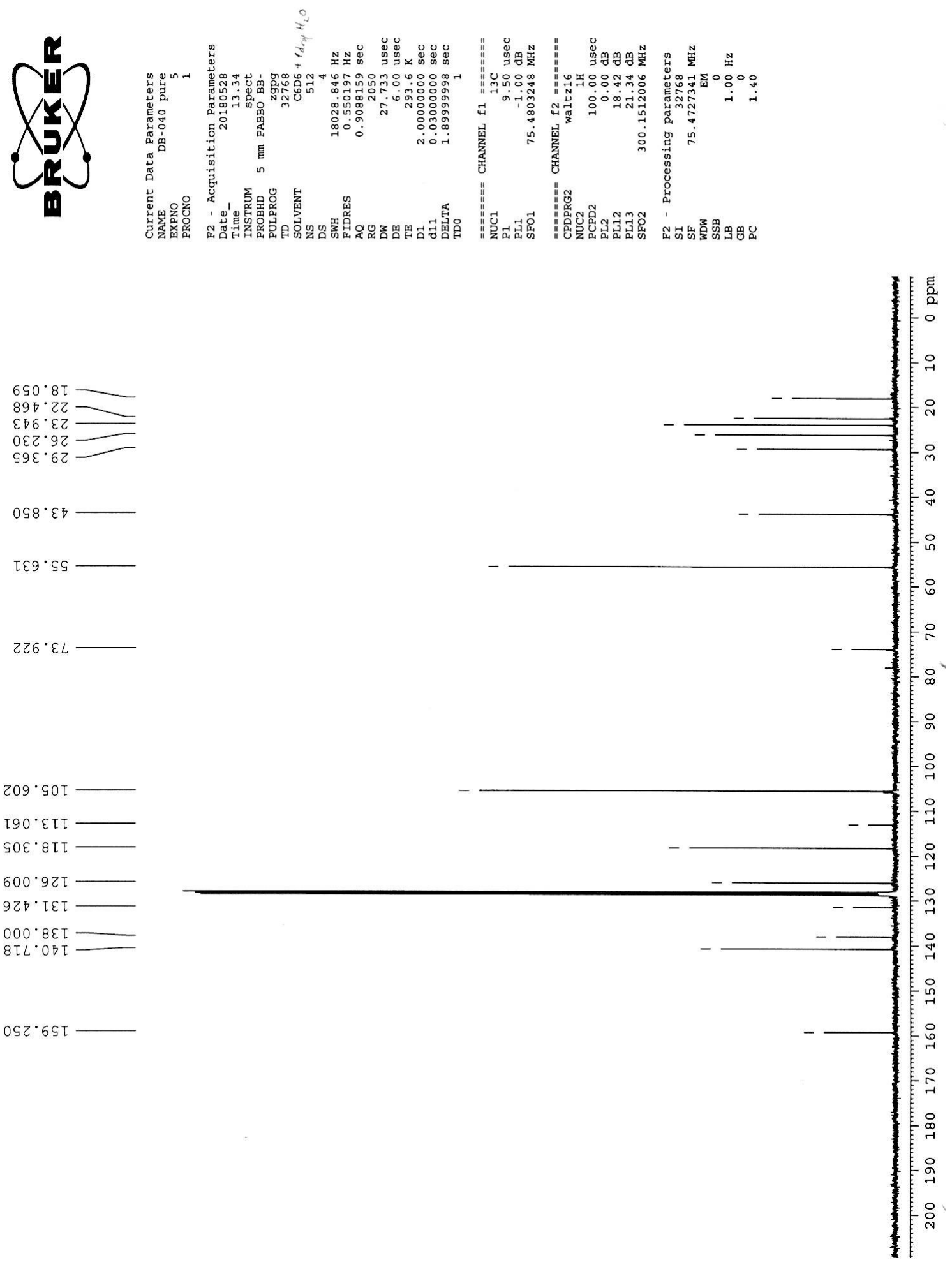

Figure A14. ${ }^{13} \mathrm{C}$ NMR of (E)-1-(2,6-dimethoxy-4-methylphenyl)-3,7-dimethylocta-1,6dien-3-ol (46c) 


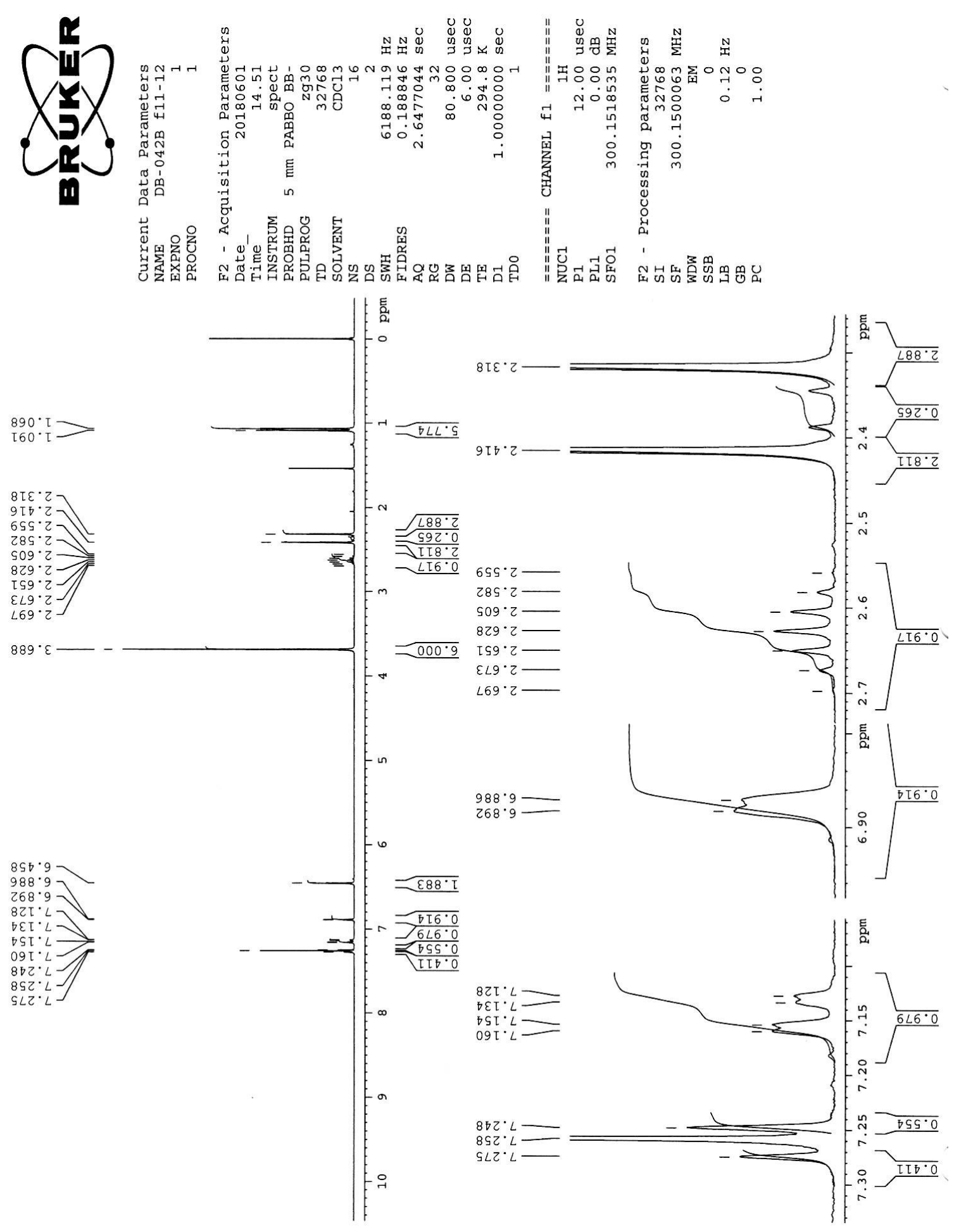

Figure A15. ${ }^{1} \mathrm{H}$ NMR of 2'-isopropyl-2,6-dimethoxy-4,5'-dimethyl-1,1'-biphenyl (63) 

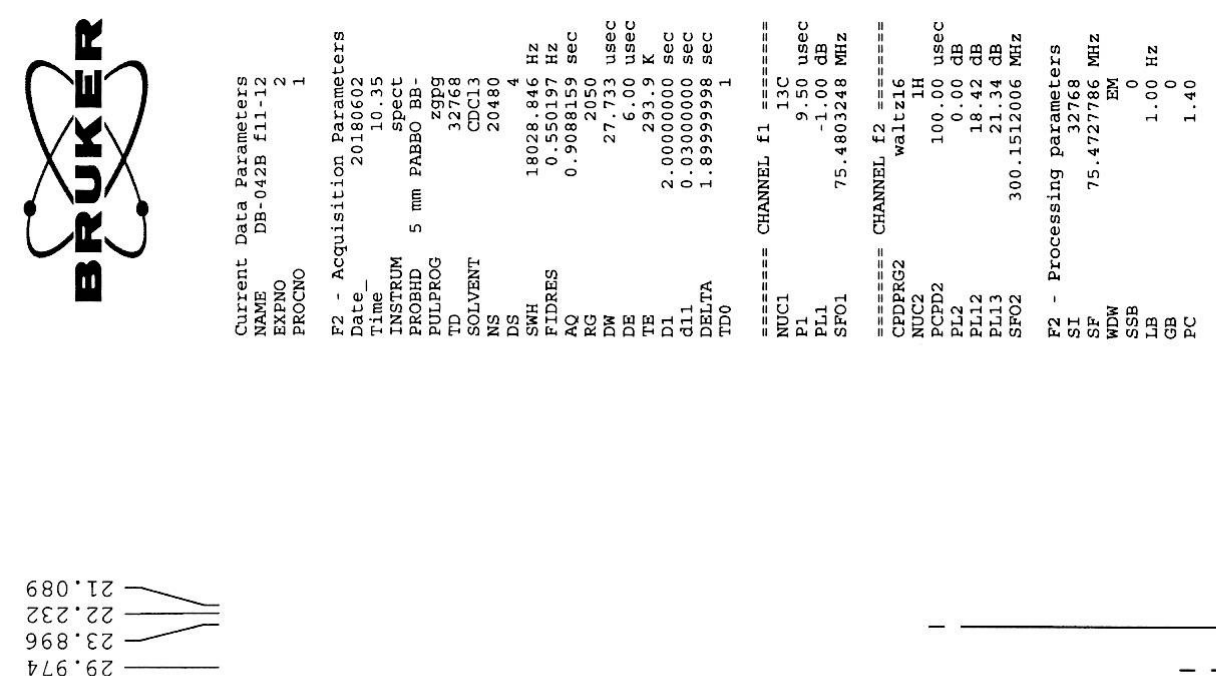

$\tau \angle 9 \cdot \varsigma \subseteq$

$8 \varepsilon 9^{\cdot}$ เOโ

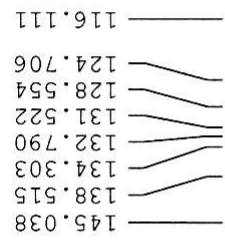

$\varepsilon 69^{\circ} \angle S T$

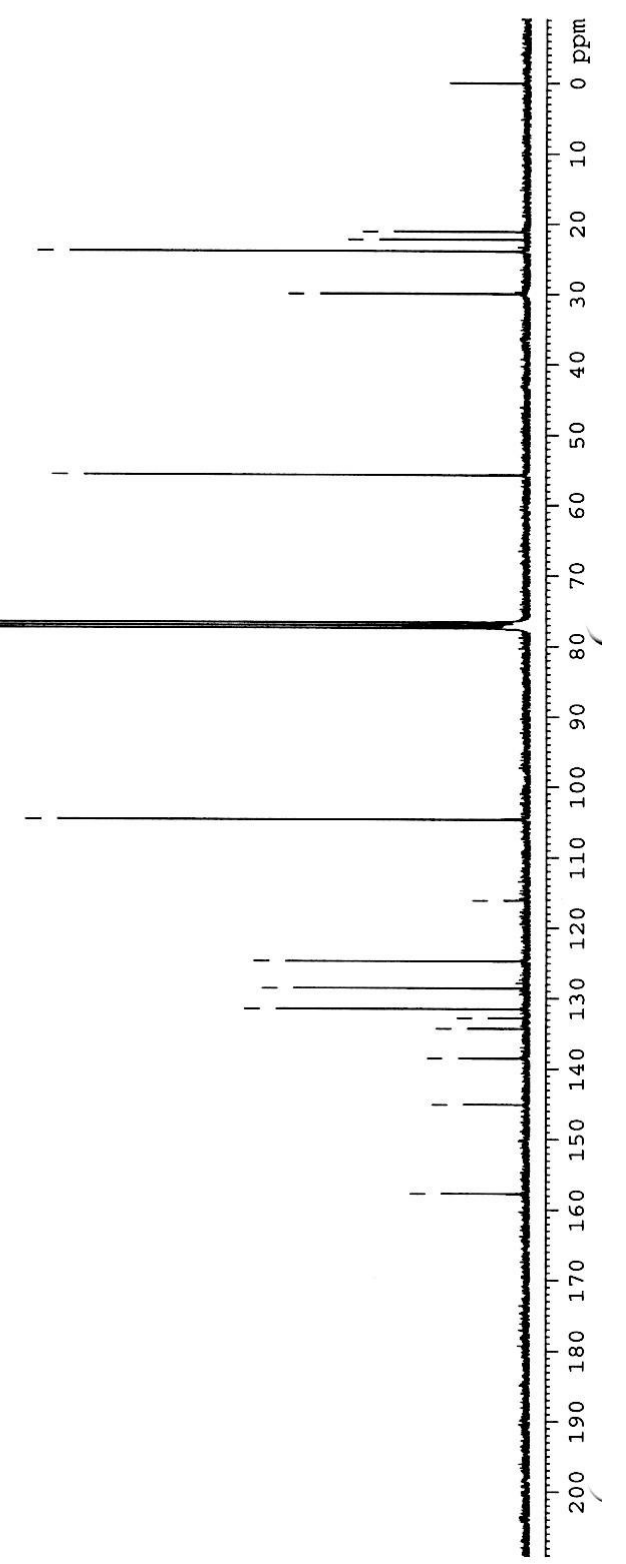

Figure A16. ${ }^{13} \mathrm{C}$ NMR of 2'-isopropyl-2,6-dimethoxy-4,5'-dimethyl-1,1'-biphenyl (63) 

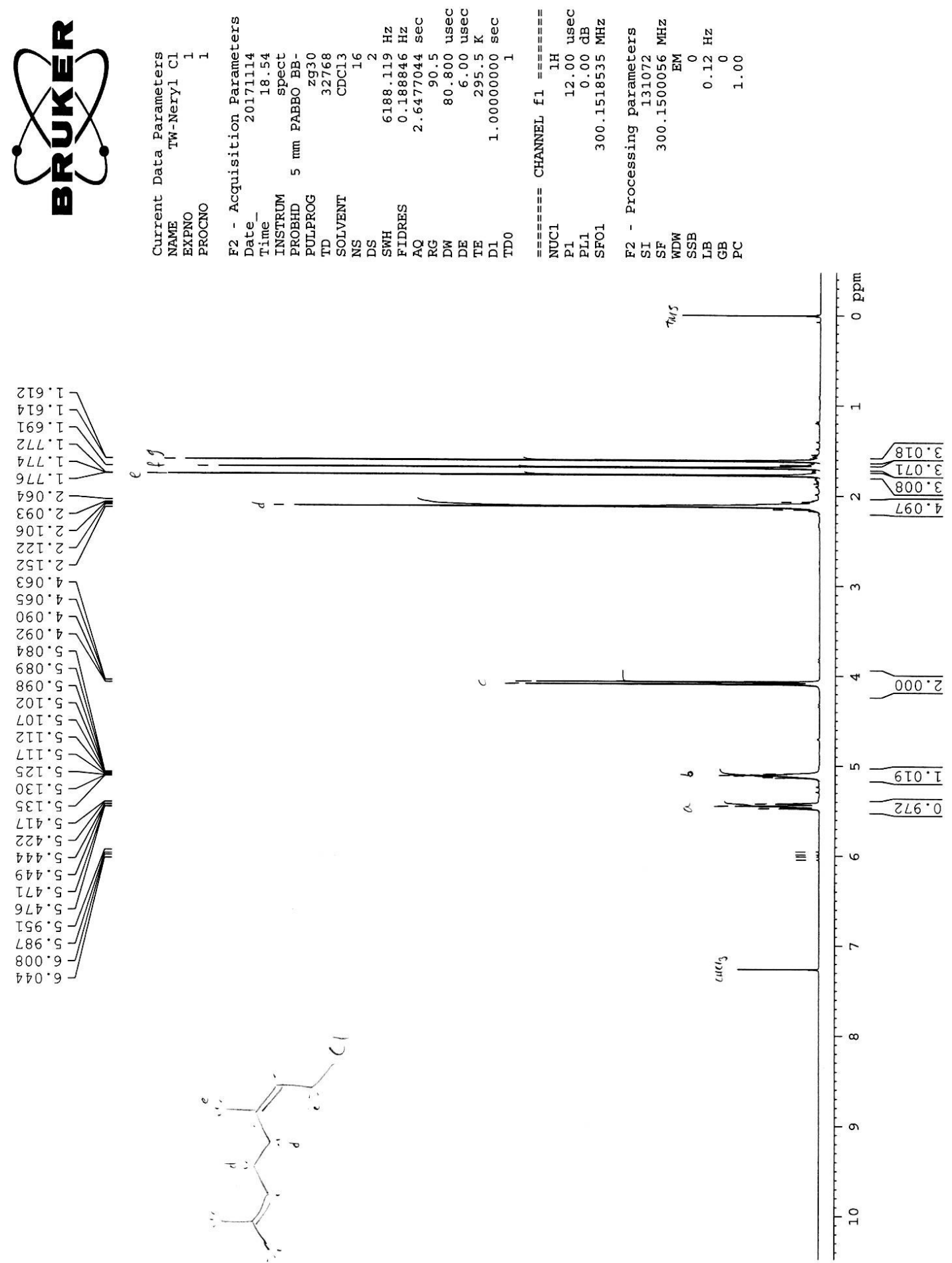

Figure A17. ${ }^{1} \mathrm{H}$ NMR of (Z)-1-chloro-3,7-dimethylocta-2,6-diene (neryl chloride)(68) 

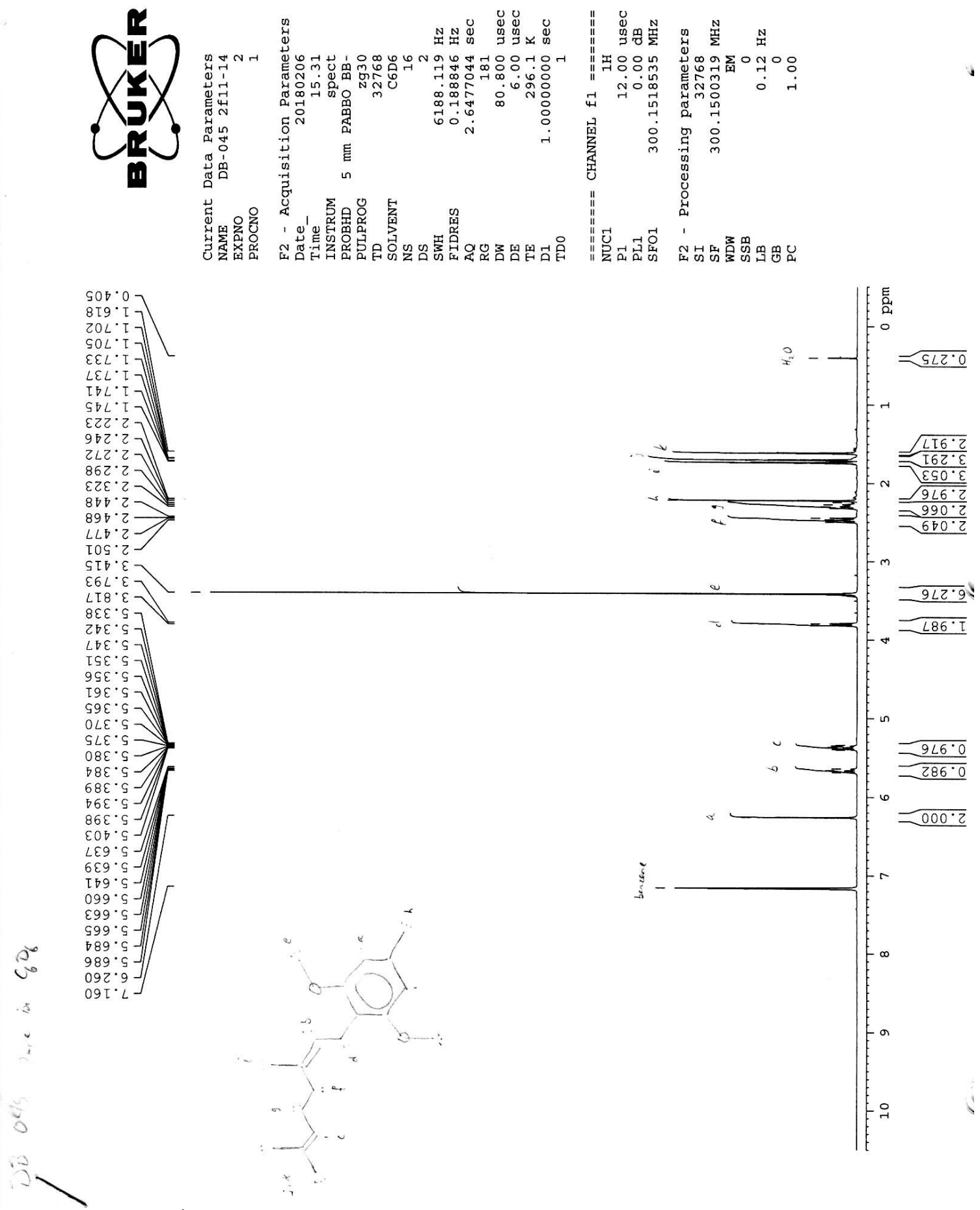

Figure A18. ${ }^{1} \mathrm{H}$ NMR of (Z)-2-(3,7-dimethylocta-2,6-dien-1-yl)-1,3-dimethoxy-5methylbenzene(69a) 

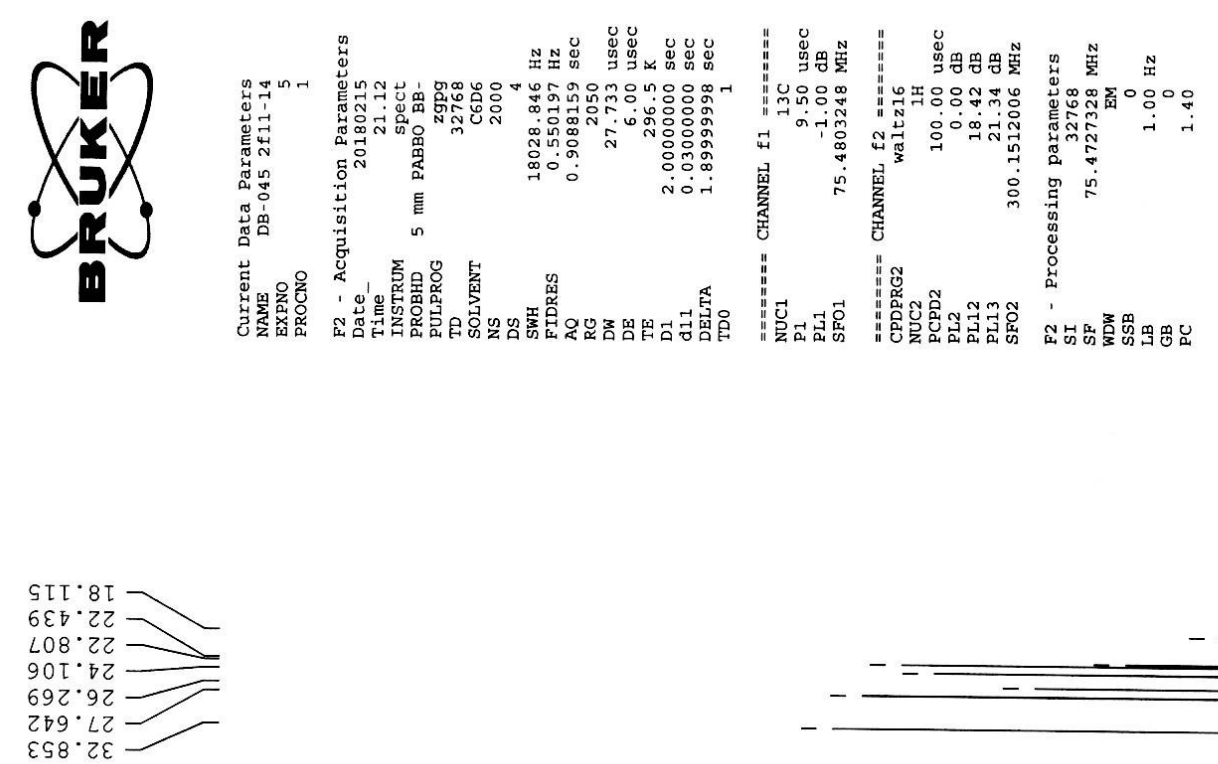

609 ५५

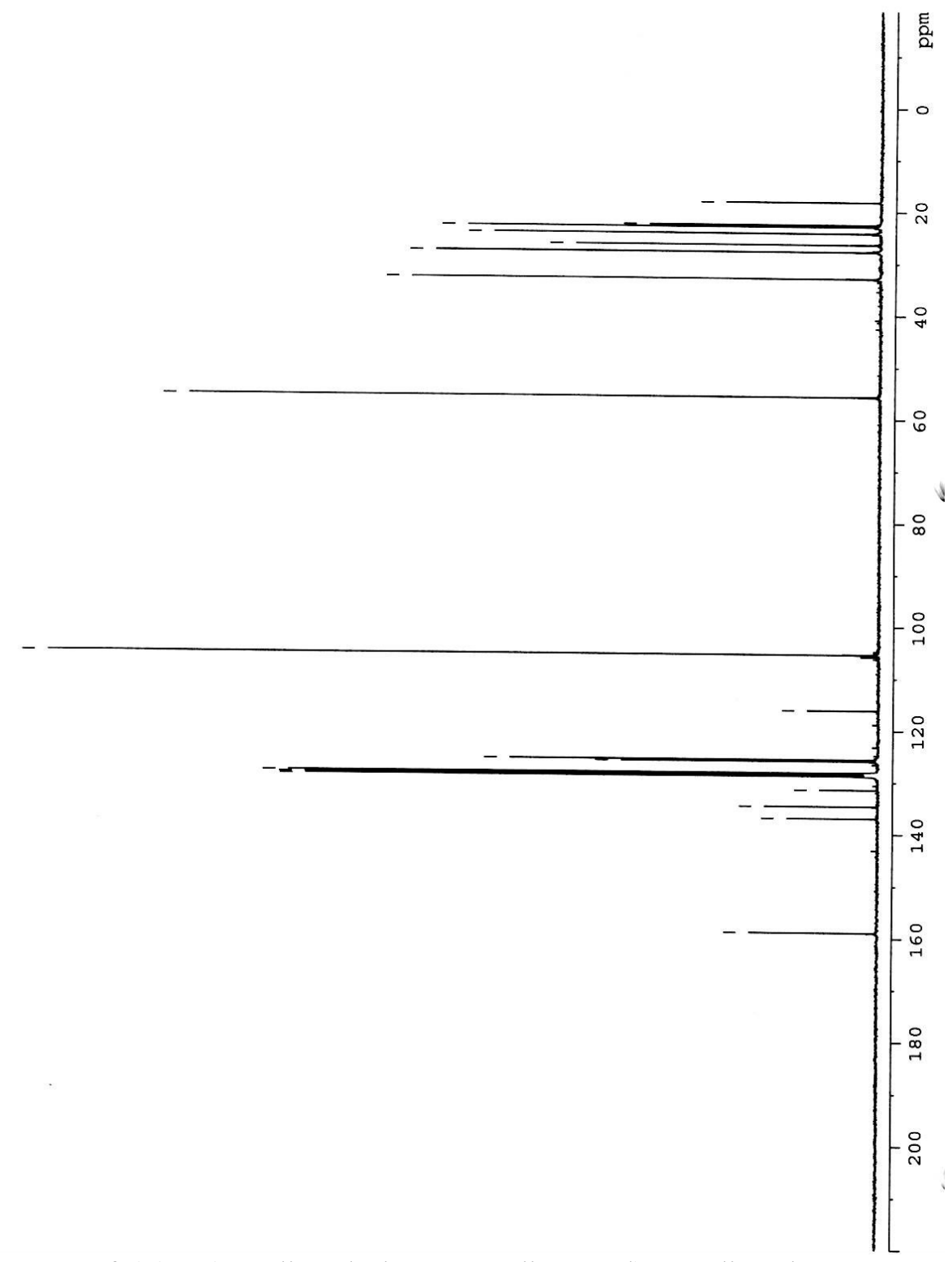

Figure A19. ${ }^{13} \mathrm{C}$ NMR of (Z)-2-(3,7-dimethylocta-2,6-dien-1-yl)-1,3-dimethoxy-5methylbenzene(69a) 

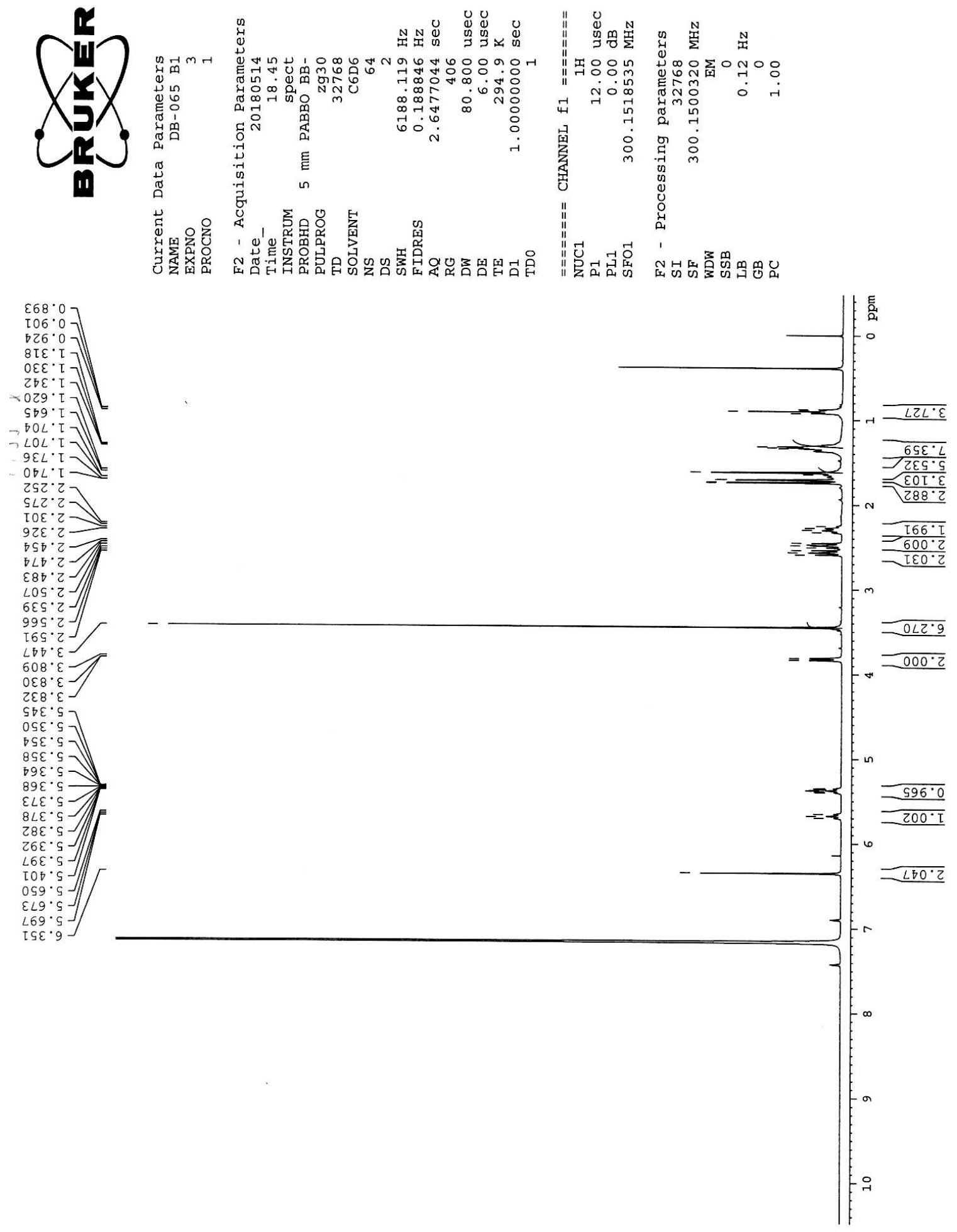

Figure A20. ${ }^{1} \mathrm{H}$ NMR of (Z)-2-(3,7-dimethylocta-2,6-dien-1-yl)-1,3-dimethoxy-5pentylbenzene (69b) 

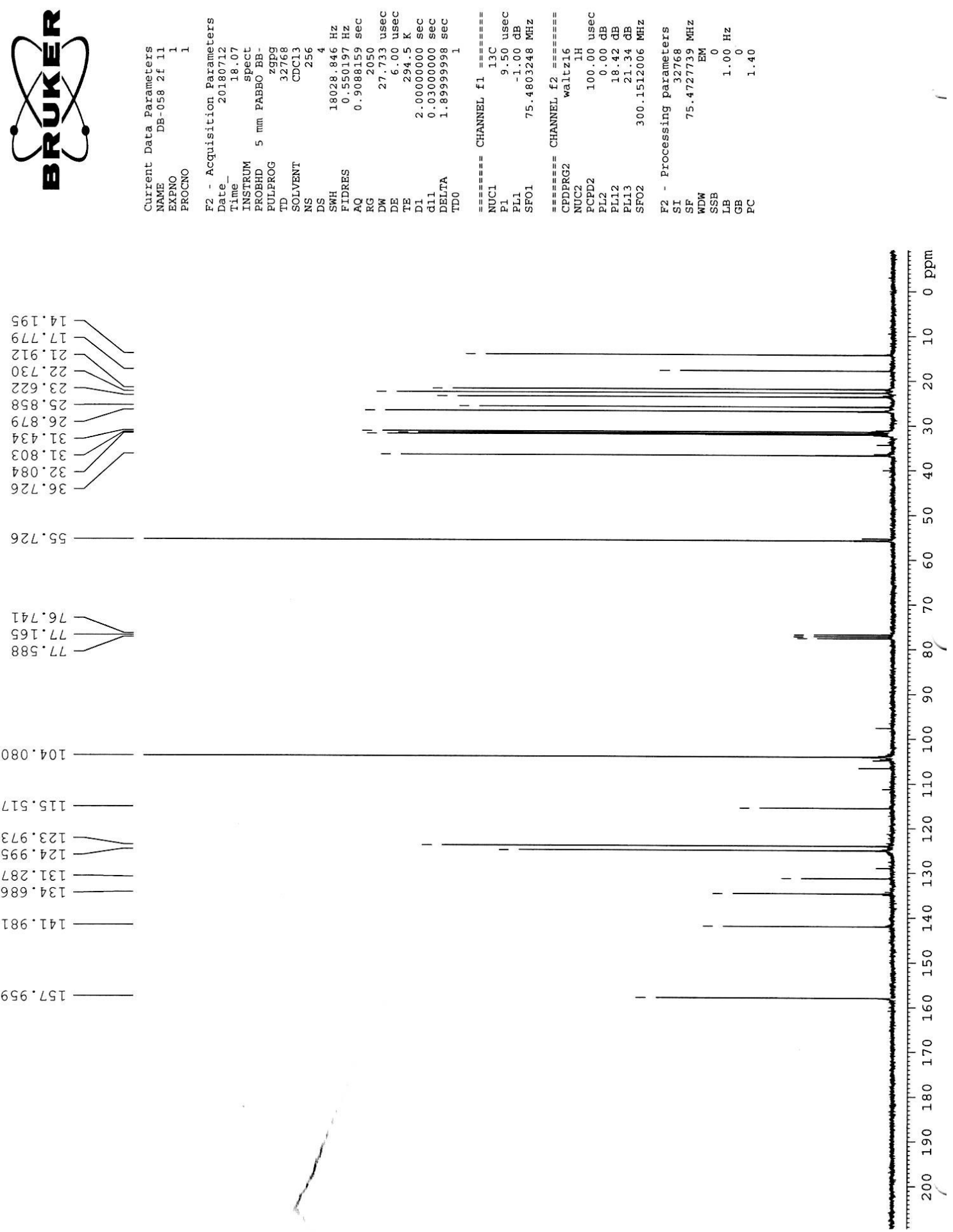

Figure A21. ${ }^{13} \mathrm{C}$ NMR of (Z)-2-(3,7-dimethylocta-2,6-dien-1-yl)-1,3-dimethoxy-5pentylbenzene $(69 \mathrm{~b})$ 

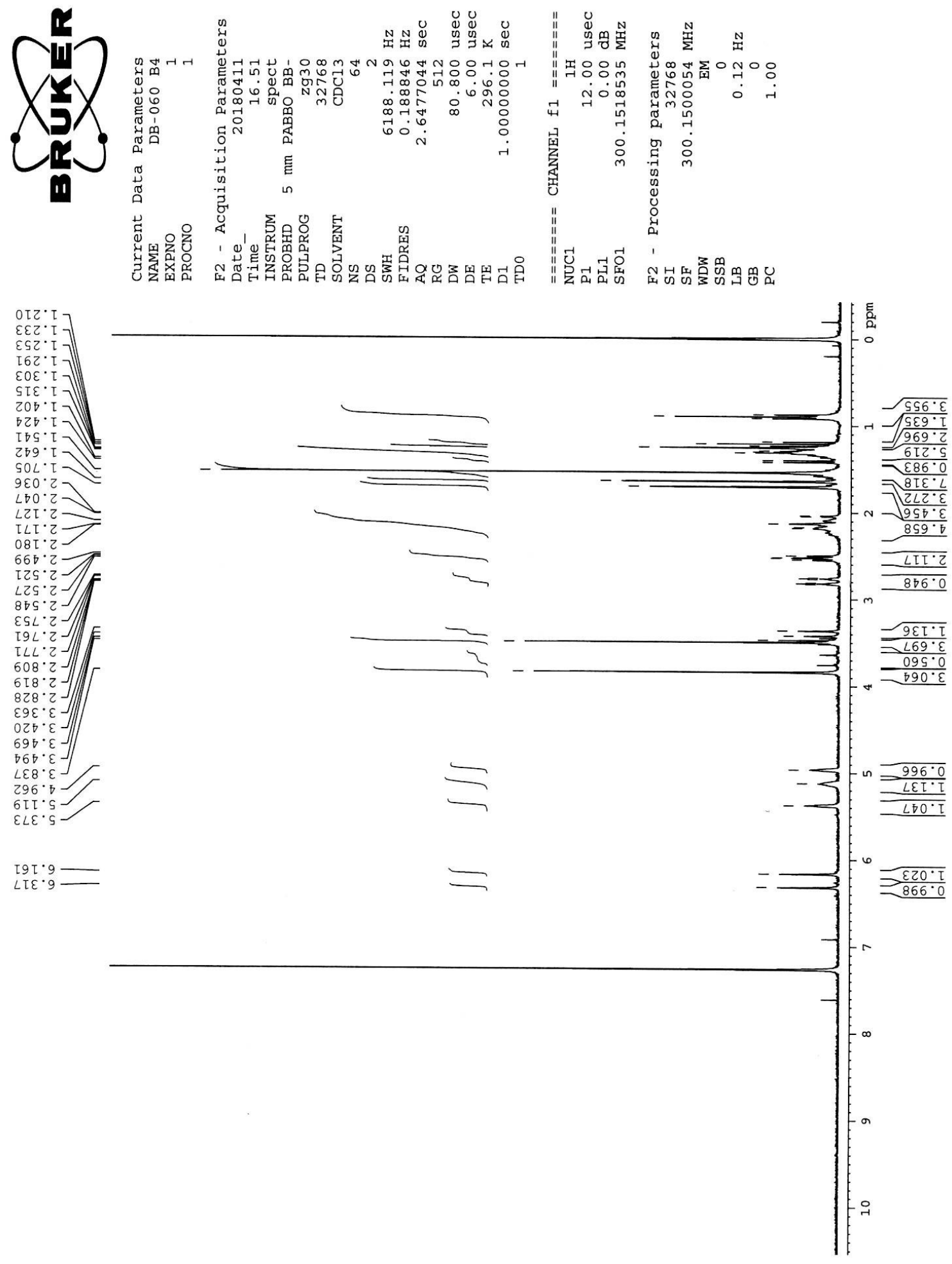

Figure A22. ${ }^{1} \mathrm{H}$ NMR of 2,3-dichloro-5-(2,6-dimethoxy-4-pentylphenyl)-7-(4methylpent-3-en-1-yl)-1,4-dioxo-1,4,4a,5,8,8a-hexahydronaphthalene-4a,8adicarbonitrile (80) 

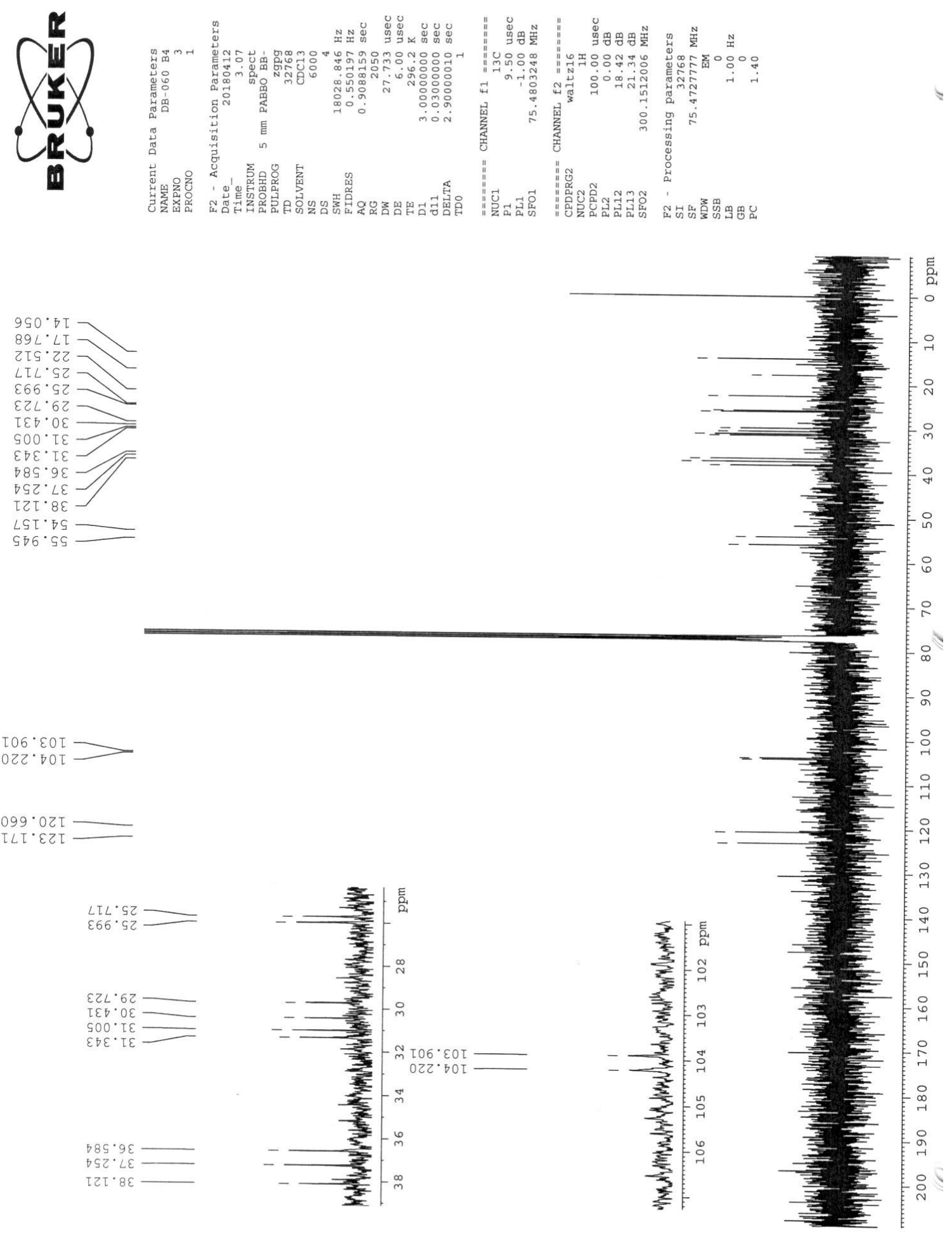

Figure A23. ${ }^{13} \mathrm{C}$ NMR of 2,3-dichloro-5-(2,6-dimethoxy-4-pentylphenyl)-7-(4methylpent-3-en-1-yl)-1,4-dioxo-1,4,4a,5,8,8a-hexahydronaphthalene-4a,8adicarbonitrile $(\mathbf{8 0})$ 

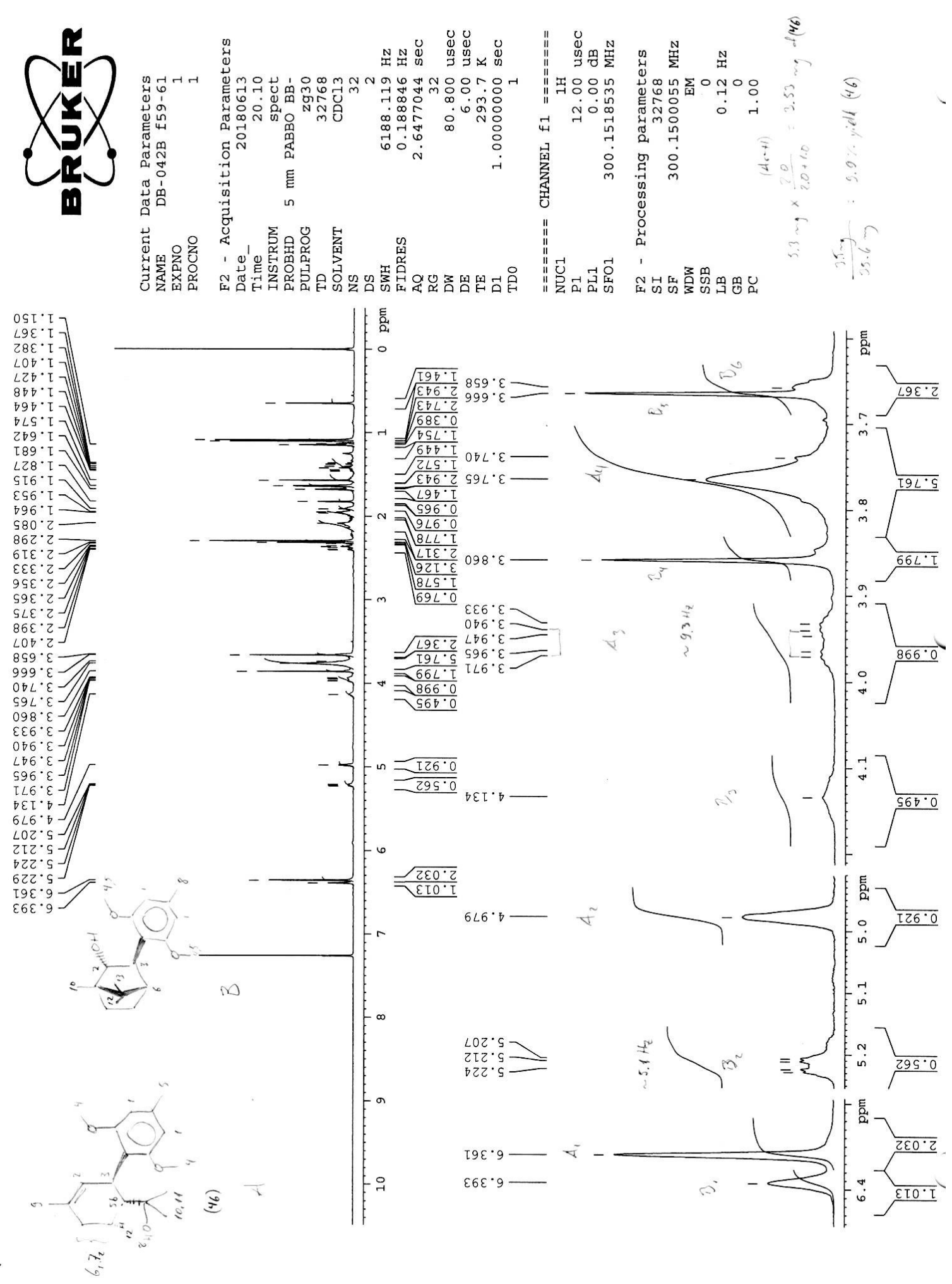

Figure A24. ${ }^{1} \mathrm{H}$ NMR of mixture of compounds 64 and 65 

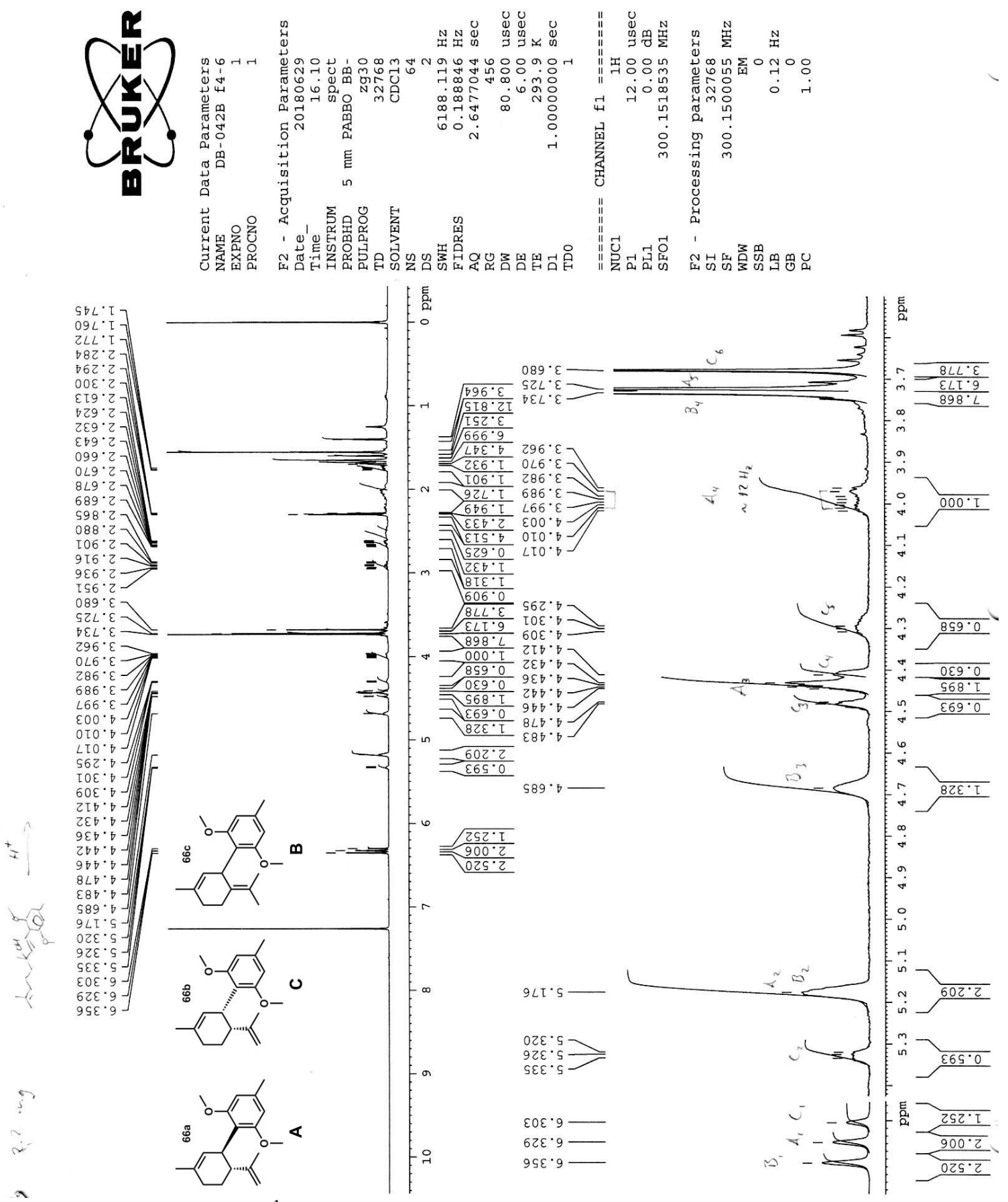

Figure A25. ${ }^{1} \mathrm{H}$ NMR of mixture of compounds $66 \mathbf{a}, 66 \mathbf{b}$ and $66 \mathbf{c}$ 

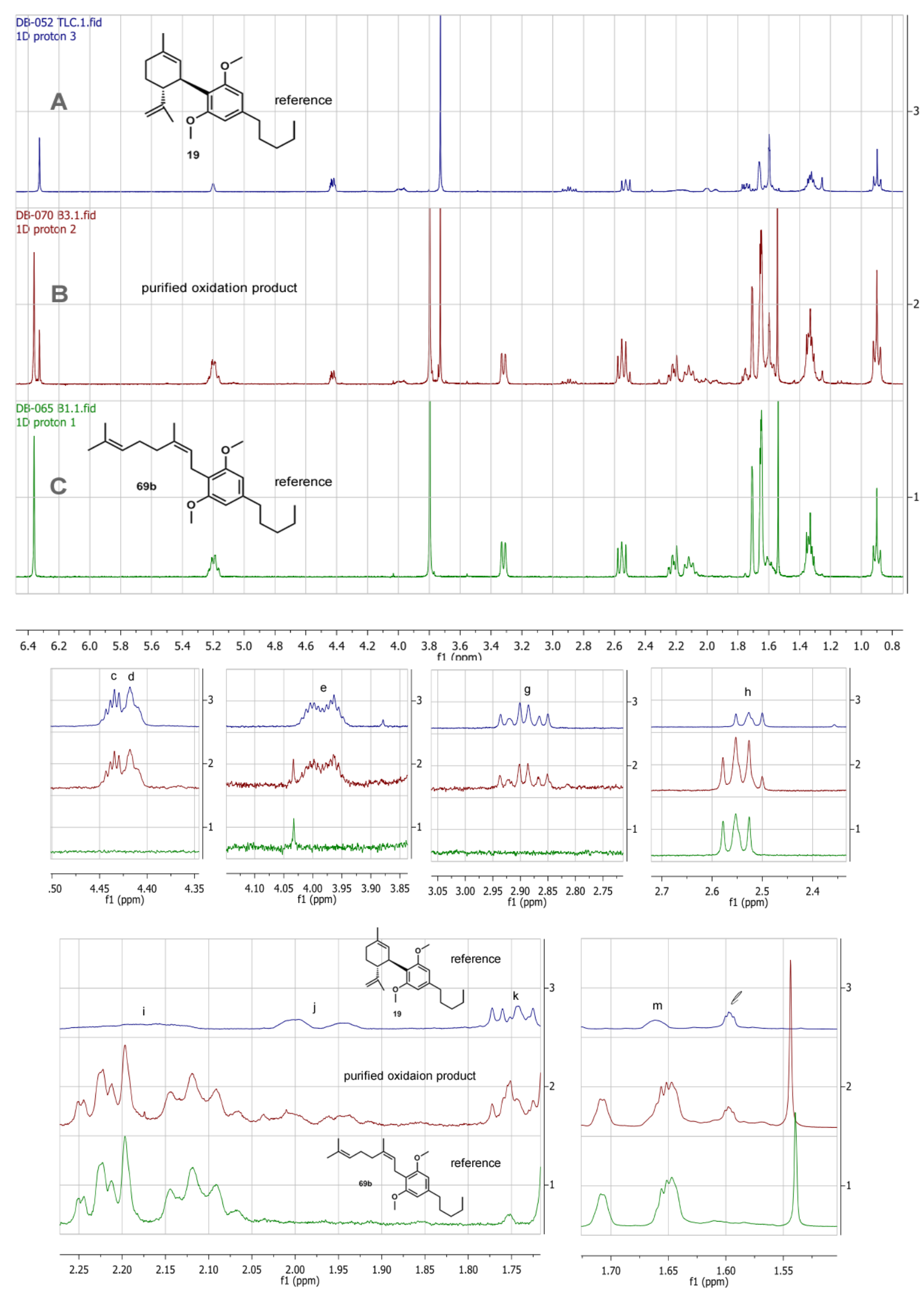

Figure A26. ${ }^{1} \mathrm{H}$ NMR of semi-isolated 19, produced by oxidative cyclization with $\mathrm{Mn}(\mathrm{III})$, and compared to authentic reference standards of $69 \mathrm{~b}$ and 19. 


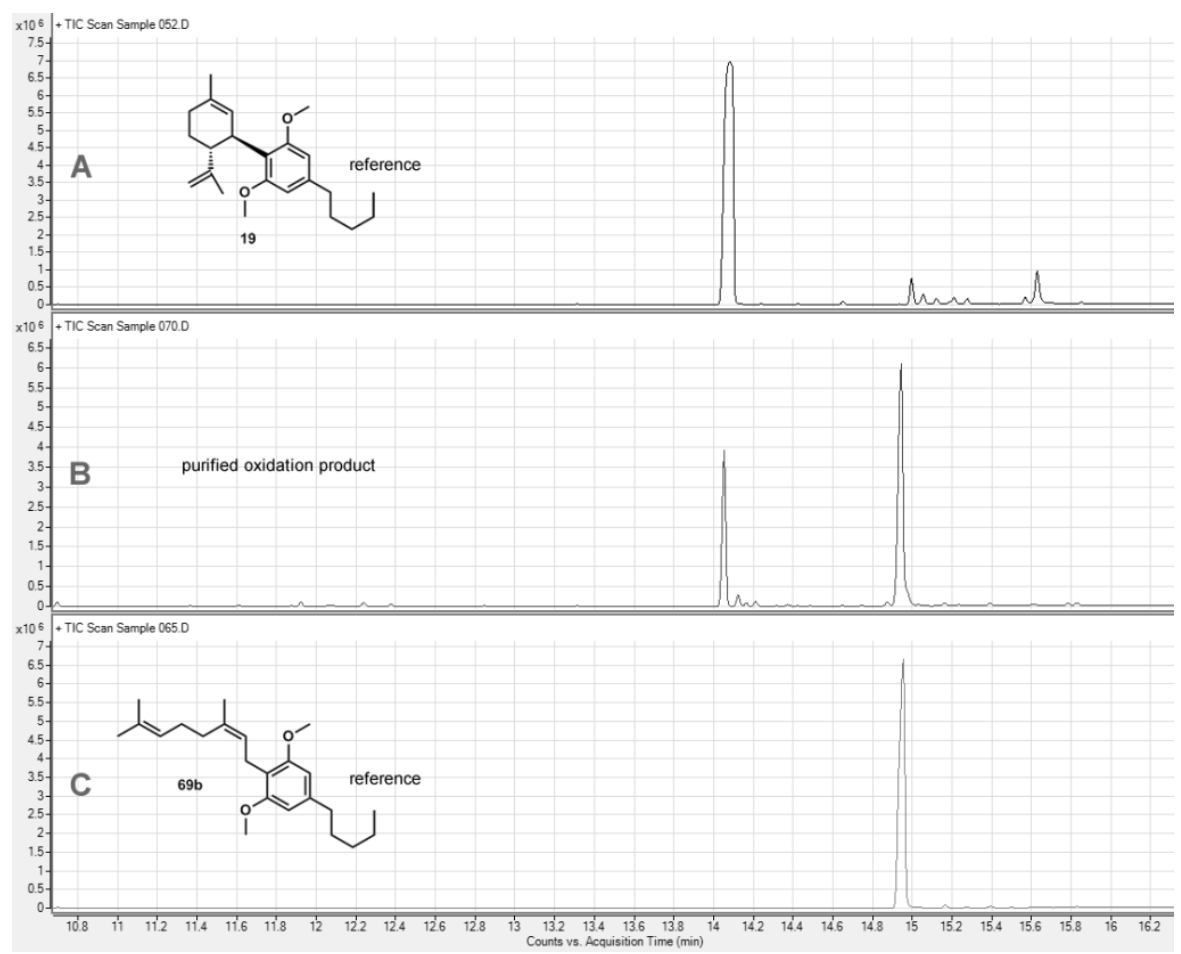

Figure A27. GCMS chromatogram of semi-isolated 19, produced by oxidative cyclization with $\mathrm{Mn}(\mathrm{III})$, and compared to authentic reference standards of $69 \mathrm{~b}$ and $\mathbf{1 9}$.
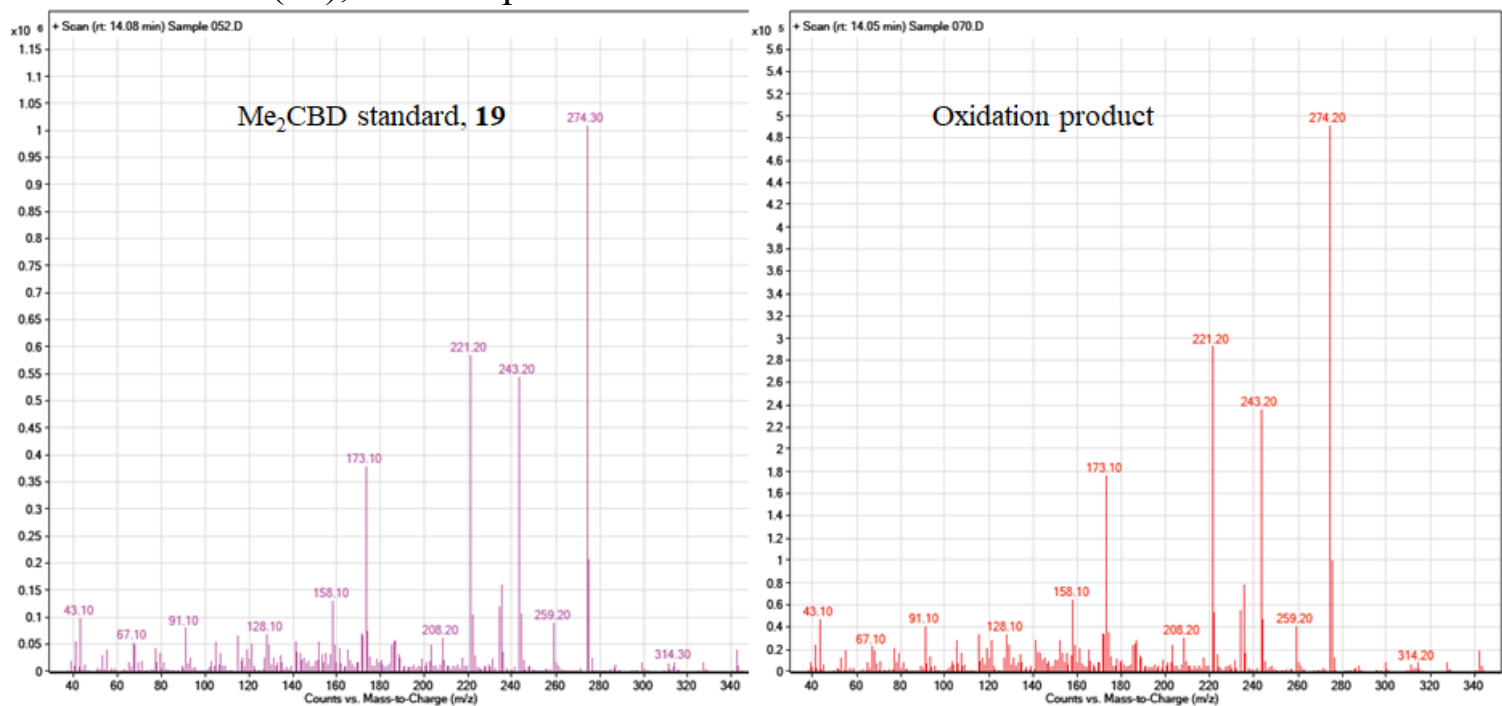

Figure A28. GCMS of 19 from oxidative cyclization with $\mathrm{Mn}(\mathrm{III})$

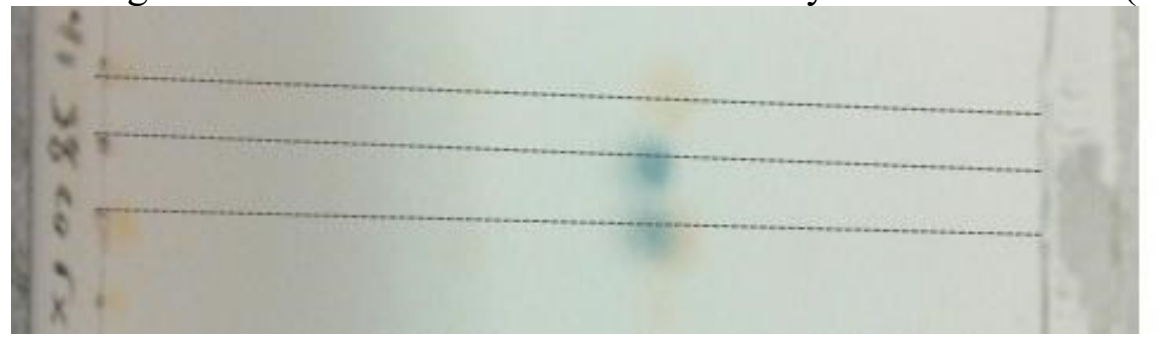

$69 \mathrm{~b}$

19

both

Figure A29. TLC of $\mathbf{6 9 b}$ and $\mathbf{1 9}$ on silica, developed with 30:70 o-DCB:CyH and stained with anisaldehyde 


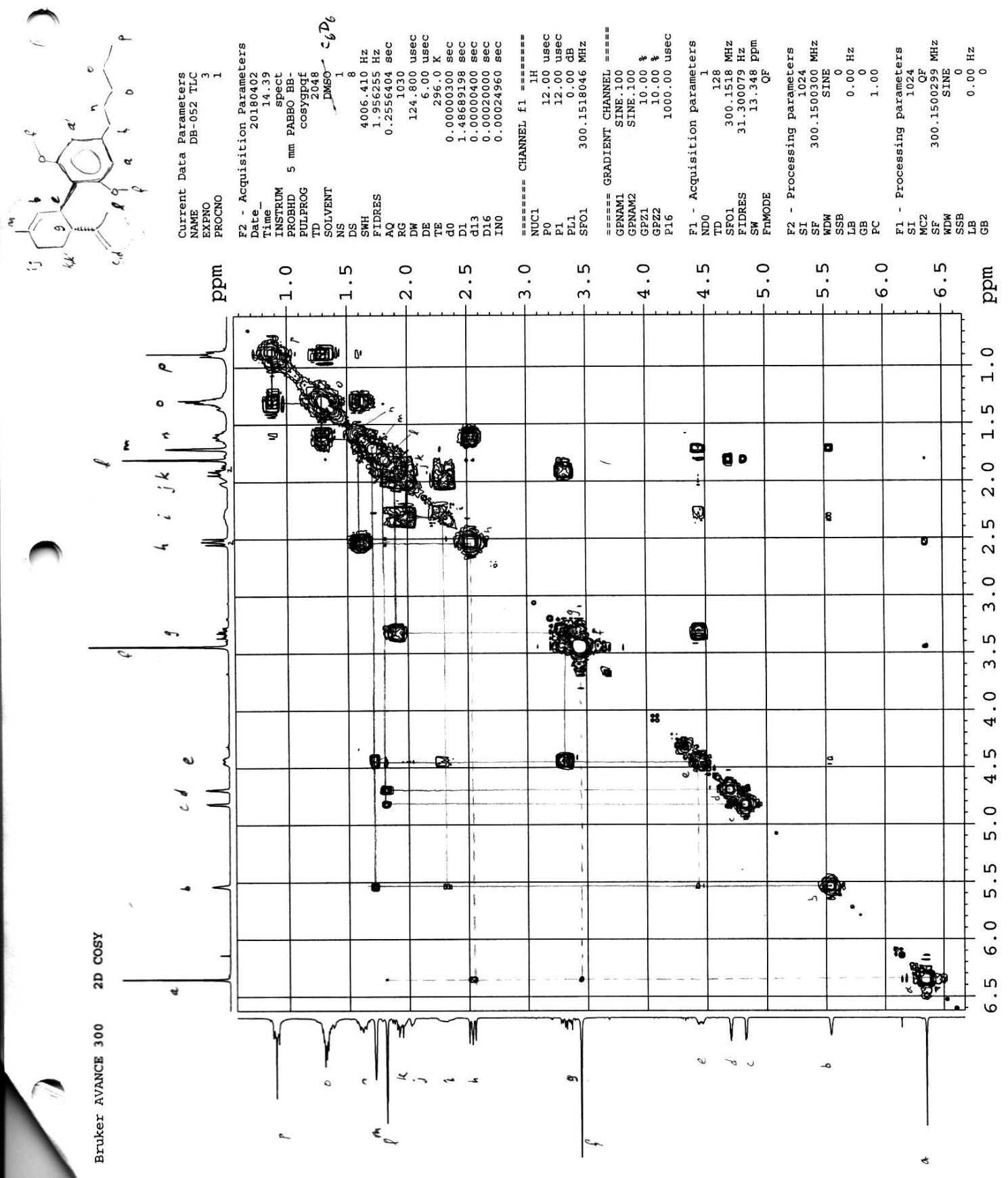

Figure A30. ${ }^{1} \mathrm{H}-{ }^{1} \mathrm{H}$ COSY in $\mathrm{C}_{6} \mathrm{D}_{6}$ of (1R,2R)-2',6'-dimethoxy-5-methyl-4'-pentyl-2(prop-1-en-2-yl)-1,2,3,4-tetrahydro-1,1'-biphenyl (dimethyl CBD) (19) 


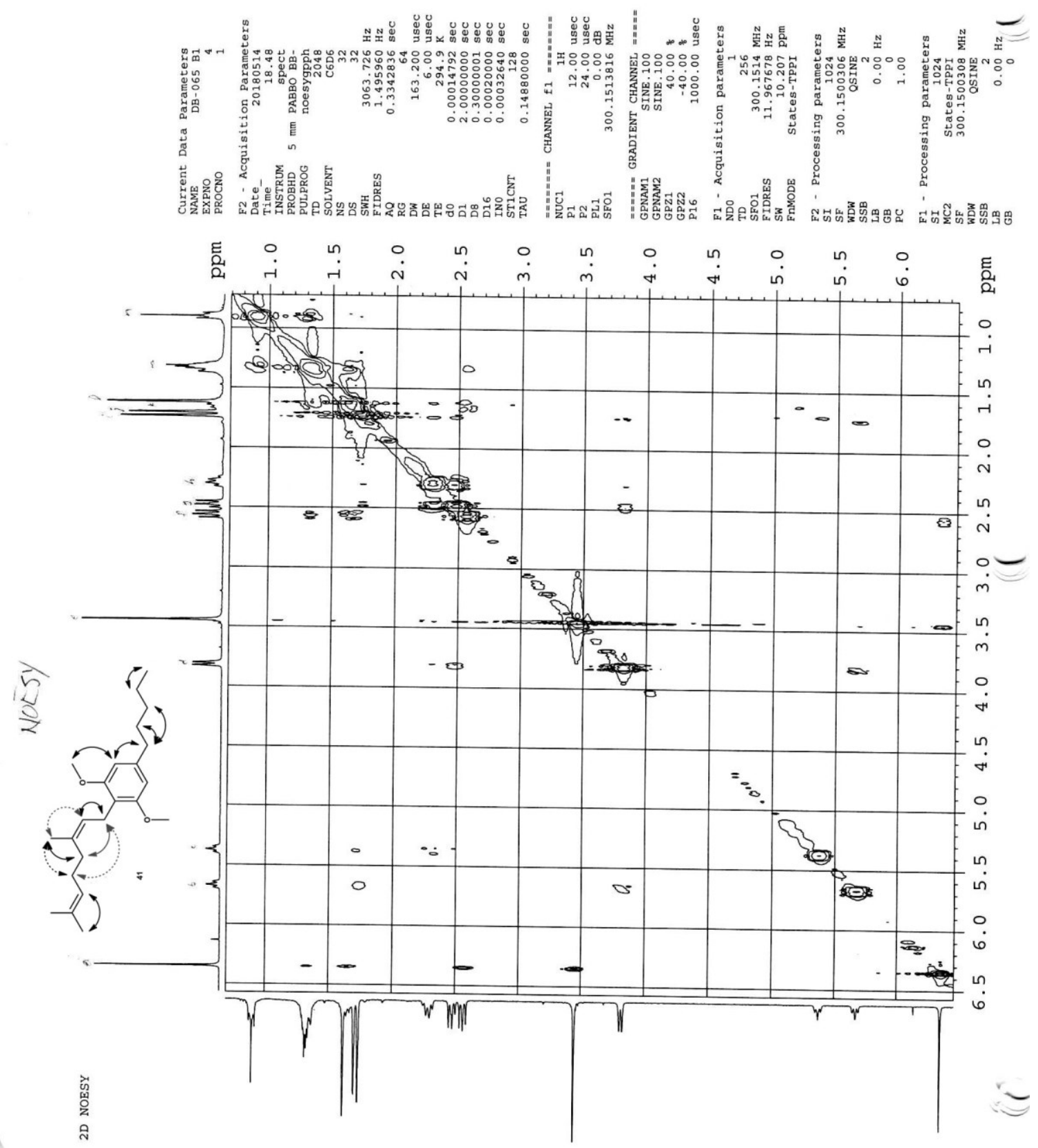

Figure A31. ${ }^{1} \mathrm{H}-{ }^{1} \mathrm{H}$ NOESY in $\mathrm{C}_{6} \mathrm{D}_{6}$ of (Z)-2-(3,7-dimethylocta-2,6-dien-1-yl)-1,3dimethoxy-5-pentylbenzene $(\mathbf{6 9 b})$ 

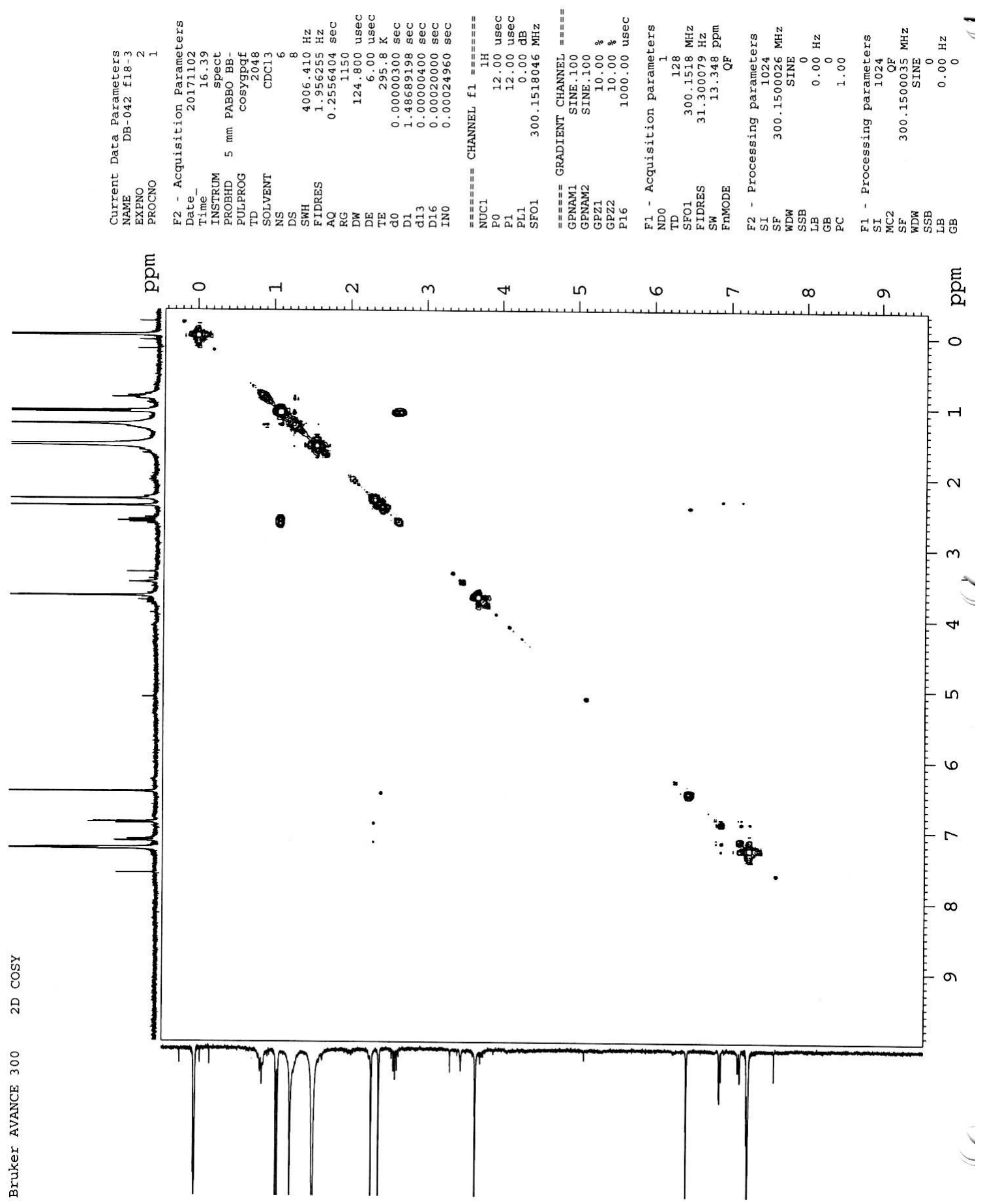

Figure A32. ${ }^{1} \mathrm{H}-{ }^{1} \mathrm{H}$ COSY of 2'-isopropyl-2,6-dimethoxy-4,5'-dimethyl-1,1'-biphenyl (63) 